Eduardo Takeo Ueda

\title{
Análise de Políticas de Controle de Acesso Baseado em Papéis com Rede de Petri \\ Colorida
}

Tese apresentada à Escola Politécnica da Universidade de São Paulo para obtenção do Título de Doutor em Engenharia Elétrica. 
Eduardo Takeo Ueda

\section{Análise de Políticas de Controle de Acesso Baseado em Papéis com Rede de Petri Colorida}

Tese apresentada à Escola Politécnica da Universidade de São Paulo para obtenção do Título de Doutor em Engenharia Elétrica.

Área de concentração:

Engenharia de Computação e Sistemas Digitais

Orientador:

Prof. Dr. Wilson Vicente Ruggiero 
Este exemplar foi revisado e alterado em relação à versão original, sob responsabilidade única do autor e com a anuência de seu orientador.

São Paulo, 20 de julho de 2012.

Assinatura do autor

Assinatura do orientador

FICHA CATALOGRÁFICA

Ueda, Eduardo Takeo

Análise de políticas de controle de acesso baseado em papéis com rede de Petri colorida / E.T. Ueda. -- ed.rev. -- São Paulo, 2012.

$112 \mathrm{p}$.

Tese (Doutorado) - Escola Politécnica da Universidade de São Paulo. Departamento de Engenharia de Computação e Sistemas Digitais.

1. Redes de Petri 2. Políticas de controle de acesso I. Universidade de São Paulo. Escola Politécnica. Departamento de Engenharia de Computação e Sistemas Digitais II. t. 


\section{DEDICATÓRIA}

A Carl Adam Petri (1926 - 2010), cuja valiosa contribuição à ciência permitiu a realização desta pesquisa. 


\section{AGRADECIMENTOS}

À minha família - pais e irmãos - pelo carinho, apoio e compreensão durante todos os momentos de minha vida.

Ao meu orientador, Prof. Dr. Wilson Vicente Ruggiero, por acreditar na minha capacidade, pela excelente orientação, por me ensinar tanto ao longo dos últimos anos, e principalmente pela amizade.

Aos professores Paulo Sérgio Licciardi Messeder Barreto e Graça Bressan, pelas valiosas críticas e sugestões durante o processo de qualificação de doutorado.

A todos os professores, alunos e funcionários do Laboratório de Arquitetura e Redes de Computadores (LARC), por me proporcionarem participar de um ambiente de altíssimo conhecimento científico e tecnológico.

Aos meus amigos Claudia de Oliveira Melo, Thiago Carvalho de Sousa e Percy Javier Igei Kaneshiro, por todas as discussões referentes a meu doutorado, acrescidas muitas vezes com importantes pausas para um "cafezinho".

Ao Michael Westergaard, principal desenvolvedor da ferramenta CPN Tools, pela valiosa troca de conhecimento sobre modelagem com rede de Petri colorida.

Ao Conselho Nacional de Desenvolvimento Científico e Tecnológico (CNPq), pela concessão da bolsa de doutorado e pelo apoio financeiro em todas as minhas atividades de pesquisa durante o programa de pós-graduação.

Por fim, a todos que porventura deixei de mencionar mas que contribuíram direta ou indiretamente para que eu pudesse ter êxito na conclusão desta tese de doutorado. 


\section{RESUMO}

Controle de acesso é um tópico de pesquisa importante tanto para a academia quanto para a indústria. Controle de Acesso Baseado em Papéis (CABP) foi desenvolvido no início dos anos 1990, tornando-se um padrão generalizado para controle de acesso em vários produtos e soluções computacionais. Embora modelos CABP sejam largamente aceitos e adotados, ainda existem questões para responder. Um dos principais desafios de pesquisa em segurança baseada em papéis é determinar se uma política de controle de acesso é consistente em um ambiente altamente dinâmico. Nossa pesquisa visa preencher essa lacuna fornecendo um método para analisar políticas CABP com respeito a dois aspectos significativos: segurança e dinamismo envolvendo papéis e objetos. Para este propósito, desenvolvemos um modelo de descrição e simulação de política usando rede de Petri colorida e CPN Tools. O modelo descreve e é capaz de simular vários estados $\mathrm{CABP}$ em um contexto de educação a distância típico. Usando este modelo, foi possível analisar o espaço de estados produzido pela rede de Petri colorida em um cenário dinâmico envolvendo a criação de novos papéis e objetos. O resultado da análise de alcançabilidade da rede de Petri da política demonstrou que é possível verificar a consistência de políticas de controle de acesso considerando a dinamicidade de papéis e objetos, e apontou vantagens de aplicabilidade da modelagem de políticas de segurança em ambientes distribuídos utilizando rede de Petri colorida.

Palavras-chave: Políticas de Segurança, Controle de Acesso Baseado em Papéis, Rede de Petri Colorida, Modelagem, Simulação. 


\section{ABSTRACT}

Access control is an important research topic both for academia and industry. Role Based Access Control (RBAC) was developed in the early 1990s, becoming a generalized standard of access control for many products and computing solutions. Although RBAC models have been widely accepted and adopted, there are issues to answer. One of the key challenges for role-based security research is to characterize whether an access control policy is consistent in a highly dynamic environment. Our research aims filling this gap providing a method to analyze RBAC policies with respect to two significant aspects: security and dynamics involving roles and objects. For this purpose, we developed a policy description and simulation model using colored Petri net and the CPN Tools. The model describes and is capable to simulate many RBAC states in a typical distance education context. Using this model it was possible to analyze the state space provided by colored Petri net that simulates a dynamic environment and the creation of new roles and objects. The result of the reachability analysis of Petri net policy showed that it is possible to check the consistency of access control policies considering dynamic of roles and objects, and point out the advantages and applicability of modeling security policies in distributed environments using colored Petri net.

Keywords: Security Policies, Role Based Access Control, Colored Petri Net, Modelling, Simulation. 


\section{Lista de Figuras}

1.1 Principais Etapas da Pesquisa . . . . . . . . . . . . . 5

2.1 Elementos do Modelo RBAC . . . . . . . . . . . . . . . . . . . . 12

2.2 Distribuição das Abordagens por Ano . . . . . . . . . . . . . . 22

3.1 Marcação inicial da rede de Petri . . . . . . . . . . . . . . . . . 29

3.2 Rede de Petri durante um disparo . . . . . . . . . . . . . . . 30

3.3 Rede de Petri após um disparo . . . . . . . . . . . . . . . . 30

3.4 Rede de Petri colorida . . . . . . . . . . . . . . . . . . 33

3.5 Interface da ferramenta CPN Tools . . . . . . . . . . . . . . . 34

3.6 Seleção de múltiplos de 2,3 e 6 - Estado inicial . . . . . . . . . . . . 35

3.7 Seleção de múltiplos de 2,3 e 6 - Estado final . . . . . . . . . . 36

3.8 Rede de Petri colorida de uma Fila Limitada . . . . . . . . . . . . . 37

3.9 Declaração de cores e variáveis para a Fila Limitada . . . . . . . . . . 38

3.10 Simulação da rede de Petri colorida de uma Fila Limitada . . . . . . . 38

3.11 Rede de Petri de uma Fila Limitada - Versão 2 . . . . . . . . . . . . . 40

3.12 Declaração de cores e variáveis para a Fila Limitada - Versão 2 . . . . 41

3.13 Simulação da rede de Petri colorida de uma Fila Limitada - Versão 2 . 42

3.14 Espaço de estados com 2 usuários na fila . . . . . . . . . . . . . 43

3.15 Estados em que o usuário 1 ocupa o servidor $1 \ldots \ldots$. . . . . . . . . 44

3.16 Usuário 1 nunca ocupa o servidor $2 \ldots \ldots$. . . . . . . . . . . 44

3.17 Estados em que os usuários 1 e 2 estão juntos . . . . . . . . . . . . 45 
3.18 Espaço de estados com 3 usuários na fila . . . . . . . . . . . . . 46

3.19 Workflow de uma conferência . . . . . . . . . . . . . . 48

3.20 Declaração de cores e variáveis para o Workflow . . . . . . . . . . . . 49

3.21 SubPage Evaluation do Workflow . . . . . . . . . . 50

3.22 Detecção de inconsistência . . . . . . . . . . . . . . . 50

3.23 Representação de 3 nós do espaço de estados que satisfazem a consulta da Figura $3.22 \ldots \ldots \ldots \ldots$. . . . . . . . . . . . . . . . . .

3.24 Workflow de uma conferência com regra de autorização . . . . . . . 51

3.25 Inconsistência corrigida . . . . . . . . . . . . . . 52

3.26 Estado final do Workflow da conferência com 10 submissões . . . . . 52

5.1 Modelo de Dados . . . . . . . . . . . . . . . . . . . . 67

5.2 Tokens Coloridos da Rede do Workflow . . . . . . . . . . . . . 72

5.3 Variáveis da Rede do Workflow . . . . . . . . . . . . . . . 72

5.4 Parâmetros constantes da Rede do Workflow . . . . . . . . . . . . 73

5.5 Funções Definidas na Rede do Workflow . . . . . . . . . . . . . . . . 74

5.6 Workflow do Cenário Educacional . . . . . . . . . . . . 75

5.7 Módulo Request Offer . . . . . . . . . . . . . . . . . . . . 77

5.8 Módulo Register Student . . . . . . . . . . . . . . . . . . . . 77

5.9 Módulo Attend Class _ . . . . . . . . . . . . . . . . . . . . 78

5.10 Módulo Close Class . . . . . . . . . . . . . . . . . . . . . . . . 78

5.11 Módulo Take Exam . . . . . . . . . . . . . . . . . . . . . . . 79

5.12 Módulo Close Exam _ . . . . . . . . . . . . . . . . . . . . . 79

5.13 Módulo Evaluate Exam . . . . . . . . . . . . . . . . . . . . . . 80

5.14 Módulo Close Offer . . . . . . . . . . . . . . . . . . . . . . . . 80

5.15 Estado Final do Workflow do Cenário Educacional . . . . . . . . 81 
6.1 Verificação de Propriedade na Modelagem . . . . . . . . . . . . 86

6.2 Consulta para determinar conflito entre Professor e Aluno . . . . . . . 89

6.3 Consulta para determinar autorização não permitida do papel Monitor 89

6.4 Dinamicidade com um novo papel ouvinte . . . . . . . . . . . . . 91

6.5 Módulo Take Exam com papel Ouvinte . . . . . . . . . . . . . . 92

6.6 Consulta para determinar conflito entre Professor e Ouvinte . . . . . . 92

6.7 Consulta para determinar autorização não permitida do papel Ouvinte 93 


\section{Lista de Tabelas}

2.1 Número de Publicações por Tipo de Abordagem . . . . . . . . . . . 18

2.2 Artigos Distribuídos por Tipo de Abordagem . . . . . . . . . . 20

2.3 Aspectos de Análise em Modelos RBAC . . . . . . . . . . . . . 23

3.1 Número de estados . . . . . . . . . . . . . . . . . . 45

5.1 Relação Usuário-Papel . . . . . . . . . . . . . . . . . . . . . . 69

5.2 Permissões no modelo de controle de acesso . . . . . . . . . . . . . 69

5.3 Relação Papel-Permissão . . . . . . . . . . . . . . . . . . . . . . 70

5.4 Restrições de controle de acesso . . . . . . . . . . . . . . . . 71

5.5 Metamodelo . . . . . . . . . . . . . . . . . 83

6.1 Restrições Política de Controle de Acesso do Capítulo 5 . . . . . . . . 88

6.2 Permissões para o papel ouvinte . . . . . . . . . . . . . . . 90

6.3 Restrições da política de controle de acesso com papel aluno ouvinte . 90 


\section{Lista de Abreviaturas e Siglas}

CPN Colored Petri Net

DSD Dynamic Separation of Duty Relations

ML Modelling Language

NIST National Institute of Standards and Technology

RBAC Role-Based Access Control

RP Rede de Petri

RPC Rede de Petri Colorida

SSD Static Separation of Duty Relations

UML Unified Modeling Language 


\section{Sumário}

1 Introdução 1

1.1 Motivação . . . . . . . . . . . . . . . . . . 1

1.2 Problema de Pesquisa . . . . . . . . . . . . . . . 3

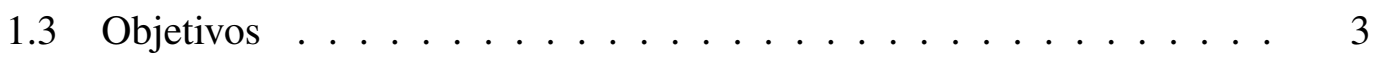

1.4 Questões de Pesquisa . . . . . . . . . . . . . . . . . 4

1.5 Metodologia ...................... 4

1.6 Contribuições Esperadas . . . . . . . . . . . . . . . . 6

1.7 Descrição Estrutural . . . . . . . . . . . . . . . . . . . 7

2 Controle de Acesso Baseado em Papéis $\quad 10$

2.1 Introdução . . . . . . . . . . . . . . . . . 10

2.2 Características do Modelo Baseado em Papéis . . . . . . . . . . . 10

2.2.1 Usuários, Papéis e Permissões . . . . . . . . . . . . . . 10

2.2.2 Princípio do Privilégio Mínimo _. . . . . . . . . . . 12

2.3 Modelo RBAC Padronizado pelo NIST . . . . . . . . . . . . . . . 13

2.3.1 Modelo de Referência . . . . . . . . . . . . . . 13

2.3.2 Especificação Funcional . . . . . . . . . . . . . . . 15

2.4 Abordagens para Estabelecimento da Relação Papel-Permissão . . . . 16

2.4.1 Planejamento do Mapeamento Sistemático . . . . . . . . . . 16

2.4 .2 Estratégias Identificadas . . . . . . . . . . . . . . . . 18 
2.4.3 Avaliação das Técnicas Encontradas . . . . . . . . . . . 21

2.5 Síntese e Desafios de Pesquisa . . . . . . . . . . . . . . . 24

3 Rede de Petri e sua Aplicabilidade 2

3.1 Introdução . . . . . . . . . . . . . . . . . . . . 26

3.2 Rede de Petri . . . . . . . . . . . . . . . . . 26

3.2.1 Histórico da Rede de Petri . . . . . . . . . . . . . . . 26

3.2.2 Estrutura de uma Rede de Petri . . . . . . . . . . . . . 28

3.2.3 Representação Gráfica . . . . . . . . . . . . . . . . . . 29

3.2 .4 Propriedades . . . . . . . . . . . . . . . 29

3.2.5 Classificação de uma Rede de Petri . . . . . . . . . . . 32

3.3 Rede de Petri Colorida . . . . . . . . . . . . . . . . . . . 32

3.3 .1 Definição Formal . . . . . . . . . . . . . . . . . . . 32

3.3.2 Ferramenta CPN Tools . . . . . . . . . . . . . . 34

3.3.3 Técnicas de Análise e Validação . . . . . . . . . . . . . . 39

3.3.4 Espaço de Estados . . . . . . . . . . . . . . . . . . . . 39

3.4 Aplicações de Rede de Petri . . . . . . . . . . . . . . . . . . . . . . 47

3.5 Síntese e Desafios de Pesquisa . . . . . . . . . . . . . . . . 52

4 Método de Pesquisa $\quad 54$

4.1 Introdução . . . . . . . . . . . . . . . . . . . . . 54

4.2 Métodos de Pesquisa na Área de Segurança . . . . . . . . . . . . . 54

4.3 Simulação de Sistemas . . . . . . . . . . . . . . . . . . . . 56

4.3.1 Verificação e Validação de Modelos . . . . . . . . . . . . . . 59

4.4 Características de um Ambiente Educacional . . . . . . . . . . . 60

4.5 Síntese e Desafios de Pesquisa . . . . . . . . . . . . . . . . 63 
5 Modelagem de Política de Controle de Acesso com Rede de Petri Colorida 64

5.1 Introdução . . . . . . . . . . . . . . . . . . . . 64

5.2 Ambiente Educacional . . . . . . . . . . . . . . . . 65

5.2 .1 Atores e Objetos . . . . . . . . . . . . . 65

5.2.2 Direitos, Obrigações e Responsabilidades . . . . . . . . . . 66

5.3 Política de Controle de Acesso do Cenário Proposto . . . . . . . . . . 68

5.4 Modelagem do Sistema com Rede de Petri Colorida . . . . . . . . . . 71

5.4.1 Workflow Operacional .............. 71

5.5 Metamodelo ......................... 82

5.6 Síntese . . . . . . . . . . . . . . . . . . . . . . 84

6 Avaliação de Consistência da Política $\quad 85$

6.1 Introdução . . . . . . . . . . . . . . . . . . . 85

6.2 Ciclo de Vida de uma Política . . . . . . . . . . . . . 85

6.3 Técnica para Análise de Políticas com Rede de Petri Colorida . . . . . 87

6.3.1 Análise de Alcançabilidade . . . . . . . . . . . . . . . 87

6.3.2 Verificação de Violação da Política . . . . . . . . . . . . . 88

6.4 Avaliação com Dinamicidade de Papéis, Ações e Objetos . . . . . . 89

6.4.1 Dinamicidade Causada por Permissões Existentes . . . . . . . 89

6.4.2 Dinamicidade Causada por Novas Permissões . . . . . . . . . 93

6.5 Discussão . . . . . . . . . . . . . . . . . . . 95

6.6 Síntese . . . . . . . . . . . . . . . . . . . 97

7 Conclusão

7.1 Principais Contribuições . . . . . . . . . . . . . . . . . . . 99

7.2 Publicações . . . . . . . . . . . . . . . . . . . . . 100 
7.3 Limitações . . . . . . . . . . . . . . . . . . . . . . 102

7.4 Trabalhos Futuros . . . . . . . . . . . . . . . 103

$\begin{array}{ll}\text { Referências } & 105\end{array}$ 


\section{Introdução}

\subsection{Motivação}

Controle de acesso é um tema de pesquisa importante dentro do contexto de segurança de sistemas, pois é um dos componentes de segurança fundamentais em qualquer sistema de computação. No início da década de 90, o modelo de Controle de Acesso Baseado em Papéis (Role-Based Access Control - RBAC) começou a ganhar destaque, devido, principalmente, à sua flexibilidade e facilidade de gerenciamento (FERRAIOLO; KUHN, 1992).

Em um modelo de Controle de Acesso Baseado em Papéis, as permissões são atribuídas a papéis em vez de serem associadas diretamente a usuários. Desta forma, os papéis é que devem ser atribuídos aos usuários (SANDHU, 1998). Formalmente, sob um ponto de vista matemático, podemos compreender um modelo RBAC como sendo formado por conjuntos de $(\mathrm{U})$ usuários, $(\mathrm{R})$ papéis, $(\mathrm{P})$ permissões e $(\mathrm{S})$ sessões, com relacionamentos matemáticos associados a esses conjuntos. Esses relacionamentos são a relação Usuário-Papel, que atribui papéis a usuários, a relação Papel-Permissão, que atribui permissões a papéis, e a relação Papel-Papel, que é uma atribuição hierárquica entre papéis.

Um aspecto muito relevante e muitas vezes tratado com pouca ênfase na construção de sistemas é a formulação de políticas robustas de controle de acesso (LI; TRIPUNITARA, 2006). A definição dessas políticas é normalmente orientada por modelos que fornecem um conjunto de regras e mecanismos para o funcionamento seguro de uma representação abstrata de sistemas. Porém, a administração de tais políticas frequentemente se torna um processo complexo, pois deve garantir que elas sejam eficientes e que não comprometam o desempenho dos sistemas. 
A grande vantagem do RBAC em relação aos sistemas de controle de acesso anteriores está na administração das autorizações de acesso. Desta forma, a administração do controle de acesso torna-se mais simples e viável para sistemas com grande número de usuários, trazendo inclusive benefícios financeiros em sua utilização devido à redução de custos operacionais (GALLAHER; CONNOR; KROPP, 2002).

Um dos maiores desafios em grandes redes de informação é a complexidade de administração de segurança. O modelo RBAC tem contribuído para reduzir esse problema, diminuindo custos. Hoje em dia, a maioria das empresas fornecedoras de tecnologia da informação tem incorporado RBAC em suas soluções e produtos. Assim, é possível encontrar implementações de modelos RBAC em áreas que vão desde saúde e medicina até defesa militar.

Com a enorme aplicação do modelo RBAC, muitas pesquisas foram direcionadas para estudar maneiras de verificar a consistência desse tipo de política de controle de acesso. Verificar a consistência de uma política de segurança corresponde a analisar a aderência das regras desta política ao cenário que ela é aplicada; com isso, uma inconsistência na política é representada por uma violação de uma regra (CHOLVY; CUPPENS, 1997; RIBEIRO et al., 2000; CHANGHUA; YAQIN; ZHENSONG, 2009).

Uma iniciativa relativamente recente para a análise de consistência de políticas de segurança diz respeito à modelagem de RBAC usando rede de Petri colorida (RAKKAY; BOUCHENEB, 2009). Por meio desse tipo de abordagem, é possível simular o comportamento das relações de uma especificação RBAC e analisar o espaço de estados da rede para tentar descobrir se existe a possibilidade de o sistema chegar em algum estado considerado inseguro.

Kahloul et al. (2010) mostraram como efetuar uma modelagem e análise de uma política RBAC utilizando rede de Petri colorida e a ferramenta CPN Tools. Nesse artigo, os autores deram significativa ênfase ao processo de modelagem, mas dedicaram pouco destaque na explicação do método de análise do espaço de estados.

Em trabalho posterior, Laid, Djouani e Tfaili (2010) utilizaram rede de Petri colorida temporizada para modelar e analisar um modelo RBAC temporal. Os autores concentraram-se na modelagem de restrições temporais, que representam um aspecto adicional que não é considerado no RBAC tradicional. 
Por fim, a modelagem e análise de ambientes RBAC é um eixo de pesquisa ambicioso que pretende desenvolver técnicas que possam verificar a consistência de políticas de controle de acesso baseado em papéis.

\subsection{Problema de Pesquisa}

Desenvolver técnicas ou métodos que avaliem a consistência de políticas de controle de acesso é um desafio crucial na área de segurança baseada em papéis (RAKKAY; BOUCHENEB, 2009). Esse problema fica mais difícil de ser abordado quando são considerados aspectos dinâmicos, tais como o surgimento de um novo papel, ação ou objeto.

Ao longo do tempo, políticas de controle de acesso podem apresentar mudanças, ou seja, elas se caracterizam por apresentar ciclos de vida. Essas mudanças são uma característica evolucionária importante que vem sendo analisada por pesquisadores que se dedicam a investigar modelos baseados em papéis (SOHR et al., 2008). Neste contexto, existe a necessidade de se buscar métodos para verificar se uma política permanece consistente mesmo após ela sofrer alterações (KAHLOUL et al., 2010).

O problema de pesquisa desta tese consiste em descobrir uma metodologia que possa capturar o comportamento de uma política de controle de acesso baseada em papéis por meio de uma representação que permita avaliar sua consistência. Em particular, deseja-se considerar o efeito da dinamicidade que novos papéis e objetos provocam na política.

\subsection{Objetivos}

O principal objetivo desta tese é fornecer um método que demonstre a aplicabilidade da modelagem e análise de políticas de segurança baseada em papéis, a partir de um modelo de dados, utilizando rede de Petri colorida, considerando o aspecto de dinamicidade de papéis, ações e objetos.

Visando atingir tal objetivo geral, devemos considerar a formulação de objetivos específicos, que são explicados a seguir. 
Modelagem e Simulação. Mostrar a eficácia de modelagem e simulação de um sistema que adota uma política de controle de acesso baseada em papéis com rede de Petri colorida. Desenvolver o modelo a partir do modelo de dados, ou seja, elaborar um metamodelo. Ressaltar a facilidade de incrementar o modelo quando surge um novo papel, ação ou objeto, devido às características expansíveis que apresenta uma rede de Petri colorida.

Análise de Consistência. Desenvolver um procedimento de análise de consistência da política de segurança do metamodelo com rede de Petri colorida. Em tal análise, deve ser possível avaliar a segurança da política de controle de acesso, bem como verificar o efeito da dinamicidade do sistema caracterizado pelo surgimento de um novo papel que afeta o ciclo de vida da política adotada.

\subsection{Questões de Pesquisa}

Levando em consideração o problema de pesquisa e os objetivos desta pesquisa, pretende-se responder às seguintes questões de pesquisa $(\mathrm{QP})$ :

- QP1: Quais tipos de estratégias podem ser utilizadas na criação de papéis em um modelo de controle de acesso baseado em papéis?

- QP2: Como descrever e simular uma política de controle de acesso baseado em papéis e capturar a dinamicidade de um novo papel ou objeto?

- QP3: Considerando que uma política de controle de acesso baseada em papéis esteja bem descrita, como avaliar a consistência desta política?

\subsection{Metodologia}

O método de pesquisa adotado nesta pesquisa é composto de cinco etapas, como mostra a Figura 1.1. As questões de pesquisa relacionadas a cada etapa foram devidamente marcadas.

A Etapa 1 consiste em estudar e compreender profundamente os detalhes do modelo de controle de acesso baseado em papéis. Isso inclui conhecer os principais as- 
pectos relacionados a esse tipo de controle de acesso, e os desafios de pesquisa da área representa a primeira etapa.

A Etapa 2 consiste em realizar um mapeamento sistemático dentro da área de pesquisa sobre controle de acesso baseado em papéis, com a finalidade de identificar quais são as principais abordagens propostas na literatura para o estabelecimento da relação papel-permissão. Este estudo sistemático é necessário para auxiliar a delimitação do escopo de pesquisa que é considerado nesta tese.

Uma vez identificadas e avaliadas as abordagens, tornou-se possível concluir que a modelagem com rede de Petri colorida representa uma ferramenta poderosa que pode ser utilizada para resolver o problema de pesquisa da tese. A partir dessa constatação, nossa atenção foi direcionada para o estudo da teoria de rede de Petri, em especial rede de Petri colorida, no que consiste a Etapa 3.

A Etapa 4 consiste em realizar a modelagem de uma política de segurança em um cenário educacional, que representa um ambiente real e com características dinâmicas, a partir de um modelo de dados já especificado. Essa modelagem através de rede de Petri colorida foi possível com o auxílio da ferramenta CPN Tools (JENSEN; KRISTENSEN; WELLS, 2007), desenvolvida pela Universidade de Aarhus (Dinamarca).

Finalmente, uma vez realizada a modelagem de um ambiente educacional e a política de segurança baseada em papéis dentro desse contexto, é possível verificar a consistência dessa política. Com o software CPN Tools é possível analisar o espaço de estados gerado pelo modelo com rede de Petri colorida e buscar possíveis ocorrências de violações da política, levando em consideração a dinamicidade decorrente do surgimento de novos papéis ou objetos. A Etapa 5 compreende a análise de consistência da política.

\subsection{Contribuições Esperadas}

Uma vez definido o problema de pesquisa da tese, assim como nossos objetivos, questões de pesquisa e a metodologia utilizada, é possível destacarmos quais são as contribuições que são esperadas para esta tese. 


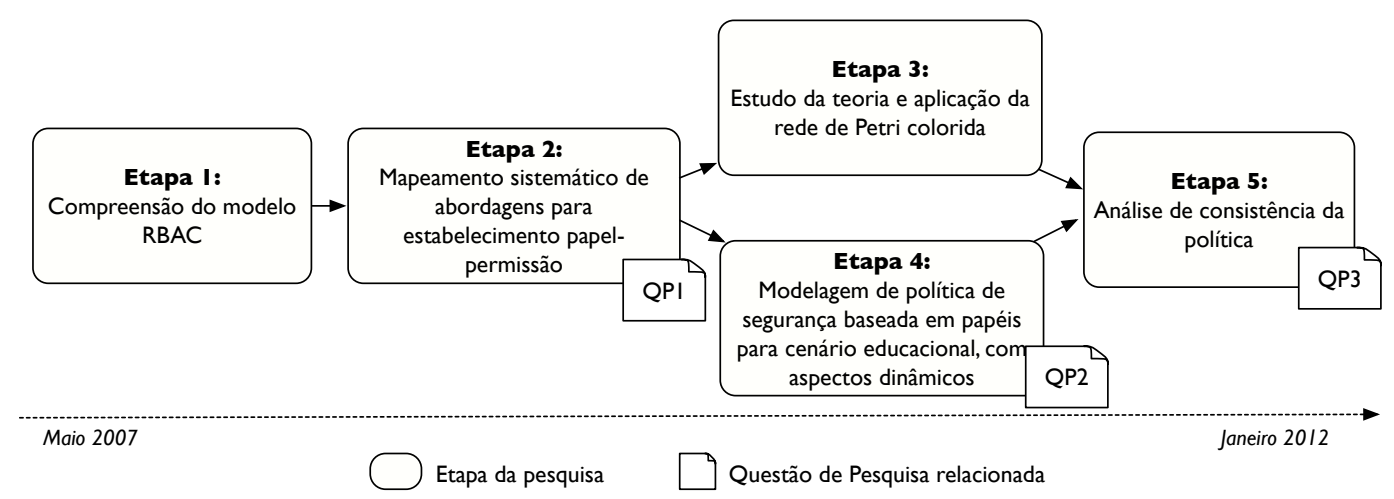

Figura 1.1: Principais Etapas da Pesquisa

A primeira contribuição relevante é representada pelo mapeamento sistemático (UEDA; RUGGIERO, 2012) discutido no Capítulo 2. Tal estudo é responsável por identificar e classificar as principais técnicas que foram propostas na literatura para tratar do estabelecimento da relação papel-permissão em modelos de controle de acesso baseados em papéis. Essa contribuição está relacionada à QP1.

Uma segunda contribuição é obtida através de um exemplo de modelagem da política de controle de acesso de um ambiente educacional que produz uma representação com rede de Petri colorida. Assim, foi possível capturar vários dos aspectos comportamentais dinâmicos dos papéis deste cenário. As regras identificadas neste processo de modelagem definem um método que pode ser aplicado para representar políticas de controle de acesso baseado em papéis em qualquer outro ambiente. Portanto, a partir de um cenário específico, foi possível desenvolver um metamodelo que pode ser aplicado em diversos tipos de contextos. Essa contribuição está relacionada à QP2.

Por fim, uma terceira contribuição consiste em demonstrar a eficácia de avaliação de consistência de uma política de controle de acesso baseado em papéis através de análise de espaço de estados da rede de Petri colorida. Nesse processo de análise, é levado em consideração o aspecto de dinamicidade de papéis e objetos, que ocorre em vários ambientes, não apenas o educacional, e pode acarretar mudanças necessárias em políticas de controle de acesso em vigor. Essa contribuição está relacionada à QP3. 


\subsection{Descrição Estrutural}

O conteúdo desta tese de doutorado foi desenvolvido e estruturado em 7 capítulos, que são descritos em detalhes a seguir.

Capítulo 1 - Introdução. Apresenta a motivação para o assunto abordado pela tese, o problema de pesquisa, os objetivos, questões de pesquisa vinculados ao problema, metodologia seguida, contribuições esperadas e a descrição organizacional.

Capítulo 2 - Controle de Acesso Baseado em Papéis. Neste capítulo, são apresentados conceitos fundamentais para a compreensão do modelo de controle de acesso baseado em papéis. Também é descrito sucintamente o padrão RBAC proposto pelo NIST (National Institute of Standards and Technology). O enfoque relevante deste capítulo é o mapeamento sistemático que foi realizado e que identifica as principais abordagens para estabelecimento da relação papel-permissão, representando uma contribuição inédita.

Capítulo 3 - Rede de Petri e sua Aplicabilidade. Este capítulo apresenta os principais conceitos e características de uma rede de Petri. Em particular, é dado destaque à rede de Petri colorida, que é uma classe de rede de Petri muito popular e utilizada para modelar sistemas distribuídos. Algumas aplicações de rede de Petri são comentadas com o intuito de demonstrar a relevância do assunto, principalmente para analisar políticas de segurança.

Capítulo 4 - Método de Pesquisa. Neste capítulo, inicialmente, são discutidos os principais métodos de pesquisa aplicados na área de segurança. O método adotado por esta tese é a simulação e análise de espaço de estados; por isso, conceitos relacionados a esse tipo de abordagem são apresentados. Este capítulo destaca a importância de processos que envolvem simulação para verificar e validar propriedades em sistemas. Por fim, discorremos sobre alguns aspectos relevantes para realizar a modelagem e simulação de um ambiente educacional.

\section{Capítulo 5 - Modelagem de Políticas de Controle de Acesso com Rede de Petri} Colorida. Este capítulo inicia com a caracterização de entidades e atividades de um ambiente educacional genérico. A partir disso, apresenta um modelo de dados deste cenário proposto, além de descrever uma política de controle de acesso. Assim, é possível realizar a modelagem do sistema que incorpora a política de controle de acesso 
baseada em papéis utilizando rede de Petri colorida e a ferramenta CPN Tools. Desta forma, fomos capazes de desenvolver um processo de metamodelagem que consiste em regras de transformação de um modelo de dados em um modelo com rede de Petri colorida.

Capítulo 6 - Avaliação de Consistência da Política. Neste capítulo, é realizada a análise de consistência da política do cenário que foi proposto e modelado. Através do modelo com rede de Petri colorida, é possível realizar consultas ao espaço de estados gerado pela ferramenta CPN Tools com a finalidade de encontrar possíveis violações da política que podem ocorrer em algum momento.

Capítulo 7 - Conclusões. O último capítulo apresenta as principais contribuições desta pesquisa de doutorado; lista cronologicamente os artigos publicados aceitos e em fase de elaboração; e discute sucintamente as limitações encontradas. Adicionalmente, são indicados possíveis caminhos de investigação que podem ser seguidos para a realização de trabalhos futuros. 


\section{Controle de Acesso Baseado em Papéis}

\subsection{Introdução}

Neste capítulo, são apresentados aspectos importantes relacionados ao modelo de controle de acesso baseado em papéis. Inicialmente, são introduzimos os conceitos fundamentais para a compreensão do controle de acesso baseado em papéis. Depois, é apresentado sucintamente o modelo RBAC padronizados pelo NIST (National Institute of Standards and Technology), uma vez que esse modelo é considerado como base referencial para diversas pesquisas na área de controle de acesso. Também é descrito um mapeamento sistemático com foco na identificação de técnicas para estabelecimento da relação papel-permissão. Por fim, é apresentada uma síntese deste capítulo e desafios de pesquisa na área de controle de acesso baseado em papéis.

\subsection{Características do Modelo Baseado em Papéis}

\subsubsection{Usuários, Papéis e Permissões}

O modelo de controle de acesso baseado em papéis (Role-Based Access Control - RBAC) flexibiliza o gerenciamento do controle de acesso através da adição de um componente que intermedia usuários e permissões (SANDHU, 1998). O modelo considera a existência de quatro componentes básicos: usuários (ou sujeitos); papéis; permissões; e sessões.

Usuários podem ser seres humanos ou outros agentes autônomos, tais como robôs, agentes de softwares e computadores. Permissões são os direitos de executar uma 
ou mais ações ou operações sobre objetos do sistema. Os objetos podem representar arquivos ou dispositivos como conexões de rede, bancos de dados, entre outros. As permissões concedidas variam conforme a semântica do objeto. Um banco de dados, por exemplo, pode conceder permissões para leitura ou alteração de registros, enquanto um sistema operacional pode permitir a execução de um programa ou a impressão de um arquivo.

Os papéis são os intermediários entre os usuários e as permissões. Em vez de conceder permissões diretamente aos usuários, as permissões são concedidas aos papéis. Papéis são funções distintas dentro do sistema ou ambiente organizacional, como por exemplo Administrador, Contador, ou Auditor.

Usuários são associados a um ou mais papéis. Quando um usuário acessa o sistema, ele inicia uma sessão e, durante essa sessão, pode haver um ou mais papéis ativos. É possível ainda que um usuário mantenha várias sessões ativas paralelamente. Conforme a especificação do modelo, o usuário pode ter ou não o poder de decidir quais papéis ativar em um dado momento.

O modelo RBAC permite que sejam impostas restrições na ativação de papéis, de modo a impedir a ativação de papéis com conflitos de interesse ou mesmo que um usuário possua papéis conflitantes. Os papéis podem ser organizados de maneira hierárquica, gerando uma cadeia de herança de permissões.

A Figura 2.1 apresenta os diversos elementos do modelo RBAC, incluindo usuários, papéis, permissões, restrições e sessões. Um usuário pode ter várias sessões abertas e cada sessão pode ter vários papéis ativados. Um papel pode estar relacionado a muitas permissões e uma mesma permissão pode estar relacionada a muitos papéis. Um usuário pode estar relacionado a muitos papéis e um papel pode estar relacionado a vários usuários. Pode haver ainda uma relação de herança entre múltiplos papéis. Por fim, as restrições podem ser aplicadas a diversas partes do modelo.

A flexibilidade do RBAC reside no fato de que o gerenciamento de permissões não precisa mais ser individualizado. Ou seja, quando um usuário deixa de ser responsável por uma função no sistema, basta desassociá-lo do papel. Caso seja necessário adicionar uma permissão ao papel, basta conceder o direito ao papel, em vez de ter que conceder o direito individualmente para todos os participantes que estão associados ao papel. 


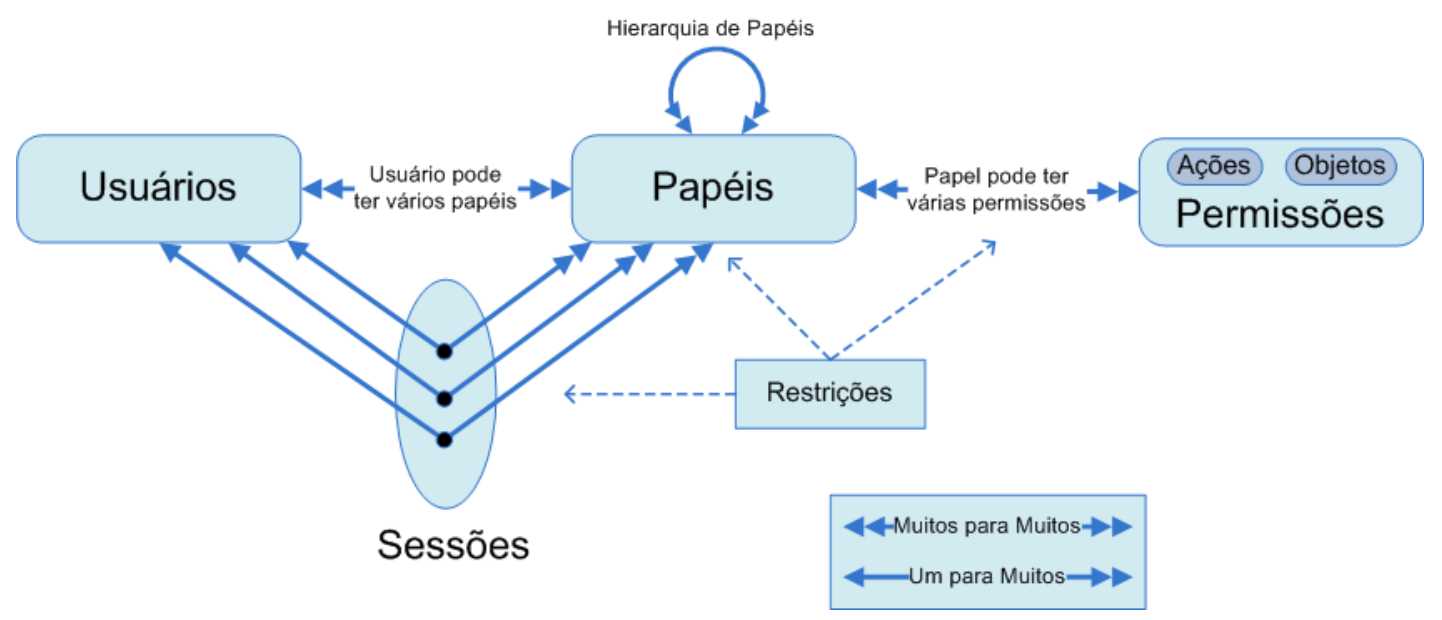

Figura 2.1: Elementos do Modelo RBAC

\subsubsection{Princípio do Privilégio Mínimo}

Um aspecto importante do Controle de Acesso Baseado em Papéis é que ele permite a implementação do princípio do privilégio mínimo - um usuário só deverá ter as permissões que precisa para realizar sua tarefa.

Papéis melhoram a segurança dentro de determinado ambiente, pois quando uma função é criada dentro de uma organização, o nível de acesso de um usuário à informação precisa ser bem definido. Privilégio mínimo nesse contexto significa que os requisitos de acesso são determinados, uma vez que para um papel só deve ser dada permissão para realizar tarefas necessárias; nenhuma permissão adicional deve ser dada.

Em ambientes distribuídos em que políticas não são baseadas em papéis, usuários muitas vezes têm permissões de acesso superior ao que é necessário. Por exemplo, quando responsabilidades de trabalho sobrepõem categorias de trabalho, os administradores podem ser incapazes de limitar o acesso a informações confidenciais. RBAC melhora a segurança dentro desse tipo de cenário, pois impede que os usuários tenham acesso a informações fora de seus papéis. Esta negação de acesso impede que os usuários contornem a política de segurança baseada em papéis. 


\subsection{Modelo RBAC Padronizado pelo NIST}

O padrão proposto pelo NIST para o RBAC compreende um modelo de referência e uma especificação funcional (FERRAIOLO et al., 2001). O modelo de referência estabelece rigorosamente os conjuntos de entidades, os relacionamentos e as restrições que constituem o RBAC. Ele também visa definir um vocabulário comum de termos para especificar coerentemente os requisitos e determinar o escopo das características do RBAC incluídas no padrão. A especificação funcional define: i) os requisitos dos procedimentos administrativos para criação e manutenção dos conjuntos de entidades e dos relacionamentos do RBAC; ii) as funções de revisão para consultas administrativas; e iii) as funções de sistema para criar e gerenciar sessões de usuários e efetuar decisões de autorização de acesso.

\subsubsection{Modelo de Referência}

O objetivo central do modelo de referência é (1) definir uma nomenclatura contendo termos para serem utilizados em aplicações RBAC; e (2) especificar as características e funcionalidades do modelo. O modelo de referência divide o RBAC em 4 componentes: (a) RBAC Básico, o qual define as entidades básicas do modelo e seus relacionamentos; (b) RBAC Hierárquico, o qual define as especificações e relacionamentos para dar suporte à hierarquia entre papéis; $(c)$ Relação de Separação Estática de Tarefas; e $(d)$ Relação de Separação Dinâmica de Tarefas, os quais definem os relacionamentos de separação de tarefas para assegurar que indivíduos não assumam papéis conflitantes de forma estática e dinâmica, garantindo assim as políticas de interesse das organizações. Os componentes $(c)$ e $(d)$ compõem o RBAC Restrito.

\section{RBAC Básico}

O RBAC Básico incorpora os aspectos que caracterizam um modelo de controle de acesso como sendo um modelo para RBAC. O essencial é que usuários estejam associados a papéis, que por sua vez estão associados às autorizações. Requer que as relações usuário-papel e papel-autorização sejam do tipo muitos-para-muitos. Introduz ainda o conceito de sessão, que permite, ao usuário que a iniciou, a ativação e desativação simultâneas de mais de um papel. 


\section{RBAC Hierárquico}

O RBAC Hierárquico adiciona, ao RBAC Básico, requisitos para dar suporte às hierarquias de papéis. Matematicamente, uma hierarquia é uma ordem parcial que define uma relação de responsabilidades entre papéis. Em geral, papéis com maior responsabilidade (mais específicos) adquirem as autorizações de papéis com menor responsabilidade (mais genéricos). Por outro lado, papéis com menor responsabilidade também podem incorporar certas permissões de papéis com maior responsabilidade. $\mathrm{O}$ RBAC Hierárquico admite duas formas possíveis de hierarquia: uma genérica, capaz de suportar uma ordem parcial arbitrária; e outra restrita, podendo suportar apenas estruturas como árvores ou árvores invertidas.

\section{Relação de Separação Estática de Tarefas}

A Relação de Separação Estática de Tarefas (Static Separation of Duty Relations - SSD) entre papéis é uma forma "forte" de estabelecer o conflito entre as atividades desempenhadas dentro de uma organização. Neste caso, se um usuário está na lista de membros de um papel A e há um relacionamento de SSD entre o papel A e um papel $\mathrm{B}$, este usuário não poderá ser incluído na lista de membros do papel B.

Para dar maior flexibilidade à construção deste relacionamento, Sandhu, Ferraiolo e Kuhn (2000) definem a relação SSD com dois argumentos. O primeiro indica um conjunto de papéis que pode ser composto por dois ou mais papéis. O segundo informa a cardinalidade do conjunto, ou seja, a quantidade máxima maior do que um de papéis pertencentes ao conjunto correspondente que um usuário pode assumir, qualquer que seja a combinação entre eles.

Essa relação de SSD também deve ser respeitada pelo RBAC Hierárquico. Por exemplo, admita um cenário contendo três papéis: A, B e C. Supondo que exista um conflito por SSD entre os papéis B e C e que o papel A herde o papel B, então A e C também possuem um conflito por SSD entre si.

\section{Relação de Separação Dinâmica de Tarefas}

De forma semelhante à Relação de Separação Estática de Tarefas, a Relação de Separação Dinâmica de Tarefas (Dynamic Separation of Duty Relations - DSD) também é utilizada para a limitação de permissões. No entanto, de forma menos restritiva, a DSD é criada no contexto dinâmico da ativação da sessão do usuário. Nesse caso, se 
um usuário está incluído na lista de membros de um papel A e há uma relação de DSD entre este papel e um papel B, o usuário também pode estar incluído na lista de membros do papel B. Entretanto, durante uma sessão de usuário, ele não poderá assumir simultaneamente os dois papéis. A relação de DSD é utilizada quando os papéis não criam conflito quando agem de forma independente, mas apenas simultaneamente.

De forma similar às relações de SSD, as relações de DSD são especificadas com dois argumentos, o primeiro indicando o conjunto de papéis e o segundo indicando a cardinalidade do conjunto.

\subsubsection{Especificação Funcional}

O modelo de referência apresentado na subseção anterior definiu uma série de entidades, componentes e relacionamentos. Para a criação e manutenção desses elementos do modelo RBAC, Sandhu, Ferraiolo e Kuhn (2000) propõem uma especificação de necessidades funcionais que fornecem a semântica de operação do modelo. Assim, eles agrupam a especificação em três categorias:

- Funções Administrativas - Funções de criação e manutenção dos elementos e relacionamentos para a construção dos vários modelos RBAC;

- Funções do Sistema - Funções de suporte necessárias durante a interação de um usuário com o sistema (por exemplo, uma sessão de usuário); e

- Funções de Revisão - Funções de verificação dos resultados das ações realizadas pelas funções administrativas.

Por ser o RBAC uma tecnologia aberta e ainda em evolução, a proposta de padronização do NIST permite que extensões do modelo básico incluam características mais avançadas, voltadas à solução de problemas específicos de controle de acesso não atendidos satisfatoriamente pelo padrão. Essa abertura representa uma possibilidade de uso do modelo do NIST em pesquisas na área de RBAC. 


\subsection{Abordagens para Estabelecimento da Relação Papel- Permissão}

\subsubsection{Planejamento do Mapeamento Sistemático}

Nesta seção, é realizado um mapeamento sistemático da literatura com o intuito de identificar e analisar as propostas mais relevantes que tratam do problema de estabelecimento do relacionamento papel-permissão em modelos de controle de acesso baseados em papéis. Para efetuar esse tipo de estudo, adaptamos as orientações propostas por Kitchenham (2004), originalmente propostas para a área de Engenharia de Software Experimental. Além disso, seguimos o protocolo desenvolvido por Biolchini et al. (2005), que facilita o planejamento e aplicação de estudos sistemáticos em Engenharia de Software.

O planejamento do mapeamento consiste em definir quais são os objetivos da pesquisa e o processo de execução do mapeamento em si. É preciso formular a questão de pesquisa, quais serão as bases de dados utilizadas como fontes, e como será realizada a seleção de estudos primários que serão incluídos no mapeamento.

\section{Formulação da Questão de Pesquisa do Mapeamento}

O principal objetivo do mapeamento é identificar quais são as iniciativas em estudos científicos que abordam a temática de criação de papéis em modelos de controle de acesso baseados em papéis. Sendo assim, a questão de pesquisa que se deseja responder é a seguinte: “Quais as abordagens (técnicas) que estão sendo utilizadas no estabelecimento do Relacionamento Papel-Permissão em modelos de Controle de Acesso Baseados em Papéis?"

Além de identificar estudos que respondam à questão formulada, também almejase classificar tais abordagens. Esse passo é fundamental para a análise dos resultados. Assim, o produto do mapeamento servirá como indicação das possíveis direções de pesquisa na área de controle de acesso baseados em papéis.

\section{Seleção de Fontes}

O objetivo desta parte é definir quais serão as bases de dados nas quais será realizada a busca de trabalhos relevantes que potencialmente respondam à questão de pesquisa. 
As bases de dados consideradas devem representar fontes de busca confiáveis para pesquisadores da área de computação. Além disso, essas fontes devem estar disponíveis na web e possibilitar busca utilizando string de palavras-chave.

Foram consideradas as seguintes fontes de busca: IEEE Digital Library, ACM Digital Library, Scopus, ISI Web of Knowledge, e Google Scholar. A escolha dessas bases de pesquisa foi baseada na opinião do autor desta tese, além de consulta a parceiros acadêmicos, que consideraram tais fontes muito relevantes para achar publicações na área de computação.

\section{Seleção de Estudos}

Uma vez definida a questão de pesquisa e as fontes de busca, é necessário elaborar uma string de busca com termos-chave para identificar estudos científicos que apresentem resultados aderentes à meta do mapeamento sistemático.

A string de busca aplicada foi ("Role-Based Access Control" OR RBAC) AND ("Permission Assignment" OR "Role-Permission Assignment" OR "Permission Relation" OR "Role-Permission Relation" OR "Permission Relationship" OR "RolePermission Relationship” OR “Permission Mapping” OR “Role-Permission Mapping”). A primeira parte dessa expressão lógica significa que a busca deve filtrar publicações sobre modelos de Controle de Acesso Baseados em Papéis; e a segunda parte representa busca por termos sinônimos para Relacionamento Papel-Permissão.

Para a seleção de estudos nas fontes de pesquisa, é preciso considerar critérios de inclusão e exclusão que devem ser aplicados nas publicações indicadas pela string de termos-chave. Considerando o critério de inclusão na análise de título e abstract das publicações seleciona-se um conjunto de estudos considerados relevantes e que possivelmente respondem à questão de pesquisa. Em seguida, com a aplicação do critério de exclusão na análise do conteúdo de cada publicação selecionada, chegase a um conjunto de estudos primários que o mapeamento sistemático se propõe-se a identificar.

O seguinte critério de inclusão foi considerado: Selecionar apenas artigos científicos nos quais o título e/ou abstract indiquem que o conteúdo da publicação aborda o estudo de Relacionamento Papel-Permissão em modelos de Controle de Acesso Baseados em Papéis. Como critério de exclusão temos: a análise de seções como Intro- 
dução, Conclusão ou alguma outra seção mostra que a publicação não representa um estudo sobre Relacionamento Papel-Permissão.

\subsubsection{Estratégias Identificadas}

Neste ponto, a busca através da string de termos-chave deve ser aplicada nas bases de dados científicas, e publicações que estão de acordo com os critérios de inclusão e exclusão devem ser selecionados como estudos primários do mapeamento sistemático. A utilização da string de busca nas 5 fontes de pesquisa retornou 378 referências. Depois de aplicar os critérios de inclusão e exclusão, foi possível chegar a um conjunto de 46 artigos.

A manipulação de 378 referências é uma tarefa bastante onerosa. Para facilitar o trabalho, foi utilizado o Gerenciador de Referências JabRef (TEAM, 2011). Através dele, foi possível aplicar o critério de inclusão sem ser preciso fazer download de nenhum artigo, pois essa ferramenta possibilita a análise de título e abstract, além de outras informações como tipo de publicação. A Tabela 2.1 apresenta as abordagens indentificadas pelo mapeamento e o número de publicações em cada uma delas.

Tabela 2.1: Número de Publicações por Tipo de Abordagem

\begin{tabular}{lc}
\hline Tipo de Abordagem & Número de Publicações \\
\hline Modelo Temporal & 1 \\
Rede Neural & 1 \\
Rede de Petri & 1 \\
Informação de Contexto & 2 \\
Álgebra Relacional & 2 \\
Conflito de Permissões & 2 \\
Estrutura Organizacional & 4 \\
\hline Engenharia/Mineração de Papéis & 34 \\
\hline
\end{tabular}

A Tabela 2.2 apresenta os artigos identificados pelo mapeamento e distribuídos de acordo com as abordagens descobertas. A seguir, cada uma dessas abordagens é descrita em maiores detalhes.

\section{Modelo Temporal}

Bertino, Bonatti e Ferrari (2001) propõem uma extensão do modelo de controle de acesso tradicional, em que papéis existem dentro de contextos temporais. Com isso, 
papéis podem ser ativados ou desativados através da consideração de dependências temporais associadas a permissões.

\section{Rede Neural}

Chae, Kim e Kim (2003) apresentam uma implementação do modelo de controle de acesso baseado em papéis utilizando redes neurais, em vez de tabelas fixadas. O algoritmo Backpropagation foi utilizado para ensinar a rede neural.

\section{Rede de Petri}

Kahloul et al. (2010) apresentam uma modelagem de Modelo de Controle de Acesso Baseado em Papéis, utilizando Redes de Petri Coloridas e a ferramenta CNPTool. Essa modelagem permite analisar propriedades importantes do modelo baseado em papéis, como por exemplo ativação de um papel.

\section{Informação de Contexto}

Choi et al. (2008) propõem um esquema adaptativo de controle de acesso em ambiente ubíquo que utiliza informação de contexto e, assim, papéis existem de acordo com tipos de contexto associados a eles. Já Park, Eom e Chung (2011) apresentam uma nova maneira de realizar o processo de Engenharia de Papéis por meio da consideração de cenários de serviços baseados em informação de contexto.

\section{Álgebra Relacional}

Li et al. (2008) e Wang et al. (2008) utilizam princípios de Álgebra Relacional para desenvolver algoritmos que resolvem dois problemas ligados ao Relacionamento Papel-Permissão. O primeiro problema é decidir se uma determinada permissão está em conflito com permissões de um papel; e o segundo é decidir se uma permissão deve ser removida de um papel.

\section{Conflito de Permissões}

Moon et al. (2004) e Moon et al. (2005) propõem modelos de Controle de Acesso Baseado em Papéis que consideram novos tipos de restrições sobre permissões, com o objetivo de evitar que permissões conflitantes sejam atribuídas a um mesmo papel.

\section{Estrutura Organizacional}

Oh e Sandhu (2002) e Perwaiz (2001) propõem modelos de controle de acesso 
Tabela 2.2: Artigos Distribuídos por Tipo de Abordagem

\begin{tabular}{|c|c|}
\hline Tipo de Abordagem & Referências \\
\hline Modelo Temporal & (BERTINO; BONATTI; FERRARI, 2001) \\
\hline Rede Neural & (CHAE; KIM; KIM, 2003) \\
\hline Rede de Petri & (KAHLOUL et al., 2010) \\
\hline Informação de Contexto & (CHOI et al., 2008; PARK; EOM; CHUNG, 2011) \\
\hline Álgebra Relacional & (LI et al., 2008; WANG et al., 2008) \\
\hline Conflito de Permissões & (MOON et al., 2004; MOON et al., 2005) \\
\hline Estrutura Organizacional & $\begin{array}{c}\text { (OH; SANDHU, 2002; PERWAIZ, 2001) } \\
\text { (ZHAO; ZHANG; ZHU, 2009b; ZHAO; ZHANG; } \\
\text { ZHU, 2009a) }\end{array}$ \\
\hline Engenharia/Mineração de Papéis & $\begin{array}{c}\text { (BLUNDO; CIMATO, 2010) } \\
\text { (COLANTONIO; PIETRO; OCELLO, 2008) } \\
\text { (COLANTONIO et al., 2010) } \\
\text { (CONSTANTINESCU; TOMA, 2009) } \\
\text { (FRANK; BASIN; BUHMANN, 2008) } \\
\text { (FRANK et al., 2009) } \\
\text { (FRANK; BUHMANN; BASIN, 2010) } \\
\text { (GIBLIN et al., 2010) } \\
\text { (GUO; VAIDYA; ATLURI, 2008) } \\
\text { (KUMAR; SURAL; GUPTA, 2010) } \\
\text { (MOLLOY et al., 2008) } \\
\text { (MOLLOY et al., 2009) } \\
\text { (MOLLOY et al., 2010) } \\
\text { (MOLLOY et al., 2010) } \\
\text { (NEUMANN; STREMBECK, 2002) } \\
\text { (PARK; EOM; CHUNG, 2011) } \\
\text { (PONISZEWSKA-MARANDA, 2005) } \\
\text { (SCHLEGELMILCH; STEFFENS, 2005) } \\
\text { (STREMBECK, 2010) } \\
\text { (TAKABI; JOSHI, 2010) } \\
\text { (VAIDYA; ATLURI; WARNER, 2006) } \\
\text { (VAIDYA; ATLURI; GUO, 2007) } \\
\text { (VAIDYA et al., 2008) } \\
\text { (VAIDYA et al., 2009) } \\
\text { (VAIDYA; ATLURI; GUO, 2010) } \\
\text { (VAIDYA et al., 2010) } \\
\text { (VAIDYA et al., 2010) } \\
\text { (ZHANG et al., 2008) } \\
\text { (ZHANG et al., 2009) } \\
\text { (ZHANG et al., 2010) } \\
\text { (ZHANG; RAMAMOHANARAO; EBRINGER, 2007) }\end{array}$ \\
\hline
\end{tabular}

baseados em papéis com ênfase em uma estrutura organizacional, de forma descentralizada, considerando permissões e papéis que podem ter características administrativas 
ou não em domínios distintos. Zhao, Zhang e Zhu (2009b) e Zhao, Zhang e Zhu (2009a) descrevem modelos de controle de acesso baseado em papéis e orientado a estrutura organizacional, que associam papéis com estrutura organizacional para reduzir a complexidade de gerenciamento de permissões.

\section{Engenharia/Mineração de Papéis}

Os artigos agrupados neste tipo de abordagem dizem respeito a estudos de engenharia de papéis, que é considerado um processo importante para implementar modelos de controle de acesso baseados em papéis. Ele foi definido pela primeira vez por Coyne (1995). Engenharia de papéis é uma abordagem para criação de papéis, e associação de usuários ou permissões com papéis. O termo Mineração de Papéis é usado em um sentido mais restrito para se referir às abordagens de engenharia de papéis automatizadas, em que se costuma empregar técnicas de Mineração de Dados (Data Mining).

Existem dois tipos de abordagem para engenharia de papéis: top-down e bottomup. Na primeira delas, pessoas realizam uma análise de processos de negócio com o objetivo de descobrir papéis. No segundo tipo, papéis são formulados através da existência de permissões associadas a usuários. Mineração de papéis é uma abordagem bottom-up.

A Figura 2.2 apresenta a distribuição das abordagens ao longo dos últimos anos. É fácil perceber que houve, recentemente, muita pesquisa relacionada à Engenharia ou Mineração de Papéis.

\subsubsection{Avaliação das Técnicas Encontradas}

"Modelo Temporal", foi a primeira abordagem que investigamos e ela considera o aspecto de tempo em modelos de Controle de Acesso Baseados em Papéis. Apesar de adicionar uma característica de dinamismo importante, essa abordagem não considera que, ao longo do tempo, dependências temporais entre papéis podem mudar devido ao surgimento ou eliminação de permissões.

Na abordagem "Rede Neural", os autores não se preocuparam em fornecer uma demonstração de segurança da proposta. Não é possível afirmar que essa técnica é robusta, mas é uma questão importante saber se essa abordagem apresenta nível de segurança equivalente ao modelo tradicional RBAC. 


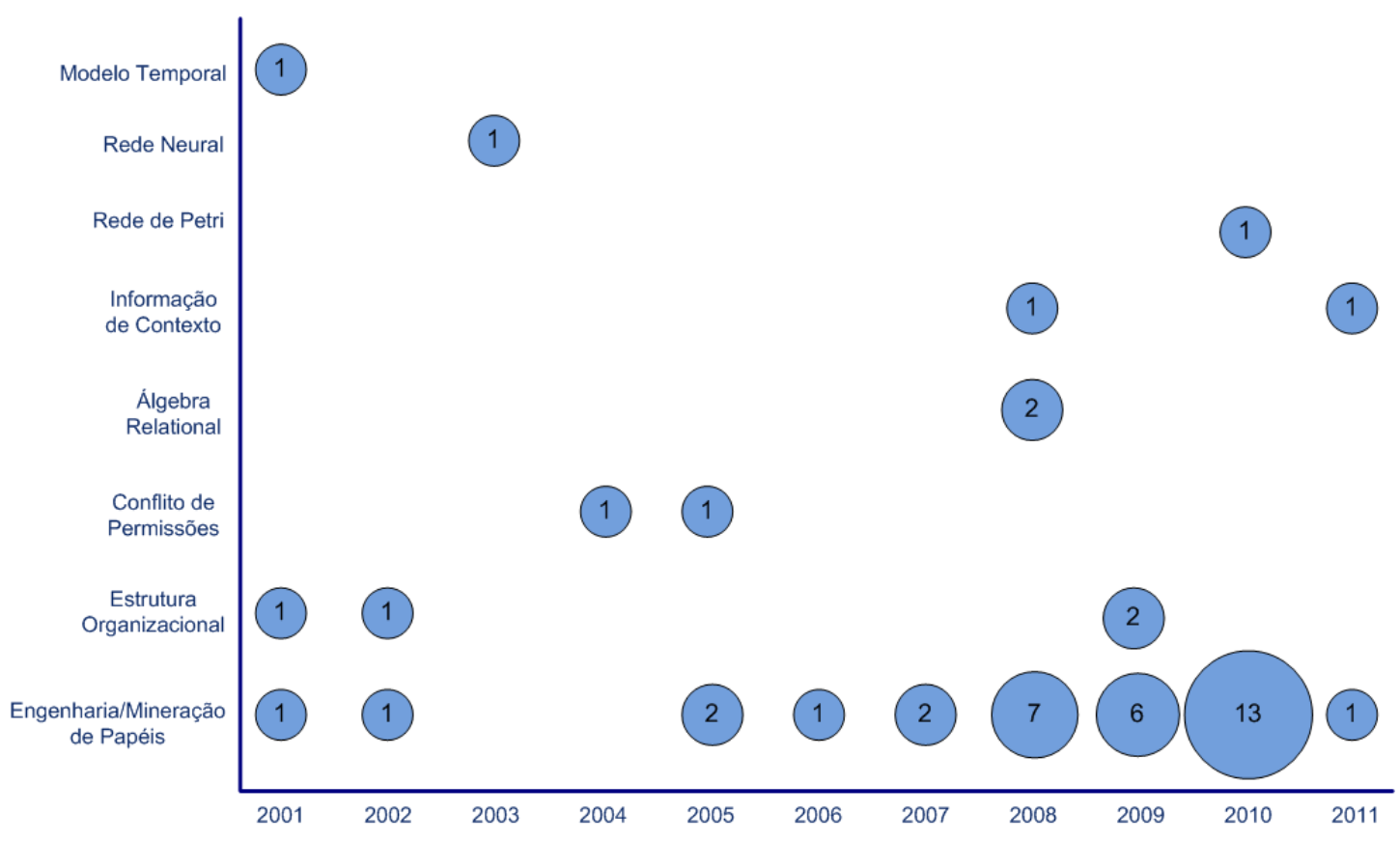

Figura 2.2: Distribuição das Abordagens por Ano

Em “'Rede de Petri'” muita ênfase é dada à parte de modelagem do modelo RBAC, mas pouca atenção é empregada na verificação de consistência da política. Nessa abordagem, a análise de espaço de estados muito grandes também é uma lacuna problemática.

A abordagem "Informação de Contexto" restringiu-se ao ambiente de computação ubíqua, e apenas aos contextos de tempo e espaço. Estes dois contextos, provavelmente, são os mais relevantes, porém, contexto é um conceito muito mais abstrato. A investigação de outros tipos de informações de contexto que capturem a natureza dinâmica em cenários de aplicação do modelo RBAC é uma direção de pesquisa que deve ser considerada.

Com relação à abordagem "Álgebra Relacional”, acreditamos que é preciso analisar qual o impacto desse tipo de proposta no desempenho de um sistema de computação que adote o modelo RBAC.

“Conflito de Permissões" reduz erros de atribuições de permissões indevidas. No entanto, nenhum dos autores dos artigos identificados preocupou-se em considerar o impacto com relação ao desempenho do modelo RBAC.

“Estrutura Organizacional” considera uma abordagem empírica em cenários 
com centenas de usuários e milhares de papéis, mas não fornece nenhuma prova formal (matemática) de efetividade desse tipo de solução em ambientes organizacionais.

Em “Engenharia/Mineração de Papéis", o esforço dos pesquisadores tem se concentrado em propor métodos para tratar do problema de realizar a identificação de papéis.

Propor métricas que comparem esses vários métodos que estão sendo propostos é um caminho de pesquisa importante. Desenvolver ferramentas (softwares) que auxiliem o processo de descoberta de papéis é outra direção possível.

Os artigos identificados pelo mapeamento sistemático apresentam mais ênfase nos aspectos de corretude e segurança do modelo RBAC. No entanto, segundo os resultados do mapeamento, aspectos importantes como desempenho, escalabilidade e dinamicidade foram de certa forma negligenciados pelos pesquisadores.

A Tabela 2.3 apresenta de forma resumida nossas considerações a respeito das várias abordagens que tratam do problema de estabelecimento do relacionamento papelpermissão. Marcamos quando a abordagem em questão (linha) considerou ou deu ênfase ao aspecto em destaque (coluna).

Tabela 2.3: Aspectos de Análise em Modelos RBAC

\begin{tabular}{lcccc}
\hline & Corretude Segurança Desempenho Escalabilidade Dinamismo \\
\hline $\begin{array}{l}\text { Modelo } \\
\text { Temporal }\end{array}$ & $\checkmark$ & $\checkmark$ & $\checkmark$ & $\checkmark$ \\
$\begin{array}{l}\text { Rede } \\
\text { Neural }\end{array}$ & $\checkmark$ & & $\checkmark$ & \\
$\begin{array}{l}\text { Rede } \\
\text { de Petri }\end{array}$ & $\checkmark$ & $\checkmark$ & & $\checkmark$ \\
$\begin{array}{l}\text { Informação } \\
\text { de Contexto }\end{array}$ & $\checkmark$ & $\checkmark$ & & \\
$\begin{array}{l}\text { Álgebra } \\
\text { Relacional }\end{array}$ & $\checkmark$ & $\checkmark$ & & \\
$\begin{array}{l}\text { Conflito de } \\
\text { Permissões }\end{array}$ & $\checkmark$ & $\checkmark$ & & \\
$\begin{array}{l}\text { Estrutura } \\
\text { Organizacional }\end{array}$ & $\checkmark$ & & $\checkmark$ & $\checkmark$ \\
$\begin{array}{l}\text { Engenharia } \\
\text { ou Mineração } \\
\text { de Papéis }\end{array}$ & $\checkmark$ & $\checkmark$ & $\checkmark$ \\
\hline
\end{tabular}


O aspecto de corretude, ou seja, garantir que a técnica proposta faça o que realmente se propõe é preocupação de todos os autores. Porém, nem todas se preocupam com a verificação da característica de segurança, ou seja, se determinada abordagem também pode fazer o que não deveria.

A Tabela 2.3 representa um forte indício de que corretude e segurança são duas características que recebem muita atenção por parte dos autores. Mas questões ligadas a desempenho, escalabilidade e dinamismo são mais difíceis de serem resolvidas, por isso apresentaram pouco destaque em nossa análise.

Todas as abordagens discutidas reforçam a ideia de que capturar a natureza dinâmica de cenários do mundo real em um modelo de controle de acesso baseado em papéis é uma tarefa difícil. Eventos dinâmicos como o surgimento de novos papéis têm impacto significativo sobre a consistência de corretude, segurança, desempenho, escalabidade e dinamicidade do modelo RBAC.

\subsection{Síntese e Desafios de Pesquisa}

Neste capítulo, foi apresentada uma breve introdução aos aspectos básicos e mais importantes relacionados ao modelo de Controle de Acesso Baseado em Papéis. É fato que controle de acesso é um requisito fundamental na área de segurança computacional; por isso, investigações nesse segmento são necessárias.

Os avanços nas pesquisas nessa área ainda apresentam muitos problemas em aberto e que despertam interesse de muitas entidades empresariais, governamentais e acadêmicas.

Com base nos resultados amostrais fornecidos pelo mapeamento sistemático, foi possível identificar alguns dos principais desafios na área de controle de acesso baseado em papéis que estão diretamente ligados às questões que envolvem desempenho, escabalibilidade e dinamismo.

Nesta tese, a ênfase é abordar o problema de conseguir verificar a consistência de uma política de controle de acesso baseada em papéis considerando eventos dinâmicos, como o surgimento de um novo papel. Para analisar uma política, primeiro é necessário representá-la de alguma forma. 
A técnica que esta tese vai aplicar utiliza rede de Petri colorida para realizar essa tarefa. Rede de Petri colorida é uma abordagem muito utilizada para modelar sistemas distribuídos por capturar adequadamente várias características que são importantes analisar. A modelagem e análise da política de controle de acesso baseado em papéis vai empregar a ferramenta CPN Tools, que permite modelar e principalmente analisar o espaço de estados de uma rede de Petri colorida. A análise de espaço de estados será fundamental para atingirmos os objetivos iniciais definidos na tese. 


\section{Rede de Petri e sua Aplicabilidade}

\subsection{Introdução}

Este capítulo introduz a teoria de rede de Petri, apresentando seus principais conceitos e aplicações. Inicialmente, são discutidos os aspectos históricos que caracterizam a evolução da teoria de rede de Petri ao longo das últimas décadas. A seguir, são apresentados o conceitos teóricos importantes como estrutura formal de uma rede de Petri, sua representação gráfica, propriedades e classes de rede. Além disso, discutimos em detalhes a rede de Petri colorida, que é uma extensão de uma rede tradicional. Por fim, discorremos sobre a aplicabilidade de rede de Petri, principalmente na área de segurança.

\subsection{Rede de Petri}

\subsubsection{Histórico da Rede de Petri}

A rede de Petri (ou simplesmente RP) foi inicialmente definida em 1962 por Carl Adam Petri em sua tese de doutorado "Kommunikation mit Automaten" pela Universidade de Darmstadt, na antiga Alemanha Ocidental. É uma ferramenta matemática e gráfica para modelar, analisar e projetar sistemas com processos paralelos, concorrentes, assíncronos e não determinísticos; especialmente aqueles caracterizados por estados discretos que são alterados abruptamente por eventos assumidos como instantâneos (MURATA, 1989).

De acordo com Heuser (HEUSER, 1991), as primeiras aplicações de RP aconte- 
ceram em 1968, no projeto norte-americano Information System Theory, da A.D.R. (Applied Data Research, Inc.). Muito da teoria inicial, da notação e da representação de RP foi desenvolvido nesse projeto e foi publicado em seu relatório final. Esse trabalho ressaltou como RP poderiam ser aplicadas na análise e na modelagem de sistemas com componentes concorrentes.

A década de 70 marcou o desenvolvimento da teoria de RP e a expansão de seu campo de aplicação. No início daquela década, o trabalho de Petri chamou a atenção de membros do Projeto MAC, do MIT (Massachusetts Institute of Technology). O Grupo de Estruturas Computacionais, deste projeto, sob a direção do Prof. Jack B. Dennis, foi a origem de consideráveis pesquisas e publicações sobre RP, envolvendo relatórios e teses de doutorado. Duas conferências importantes foram organizadas pelo grupo, quais sejam: a "Conferência sobre Sistemas Concorrentes e Computação Paralela", em Woods Hole (Projeto MAC, 1970) e a "Conferência sobre Redes de Petri e Métodos Relacionados", no MIT, em 1975.

A conferência realizada em 1975 no MIT foi, vale ressaltar, a primeira vez que o nome "Rede de Petri" foi oficialmente utilizado para se referir ao formalismo proposto por Carl Adam Petri treze anos antes, na Alemanha. Os resultados destes e de outros esforços no desenvolvimento da teoria de RP estão registrados em inúmeros artigos e em três livros principais: um destes livros foi escrito pelo Prof. Wolfgang Reisig, que foi orientado do Prof. Petri, e representa a linha de pensamento mais diretamente ligada a ele; outro livro foi escrito por diversos autores franceses, liderados pelo Prof. G. W. Brams, e representa, por assim dizer, a linha de pensamento europeia menos ligada ao Prof. Petri; e o terceiro livro foi escrito pelo Prof. James Lyle Peterson e representa a linha de pensamento norte-americana.

Em relação às aplicações, RP atingiu áreas como a modelagem de componentes de hardware, controle de processos, linguagens de programação, sistemas distribuídos e protocolos de comunicação.

Ainda na década de 70, surgiram três tipos de RP capazes de modelar características temporais determinísticas, quais sejam, as RP temporizadas de Ramchandani, de Merlin e de Sifakis.

As aplicações de RP aumentaram consideravelmente na década de 80, com o surgimento das chamadas redes de Petri de alto nível, como por exemplo as numéricas, as 
predicado/transição e as coloridas. Em meados da década de 80, surgiram também extensões de RP estocásticas. Tais inovações acrescentaram uma grande força descritiva ao processo de modelagem, pelo uso de marcas com identidade e, consequentemente, do uso de conjuntos de marcas na representação da dinâmica dos sistemas modelados, bem como pela possibilidade de se associar taxas de ocorrência não determinísticas aos eventos dos sistemas modelados.

Desta forma, as RP atingiram outras áreas, como automação de escritórios, bancos de dados, inteligência artificial e sistemas de informação de maneira geral. No final da década de 80, era publicado um artigo seminal sobre RP, pelo Prof. Tadao Murata. Embora este artigo trate primordialmente das redes de baixo nível, ele é um dos artigos mais referenciados sobre o assunto ainda nos dias de hoje.

Na década de 90, as RP tiveram como seu principal representante a segunda versão das RP Coloridas, desenvolvidas pelo Prof. Kurt Helmer Jensen, da Universidade de Aarhus, na Dinamarca. Além de trabalharem com marcas diferenciáveis, tais redes apresentam tratamento de aspectos temporais e permitem a representação de tipos de dados abstratos, um diferencial que as outras extensões existentes no final da década de 80 e início da de 90 não apresentavam.

\subsubsection{Estrutura de uma Rede de Petri}

Como acabamos de perceber, RP desperta o interesse da academia e da indústria desde a década de 60, e constitui uma das principais maneiras de se modelar Sistemas Baseados em Eventos Discretos. Murata (MURATA, 1989) apresenta um tutorial de revisão de RP no qual são mostrados exemplos de modelagem, propriedades estruturais e comportamentais, métodos de análise e aplicações.

A estrutura de uma RP pode ser definida formalmente como uma quádrupla $(P, T, F$, $W)$, sendo que (REISIG, 1991):

- $P=\left\{p_{1}, p_{2}, \ldots, p_{m}\right\}$ é o conjunto de lugares, no qual $m \in \mathbb{N}$ é a quantidade total de lugares da RP;

- $T=\left\{t_{1}, t_{2}, \ldots, t_{n}\right\}$ é o conjunto transições, no qual $n \in \mathbb{N}$ é a quantidade total de transições da RP; 
- $F \subseteq((P \times T) \cup(T \times P))$. No qual $F$ é o conjunto de arcos da rede. Os arcos podem relacionar lugares a transições ou vice-versa. $(P \times T)$ é o conjunto de arcos de entrada das transições. $(T \times P)$ é o conjunto de arcos de saída das transições; e

- $W \subseteq((P \times T) \cup(T \times P)) \mapsto \mathbb{N}$. No qual $W$ é uma função que indica o peso de cada arco possível da RP.

\subsubsection{Representação Gráfica}

Uma RP é um grafo bipartido (os arcos só podem interligar elementos de natureza diferente) constituído por lugares (representados por círculos ou elipses), transições (representadas por barras), arcos orientados interligando os componentes anteriores e marcas (utilizadas para definir o estado de uma RP). O peso de um arco indica o número de arcos orientados do mesmo sentido entre dois elementos (MURATA, 1989).

A execução de uma RP é controlada pelo número de tokens (marcas) e sua distribuição na rede. Os tokens localizam-se nos lugares e determinam o disparo das transições da rede. Uma transição dispara removendo os tokens dos seus lugares de entrada e criando novos tokens em seus lugares de saída. As Figuras 3.1, 3.2 e 3.3 representam graficamente os estados de uma RP antes, durante e depois de um disparo, respectivamente.

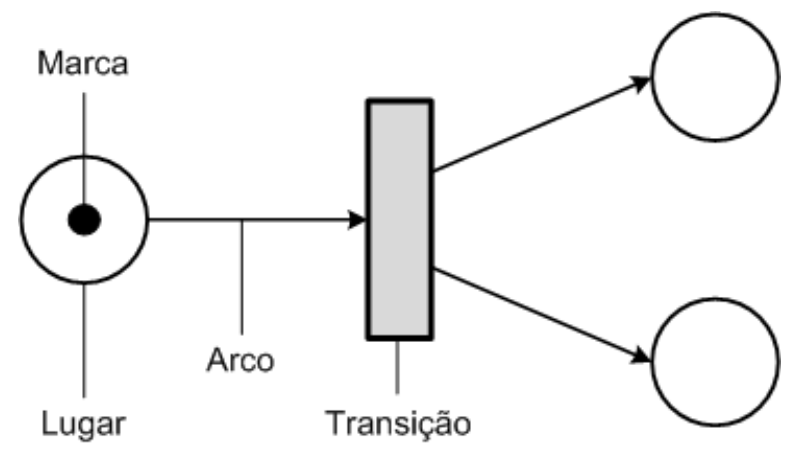

Figura 3.1: Marcação inicial da rede de Petri

\subsubsection{Propriedades}

Em geral, as técnicas de análise de RP são tradicionalmente usadas para inferir determinadas propriedades da rede, as quais podem ser usadas tanto para verificação 


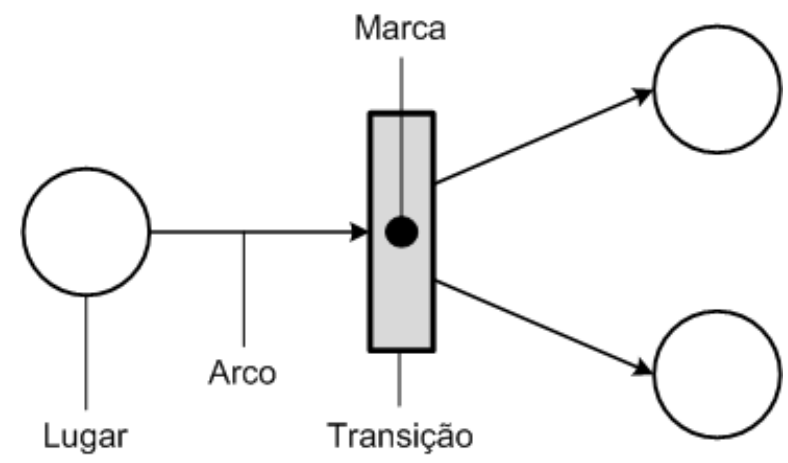

Figura 3.2: Rede de Petri durante um disparo

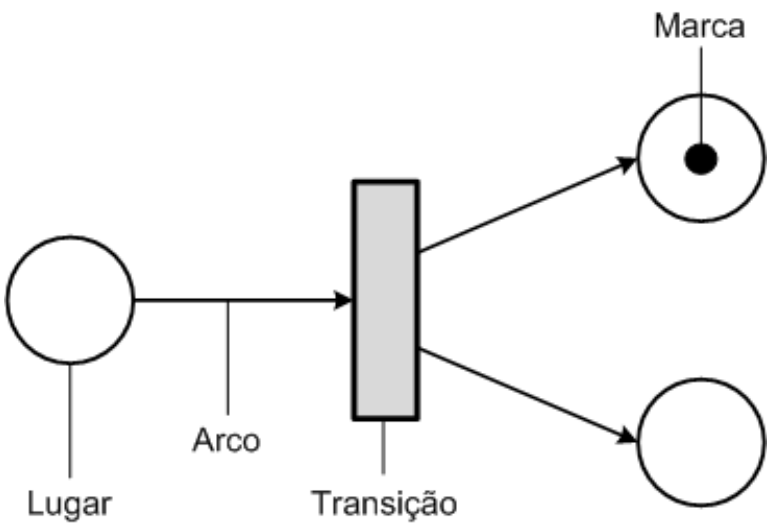

Figura 3.3: Rede de Petri após um disparo

quanto para a validação de modelos especificados pela rede. Na validação da especificação, as propriedades esperadas são derivadas a partir do sistema real e comparadas com as obtidas com a análise da rede.

Dessa forma, se a especificação não possui a propriedade esperada do sistema, conclui-se que a especificação não está correta. No entanto, em geral, a presença dessas propriedades na especificação não garante que ela esteja correta.

Deve-se observar que as propriedades analisadas da rede precisam ser interpretadas para serem usadas na validação. Por exemplo, um deadlock encontrado no modelo pode ser tanto um estado final válido do sistema quanto um problema a ser evitado. Nesta subseção, são apresentadas as principais propriedades das RP, divididas em Comportamentais e Estruturais.

Propriedades Comportamentais. As propriedades comportamentais são aquelas que dependem da marcação inicial. As principais propriedades comportamentais são: 
Alcançabilidade - A alcançabilidade é utilizada para o estudo de propriedades dinâmicas de um sistema. A alcançabilidade indica a possibilidade de se atingir uma determinada marcação pelo disparo de um número finito de transições, a partir da marcação inicial.

Limitação - A propriedade de limitação está relacionada com a existência de uma quantidade máxima de marcas que os lugares de uma RP podem conter em qualquer marcação alcançável. Se todos os lugares da rede são limitados, então a rede é denominada limitada.

Segurança - O conceito de segurança (do inglês, safeness) é uma restrição do conceito de limitação. Uma RP é segura se, e somente se, todos os seus lugares forem limitados a uma marca. Vale ressaltar que este conceito difere da definição de segurança (do inglês, security) da informação.

Vivacidade - Essa propriedade está relacionada à ausência de marcações alcançáveis que estejam em deadlock. Uma marcação está em deadlock se nenhuma transição estiver habilitada a disparar e não for uma marcação final.

Reversibilidade - Em sistemas computacionais, é comum existir uma configuração tal que deve ser possível atingi-la a partir de qualquer ponto da execução. Essa pode ser a configuração inicial, mas não necessariamente. A propriedade de reversibilidade tem relação com a capacidade de alcançar uma marcação específica a partir de qualquer outra marcação alcançável.

Justiça - O conceito de justiça (do inglês, fairness) está relacionado com a ideia de que nenhuma transição (ou conjunto de transições) da rede possa disparar indefinidamente a despeito das outras transições. Para que uma rede seja justa, é necessário que toda sequência infinita de transições tenha cada transição da rede aparecendo um número infinito de vezes.

Propriedades Estruturais. As propriedades estruturais são aquelas que não dependem da marcação inicial. As principais propriedades estruturais são:

Limitação Estrutural - Uma rede é estruturalmente limitada se ela é limitada para qualquer marcação inicial. 
Conservação - Uma RP é conservativa se a quantidade total de marcas não varia nas marcações alcançáveis, apenas sua distribuição entre os lugares. A conservação é uma importante propriedade das RP, permitindo, por exemplo, a verificação da não destruição de recursos.

\subsubsection{Classificação de uma Rede de Petri}

Os modelos em RP podem ser classificados em função do nível de detalhe que os lugares (e seus tokens) podem representar. Em (SIMÃO, 2004), três níveis são propostos.

Nível 1: nas RPs do nível 1, os tokens representam valores booleanos, isto é, um lugar pode conter no máximo um token não estruturado. As principais representantes desse grupo são as redes Condição/Evento e as redes elementares;

Nível 2: neste nível, os tokens representam valores inteiros, isto é, um lugar pode conter tokens não estruturados. Esse tipo de rede é genericamente denominado rede Lugar/Transição ou rede ordinária (ZHOU; DICESARE, 1993); e

Nível 3: nas RPs do nível 3, os tokens representam valores em alto nível, isto é, um lugar pode conter um multiconjunto de valores estruturados. As principais representantes são as redes Predicado/Transição (MURATA, 1989) e a rede de Petri colorida (JENSEN; KRISTENSEN, 2009).

Além da classificação em função da complexidade dos tokens, outras extensões têm sido propostas, como as que permitem representar: $(i)$ o tempo de disparo de uma transição (RPs temporizadas); e (ii) o tempo consumido por uma atividade, representado por um lugar (RP estocástica).

\subsection{Rede de Petri Colorida}

\subsubsection{Definição Formal}

Uma rede de Petri colorida (RPC) é uma classe de rede de Petri (RP) que adiciona recursos para definição e manipulação de tipos de tokens. Convencionou-se designar 
os tipos em uma RPC como "cores", em contraste com as redes de Petri originalmente propostas, nas quais todos os tokens são iguais, ou seja, sem cor. A Figura 3.4 apresenta, em forma gráfica, o que acabamos de explicar.

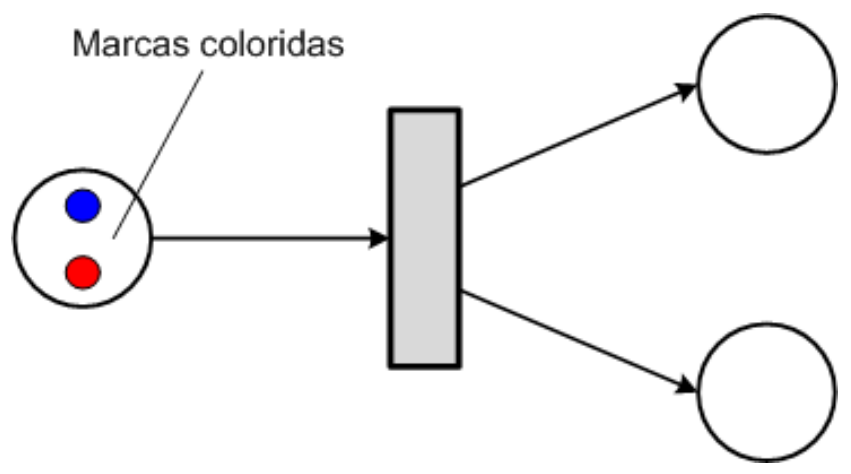

Figura 3.4: Rede de Petri colorida

Formalmente, uma RPC é uma tupla $C P N=(\Sigma, P, T, A, N, C, G, E, I)$ que satisfaz as seguintes propriedades (JENSEN; KRISTENSEN, 2009):

- $\Sigma$ é um conjunto finito não vazio de tipos chamado de conjunto de cores;

- $P$ é um conjunto finito de lugares;

- $T$ é um conjunto finito de transições, tal que $P \cap T=\emptyset$;

- $A$ é um conjunto finito de arcos, tal que $P \cap A=T \cap A=\emptyset$;

- $N$ é uma função de nós, tal que $N: A \mapsto P \times T \cup T \times P$;

- $C$ é uma função de coloração, tal que $C: P \mapsto \Sigma$;

- $G$ é uma função de guarda que associa a cada $t \in T$ uma expressão do tipo booleana;

- $E$ é uma função de anotações de arcos que associa a cada $a \in A$ uma expressão do tipo do lugar relacionado; e

- I é uma função de inicialização que associa a cada $p \in P$ uma expressão do tipo $C(p)$. 


\subsubsection{Ferramenta CPN Tools}

CPN Tools (JENSEN; KRISTENSEN; WELLS, 2007) é uma ferramenta (ou melhor dizendo, um pacote de ferramentas) para edição, simulação e análise cronometrada e não cronometrada para redes de Petri coloridas (Colored Petri Net).

A ferramenta resulta do projeto de pesquisa CPN 2000, da Universidade de Aarhus, patrocinado pelo Danish National Centre for IT Research, Universidade George Mason, Hewlett-Packard, Nokia e Microsoft. O projeto foi coordenado pela Universidade de Aarhus de 2000 até 2010, mas, a partir de 2011, passou a ser responsabilidade da Universidade de Tecnologia de Eindhoven, na Holanda.

A ferramenta CPN Tools fornece condições para modelar sistemas distribuídos, considerando os vários tipos de processos envolvidos. Adotamos essa ferramenta para auxiliar na modelagem, simulação e análise dos exemplos deste capítulo e também verificação da consistência da política de controle de acesso do cenário educacional que descrevemos nesta tese. A Figura 3.5 apresenta a interface gráfica da ferramenta CPN Tools.

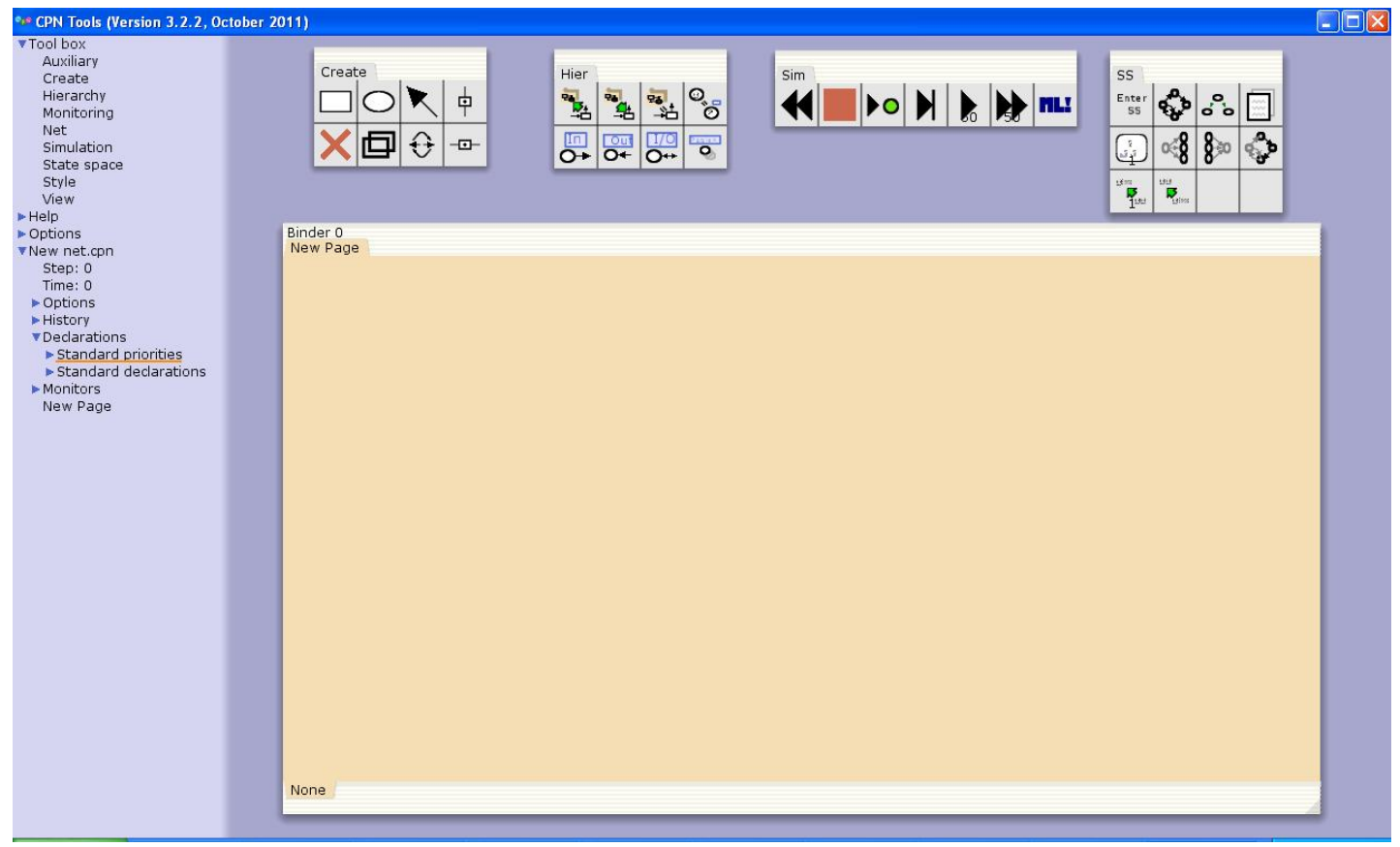

Figura 3.5: Interface da ferramenta CPN Tools

O ambiente da ferramenta CPN Tools está dividido em duas partes. A primeira, à esquerda, apresenta as opções de paletas de ferramentas para edição, simulação e aná- 
lise de uma rede de Petri colorida. Além disso, é nessa área que são declaradas cores, variáveis, valores constantes e funções da rede de Petri colorida. Todas as declarações são escritas com a linguagem ML, que é uma linguagem de programação funcional e modular.

Na parte direita da ferramenta CPN Tools, está a área de trabalho, onde a rede de Petri colorida é desenhada, ou seja, é onde aparece a representação gráfica da rede. Na Figura 3.5, aparecem em destaque na área de trabalho 4 paletas de ferramentas que foram utilizadas para desenvolver a modelagem e análise das redes de Petri coloridas desta tese. A paleta Create possui botões para criar lugares, transições, arcos, etc. A paleta Hier ajuda a desenvolver redes de Petri coloridas com hierarquia, ou seja, mais modulares. A paleta Sim sem a função de auxiliar na simulação de uma rede de Petri colorida. Por último, a paleta $\mathbf{S S}$ é utilizada para análise de espaço de estados.

\section{Exemplo 1 - Múltiplos de 2, 3 e 6}

Para ilustrarmos um primeiro exemplo de rede de Petri colorida modelada com a ferramenta CPN Tools, consideremos uma rede simples que tem o objetivo de selecionar, em um conjunto de valores inteiros, aqueles que são múltiplos de 2,3 e 6 . A Figura 3.6 apresenta essa rede de Petri colorida no ambiente CPN Tools.

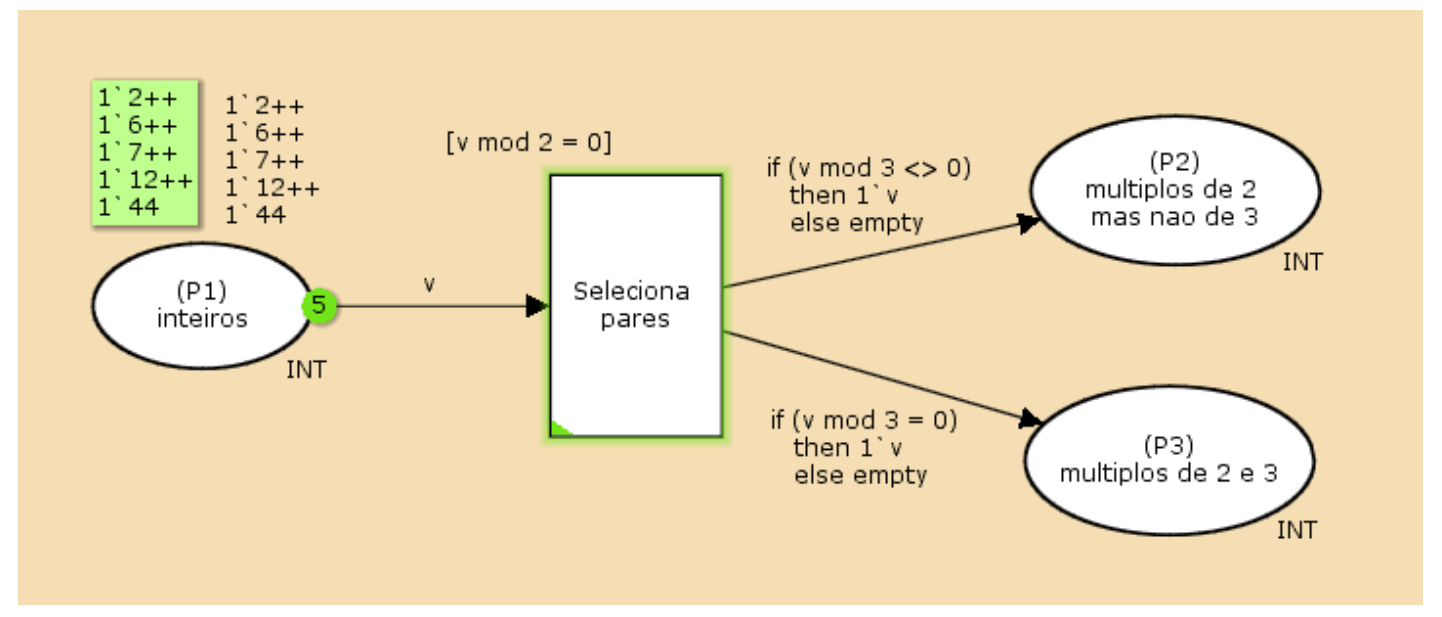

Figura 3.6: Seleção de múltiplos de 2, 3 e 6 - Estado inicial

Na rede da Figura 3.6, existem 3 lugares representados por P1, P2 e P3 que podem conter cores do tipo INT, que é um tipo de cor pré-definida em CPN Tools. A rede apresenta também uma transição que seleciona valores inteiros que satisfazem a condição estabelecida na função de guarda, ou seja, valores $\mathbf{v}$ tais que $\mathbf{v} \bmod 2=\mathbf{0}$. Em 
outras palavras, a transição seleciona apenas valores pares, pois nenhum valor ímpar satisfaz sua função de guarda.

A rede da Figura 3.6 apresenta também 3 arcos com inscrições sobre eles. No primeiro arco que sai de P1 e incide sobre a transição, a expressão impõe que apenas valores inteiros podem percorrer esse arco, pois isso foi definido na área de declaração da ferramenta com a linha de código var v: INT;. Os outros dois arcos apresentam pequenos códigos de estrutura de controle em linguagem ML. O arco que incide em P2 permite passar por ele apenas valores que não são múltiplos de 3 (condição $\mathbf{v}$ mod 3 <> 0). De maneira similar, o arco que incide em P3 permite percorrer por ele somente valores que são múltiplos de 3 (condição $\mathbf{v} \bmod 3=0$ ).

Para simularmos a rede de Petri colorida, estabelecemos uma marcação inicial com 5 valores inteiros em P1. Com a simulação da rede, ocorrem 4 disparos da transição "Seleciona pares" e o estado final pode ser observado na Figura 3.7.

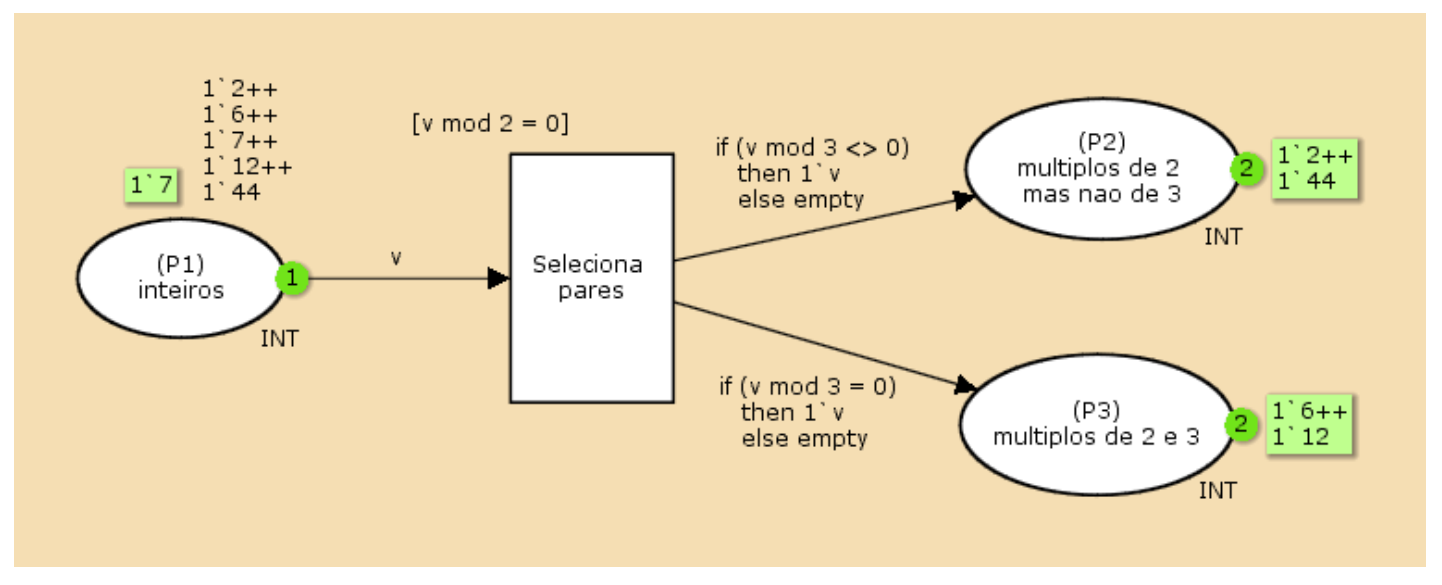

Figura 3.7: Seleção de múltiplos de 2, 3 e 6 - Estado final

Dos 5 valores inteiros, notamos que apenas o valor 7 permaneceu em P1, pois, como é um valor inteiro ímpar, ele não satisfaz a condição definida na função de guarda. Dos 4 valores pares que satisfizeram a função de guarda, dois deles percorreram o caminho até P2 e os outros dois chegaram em P3. Em P2, podem chegar apenas valores que são múltiplos de 2 mas não de 3 e, em P3, somente valores múltiplos de 2 e também de 3. Lembrando da propriedade aritmética que diz que um valor inteiro é múltiplo de 6 apenas no caso de ele ser múltiplo de 2 e 3, é possível afirmarmos que $\mathrm{P} 3$ pode conter apenas valores $\mathrm{v}$ tais que $\mathrm{v} \bmod 6=0$.

O exemplo que acabamos de discutir ilustrou o conceito de binding de variáveis em 
uma rede de Petri colorida na ferramenta CPN Tools. Ou seja, tokens não se movem livremente por uma rede de Petri colorida; funções de guarda e inscrições em arcos estão encarregados de impor condições para que um token possa deslocar-se ou não de um lugar para outro na rede.

\section{Exemplo 2 - Fila Limitada}

Para exemplificar a utilização da ferramenta CPN Tools para o desenvolvimento de uma rede de Petri colorida que representa um cenário mais concreto, consideremos a modelagem de uma fila limitada, como representada na Figura 3.8.

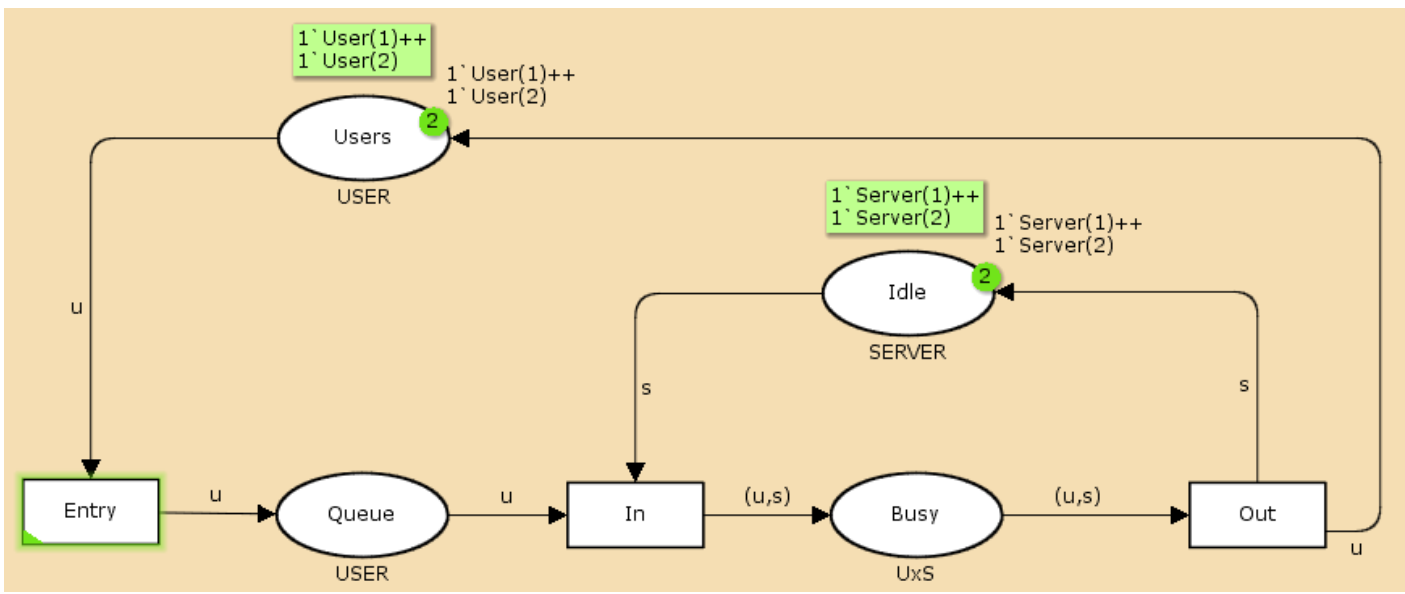

Figura 3.8: Rede de Petri colorida de uma Fila Limitada

Neste modelo de fila, é representada a interação de 2 usuários e 2 servidores. Existem 4 lugares na rede que foram definidos como Users, Queue, Idle e Busy, sendo que os 2 últimos servem para representar estados do servidor como ocioso e ocupado, respectivamente. Além disso, a rede possui 3 transições chamadas de Entry, In e Out. Entry é responsável por inserir um usuário na fila colocando-o no lugar Quеue. In associa um dos usuários que estiver na fila com um dos servidores que, antes do disparo da transição, está ocioso no lugar Idle. Dessa forma depois do disparo da transição In no lugar Busy, vai haver um par ordenado (usuário, servidor). Por último, a transição Out tem a função de liberar o servidor que estava ocupado por um usuário no lugar Busy, colocando o servidor em estado ocioso novamente no lugar Idle e pondo o usuário no lugar Users.

Para a modelagem da fila limitada é preciso definir 3 cores diferentes com o comando pré-definido colset como destacado na Figura 3.9. Para definir uma cor que representa usuários, declaramos um array com 2 índices. Declaração similar é utili- 
zada para representar os servidores na rede. Ainda é necessário uma terceira cor que é o produto entre usuários e servidores para representar pares ordenados no lugar Busy. Lembrando do conceito de binding do exemplo anterior, ainda precisamos definir duas variáveis para serem aplicadas nas expressões dos arcos da rede.

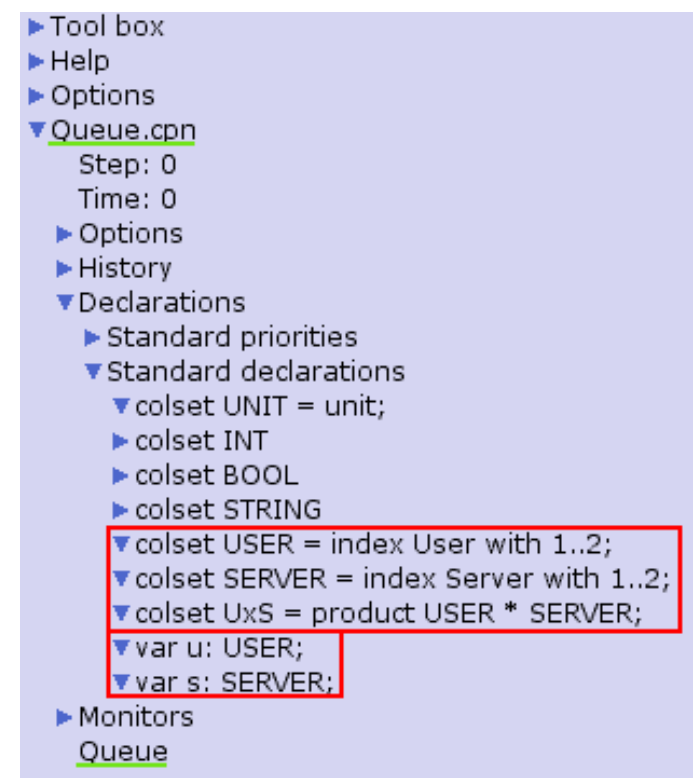

Figura 3.9: Declaração de cores e variáveis para a Fila Limitada

A Figura 3.10 apresenta um estado da rede durante uma simulação do modelo. Para chegar neste estado, uma sequência possível a partir do estado inicial na Figura 3.8 poderia ser: (1) a transição Entry dispara e User(1) entra na fila no lugar Queue, (2) a transição In dispara e User(1) passa a ocupar o servidor Server(1) no lugar Busy, (3) a transiçãoEntry dispara e $U \operatorname{ser}(2)$ entra na fila.

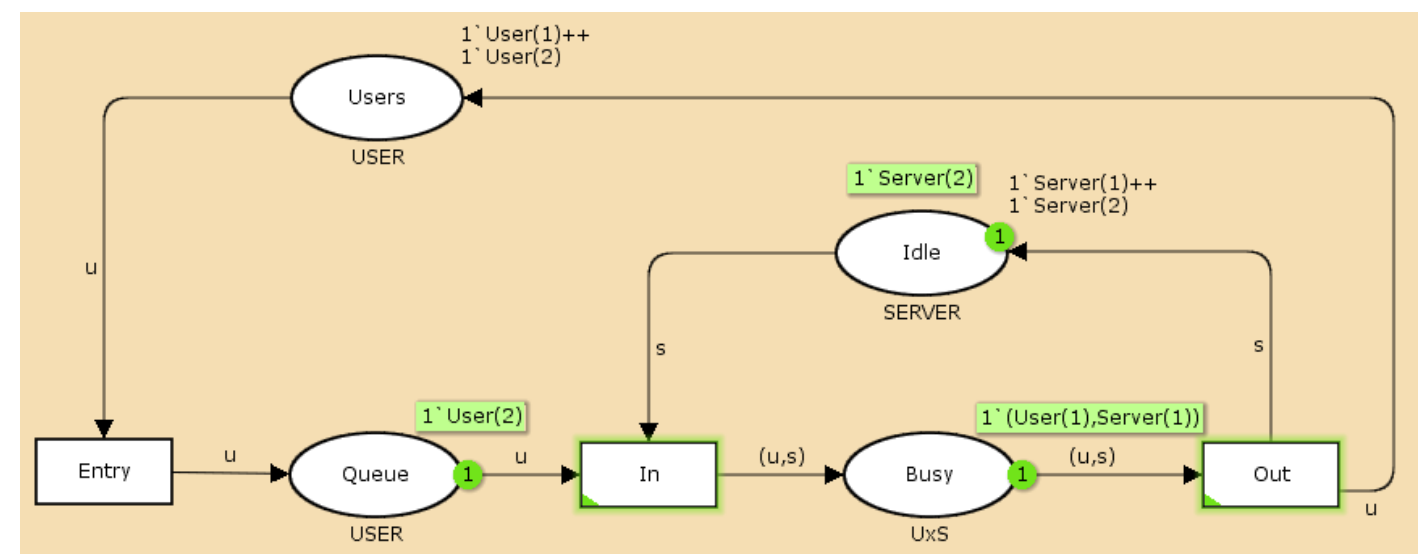

Figura 3.10: Simulação da rede de Petri colorida de uma Fila Limitada 


\subsubsection{Técnicas de Análise e Validação}

As técnicas de análise desenvolvidas para RPC são, em geral, adaptações de técnicas utilizadas para RP Lugar/Transição. Dessa forma, para a análise e validação de uma RPC, pode-se empregar a simulação, a geração do espaço de estados, que é uma representação alternativa da árvore de alcançabilidade, e também o cálculo de invariantes.

A simulação consiste em executar as transições da rede, interativa ou automaticamente, e avaliar o comportamento do sistema modelado, possibilitando visualizar o resultado de uma sequência de eventos. A simulação exaustiva (por um longo intervalo de tempo) também permite investigar questões sobre a performance do sistema, tais como a identificação de gargalos de desempenho e a predição do espaço de buffer requerido (JENSEN; KRISTENSEN, 2009).

O cálculo de invariantes é empregado para calcular relacionamentos entre o conteúdo dos lugares da rede que são válidos em qualquer marcação alcançável ou sequências de ligações que, quando disparadas, levam a rede à mesma marcação original.

O cálculo de invariantes para RPC é, em geral, indecidível, visto que é necessária a manipulação das anotações de arco, as quais podem consistir em funções arbitrárias. Assim sendo, uma das técnicas mais utilizadas para a análise de RPC é o espaço de estados, descrito a seguir e que vamos aplicar nesta tese.

\subsubsection{Espaço de Estados}

Um espaço de estados (JENSEN; KRISTENSEN, 2009) é um grafo $G=(V, E)$, tal que $V$ é o conjunto de vértices, representando o conjunto de marcações alcançáveis, e $E$ é o conjunto de arestas rotuladas, representando o conjunto de transições. Para uma rede $N, G=(V, E)$ é definido (implicitamente) pela seguinte regra de formação:

- A marcação inicial $\mu_{0}$ de $N$ pertence a $V\left(\mu_{0} \in N\right)$; e

- Para todo $\mu \in V$, tem-se que uma transição $y$ está habilitada em $\mu$ e a marcação resultante do disparo de $y$ em $\mu$ é $\mu^{\prime}$ se, e somente se, $\mu^{\prime} \in V$ e $\left(\mu, y, \mu^{\prime}\right) \in E$. 
A partir do grafo de espaço de estados, podem-se analisar diversas propriedades da rede, tais como a inexistência de deadlock, reversibilidade e alcançabilidade de uma marcação específica.

Com relação ao espaço de estados, duas perguntas são relevantes para a pesquisa desenvolvida nesta tese. (i) Quantos estados ou marcações são possíveis extrair de uma rede de Petri?; e (ii) Que tipo de notação pode ser utilizado para representar cada uma destas marcações?

Uma árvore de alcançabilidade (MURATA, 1989) é capaz de responder a estas duas perguntas. Através de uma árvore com raiz igual à marcação inicial, é possível representar todas as marcações alcançáveis.

É importante ressaltar que o conjunto de alcançabilidade pode ser finito; no entanto, é comum encontrarmos situações em que as marcações alcançadas não nos levam a um estado inicial, ou à marcação inicial, ou seja, a raiz da árvore. Portanto, o conjunto de alcançabilidade só é finito se, em algum momento, uma determinada marcação nos levar novamente à marcação inicial.

Para demonstrar a análise do espaço de estados de uma rede de Petri colorida, retornemos ao exemplo da Fila Limitada. Mas, para tornarmos o cenário mais interessante, modificamos a rede de Petri colorida que representa a fila de tal forma que os estados dos servidores não são mais caracterizados por dois lugares na rede, e sim por atributos em um único lugar, como mostra a Figura 3.11.

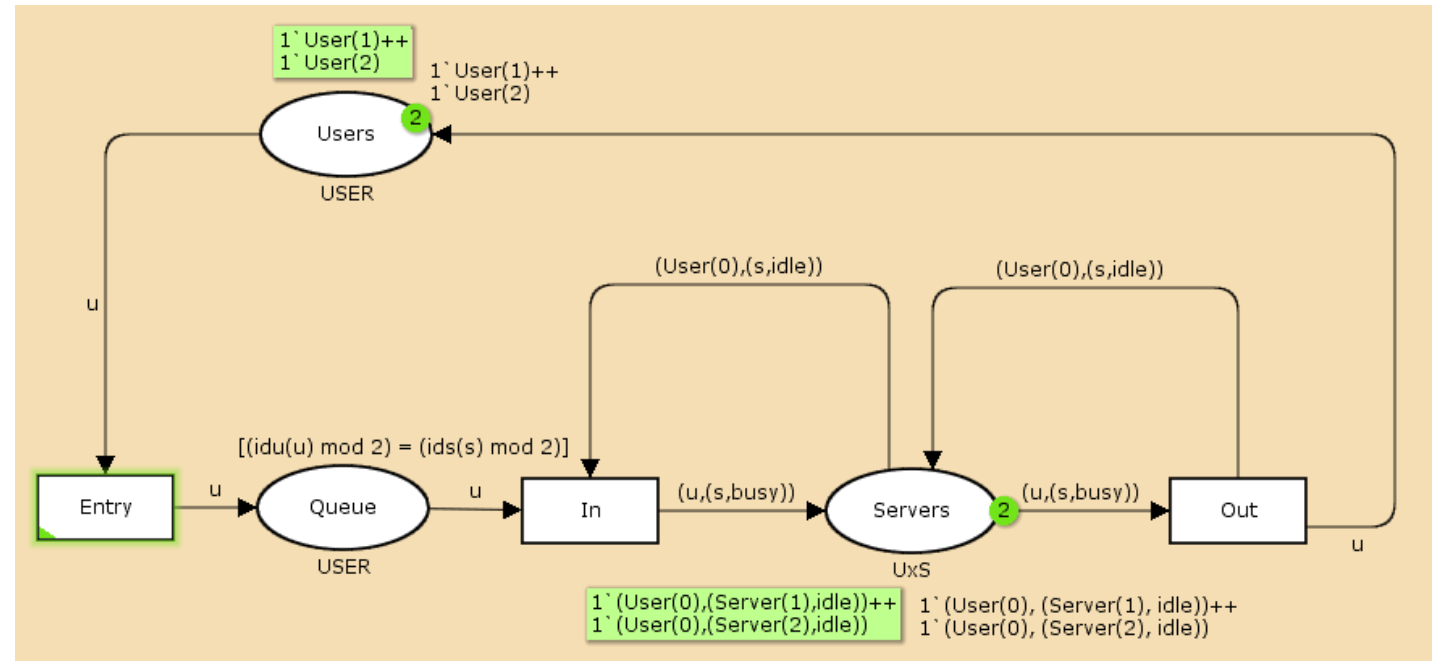

Figura 3.11: Rede de Petri de uma Fila Limitada - Versão 2 
Para modelar o exemplo de Fila Limitada de tal forma que os servidores permaneçam em um único lugar e mudem seu estado por meio de atributos, é necessário declarar cores como destacado na Figura 3.12.

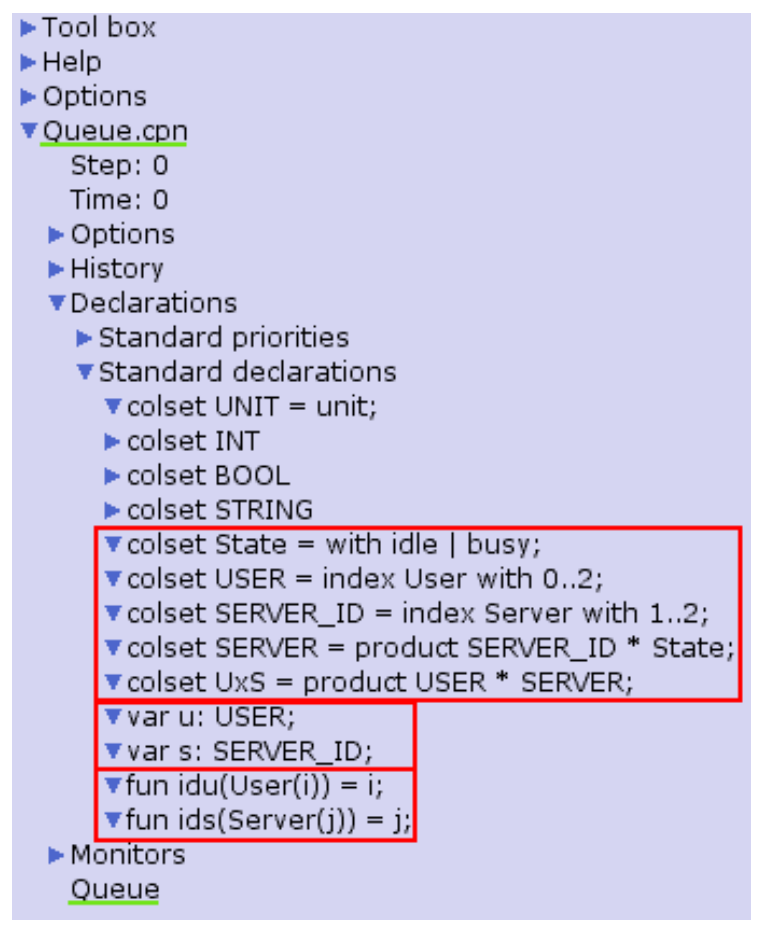

Figura 3.12: Declaração de cores e variáveis para a Fila Limitada - Versão 2

Primeiro, declaramos uma cor State que pode assumir apenas os valores idle ou busy. A cor para representar usuários continua definida como antes, porém dessa vez é preciso considerar um índice 0 para que $U \operatorname{ser}(0)$ seja interpretado como um usuário nulo ocupando o servidor e indicando que ele está idle. A cor para representar um servidor é definida de uma forma diferente da anterior, pois dessa vez é preciso declarar a cor como o produto das cores SERVER_ID e State.

Não devemos esquecer do binding das variáveis e assim precisamos declarar $u \mathrm{e}$ $s$ como sendo do tipo USER e SERVER_ID, respectivamente. Além disso, também definimos duas funções que retornam o índice de User(i) e Server $(j)$.

Outro aspecto importante que foi acrescentado nessa nova versão da Fila Limitada é a regra que diz que usuário com índice ímpar só pode ocupar o servidor 1; e, analogamente, usuário com índice par só pode ocupar o servidor 2. Tal regra vai nos permitir fazer uma análise de alcançabilidade altamente esclarecedora no espaço de estados da rede de Petri Colorida. 
A função de guarda $(i d u(u) \bmod 2)=(i d u(s) \bmod 2)$ na transição In implementa a regra que acabamos de descrever. Portanto, esta função de guarda evita que o User(1) ocupe Server(2) ou que User(2) ocupe Server(2).

Na Figura 3.13, é apresentado um estado da rede de Petri colorida que representa a Fila Limitada com atributos de estados durante uma simulação com a ferramenta CPN Tools. Uma possível sequência de passos a partir do estado inicial da Figura 3.11 seria: (1) a transição Entry dispara e coloca User(1) na fila, ou seja, no lugar Queue; (2) a transição Entry dispara novamente e coloca User(2) na fila também, junto com User (1); e (3) a transação In dispara, e devido à função de guarda, associa User(1) com Server(1) e não com Server(2).

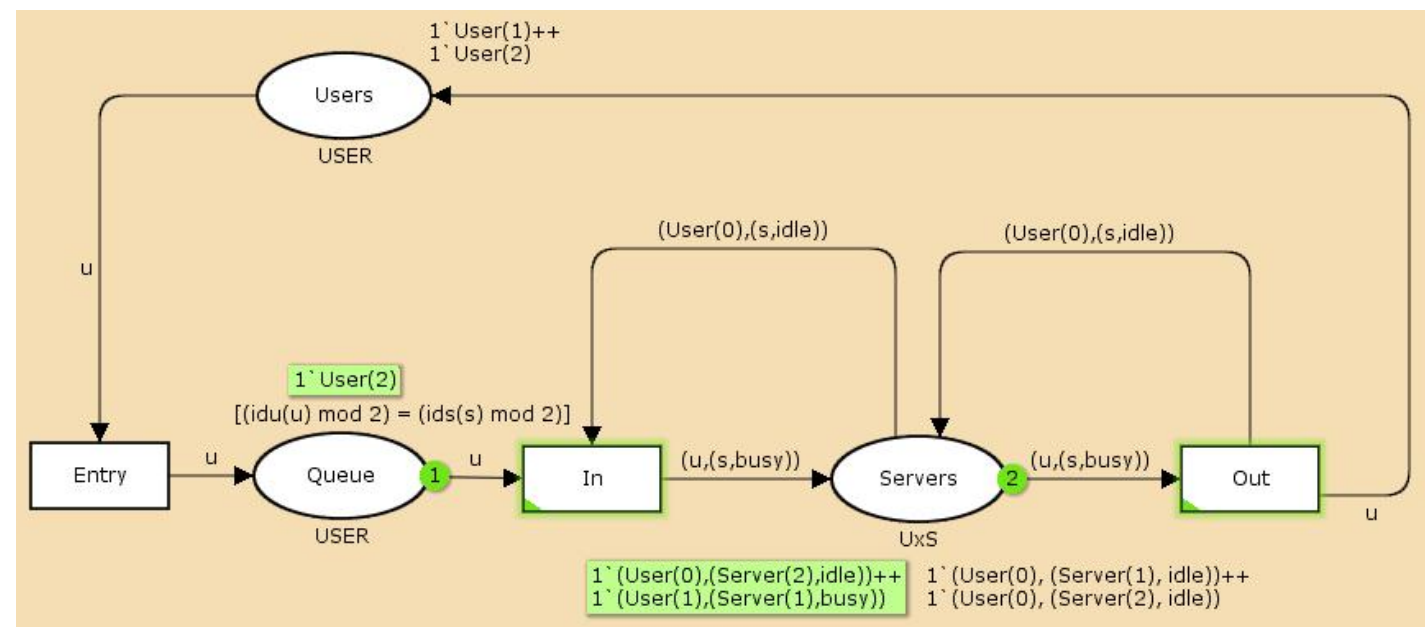

Figura 3.13: Simulação da rede de Petri colorida de uma Fila Limitada - Versão 2

Vale chamar a atenção para o fato de que, quando o User(1), ocupa Server(1) o atributo que antes era idle passa a ser busy. O mesmo acontecerá quando User(2) for associado a Server(2) pela transição In. Apesar dessa rede de Petri colorida parecer mais complexa do que o exemplo de Fila Limitada inicial, sua funcionalidade é a mesma, inclusive o número de nós do espaço de estados não se altera, apesar de termos 1 lugar a menos.

A Figura 3.14 apresenta o espaço de estados da rede de Petri colorida da Figura 3.11. Podemos observar que, com 2 usuários e 2 servidores, existem 9 estados possíveis. Cada nó do espaço de estados apresenta a marcação de cada lugar da rede de Petri colorida. Por exemplo, no estado número 1, ou seja, estado inicial da rede, a página da ferramenta CPN Tools que demos o nome de Queue apresenta 3 lugares: Users, Servers е Quеие como mostrou a Figura 3.11. A sintaxe Queue'Users 1: 1'User(1)++User(2) 


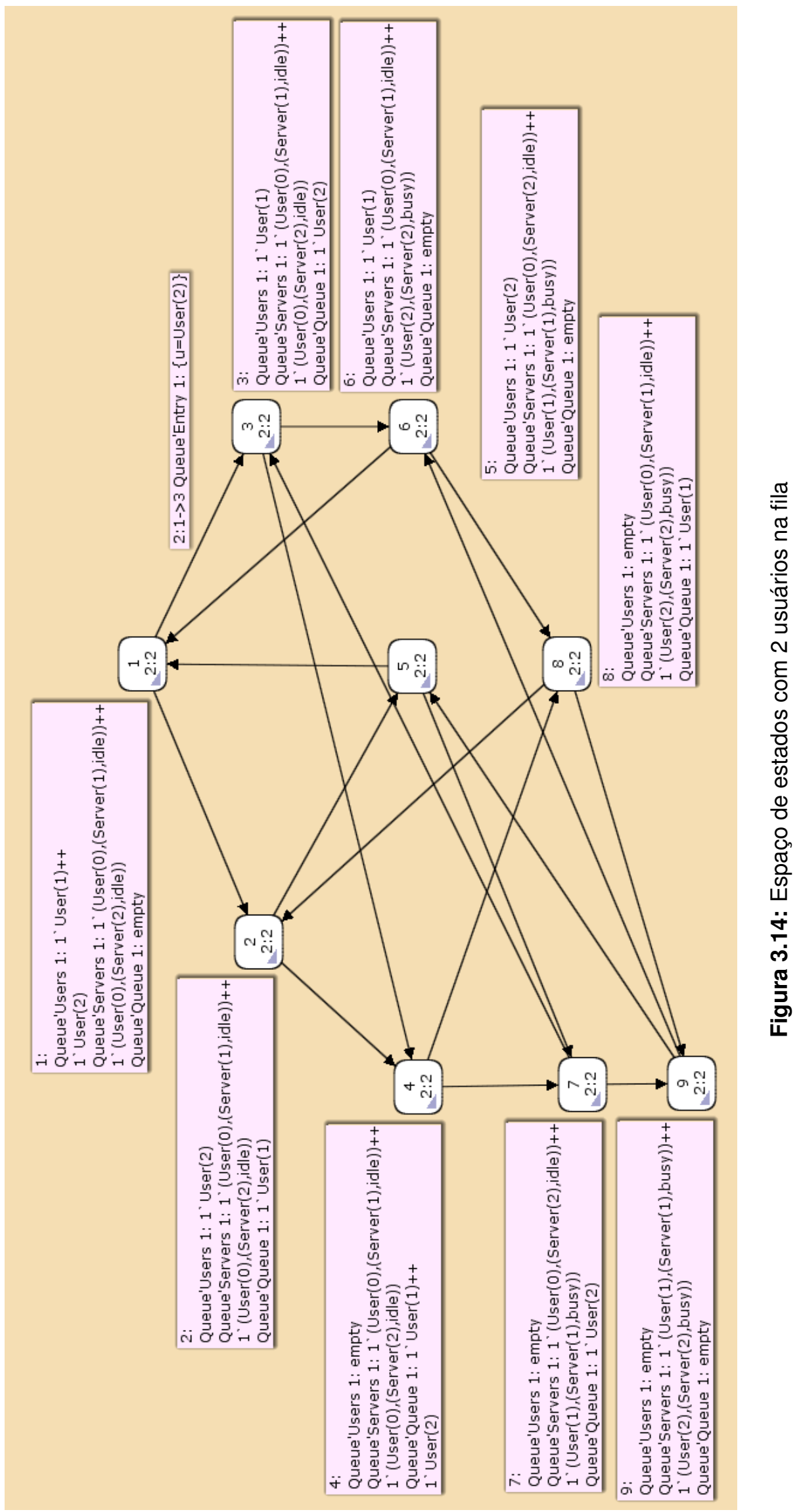


significa que, no estado 1 da rede, no lugar Users, estão presentes os tokens User(1) e User(2). Queue'Servers 1: 1 (User(0),(Server(1),idle))++(User(0),(Server(2),idle)) significa que, no lugar Servers, os servidores Server(1) e Server(2) estão idle (ociosos). Por fim, Queue'Queue 1: empty significa que o lugar Queue está vazio.

O arco que conecta o estado 1 ao estado 3, por exemplo, do espaço de estados da 3.14, descreve o token que passou pela transição Entry. Neste caso, a inscrição no arco nos informa que foi o token User(2) que saiu do lugar Users para o lugar Queue.

A Figura 3.15 apresenta, em linguagem ML, uma consulta ao espaço de estados da Figura 3.14. Tal consulta tem o objetivo de determinar se existem e quais são os estados em que o usuário 1 ocupa o servidor 1 . A resposta para essa consulta é uma lista com os estados 9, 7 e 5. Podemos verificar se essa consulta nos retornou uma resposta correta observando a Figura 3.14. E, dessa forma, confirmamos que a consulta respondeu de maneira adequada o que desejávamos saber.

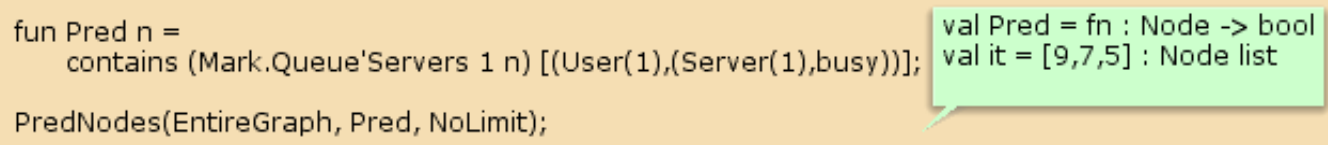

Figura 3.15: Estados em que o usuário 1 ocupa o servidor 1

Na Figura 3.16, a consulta ao espaço de estados da Figura 3.14 quer determinar se existe um estado em que o usuário 1 pode ocupar o servidor 2. A resposta para essa consulta é uma lista vazia, ou seja, não existe tal estado que contraria a regra que foi estabelecida sobre servidor ímpar ser ocupado apenas por usuário ímpar e servidor par ser ocupado apenas por usuário par. De fato, isso pode ser verificado observando-se o espaço de estados desenhado na Figura 3.14.

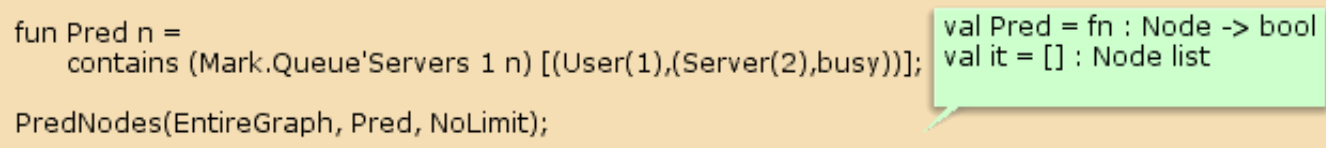

Figura 3.16: Usuário 1 nunca ocupa o servidor 2

Consideramos ainda uma configuração da rede de Petri colorida que modela uma fila limitada com 3 usuários. A consulta da Figura 3.17 retorna os estados em que os usuários 1 e 2 aparecem juntos no lugar Queue. Para o caso de 3 usuários, o número 
de estados é igual a 24 e uma visualização de todos os estados possíveis começa a ficar mais complicado de mostrar.

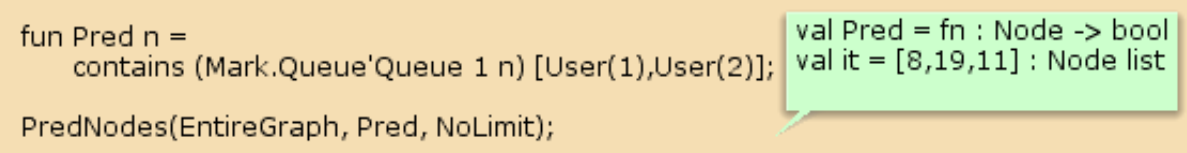

Figura 3.17: Estados em que os usuários 1 e 2 estão juntos

A Figura 3.18 apresenta os estados da rede de Petri da Figura 3.11 para o caso de existirem 3 usuários. Destacamos apenas os estados encontrados na consulta da Figura 3.17 para demonstrar mais uma vez que temos uma resposta correta à consulta.

A Tabela 3.1 apresenta o número de nós em cada espaço de estados se variarmos o número de usuários. É possível perceber que, à medida que a cardinalidade de usuários aumenta, o número de estados cresce de forma muito rápida e fica inviável representar graficamente os nós do espaço de estados. Todavia, as consultas continuam válidas independentemente do aumento crescente de estados.

Tabela 3.1: Número de estados

\begin{tabular}{cl}
\hline Número de usuários & Número de estados \\
\hline 1 & 3 \\
2 & 9 \\
3 & 24 \\
4 & 64 \\
5 & 160 \\
6 & 400 \\
7 & 960 \\
8 & 2340 \\
9 & 5376 \\
10 & 12544 \\
\hline
\end{tabular}

Além da limitação de não conseguirmos representar graficamente o espaço de estados quando o número de usuários cresce muito, existe também a questão de tempo para gerar o espaço de estados. Quanto mais for o número de usuários maior vai ser o tempo que a ferramenta irá precisar para calcular o espaço de estados para que, depois disso, possam ser feitas consultas. Porém, esse tipo de limitação não enviabiliza a análise do espaço de estados de uma rede de Petri colorida, como veremos no próximo exemplo deste capítulo. 


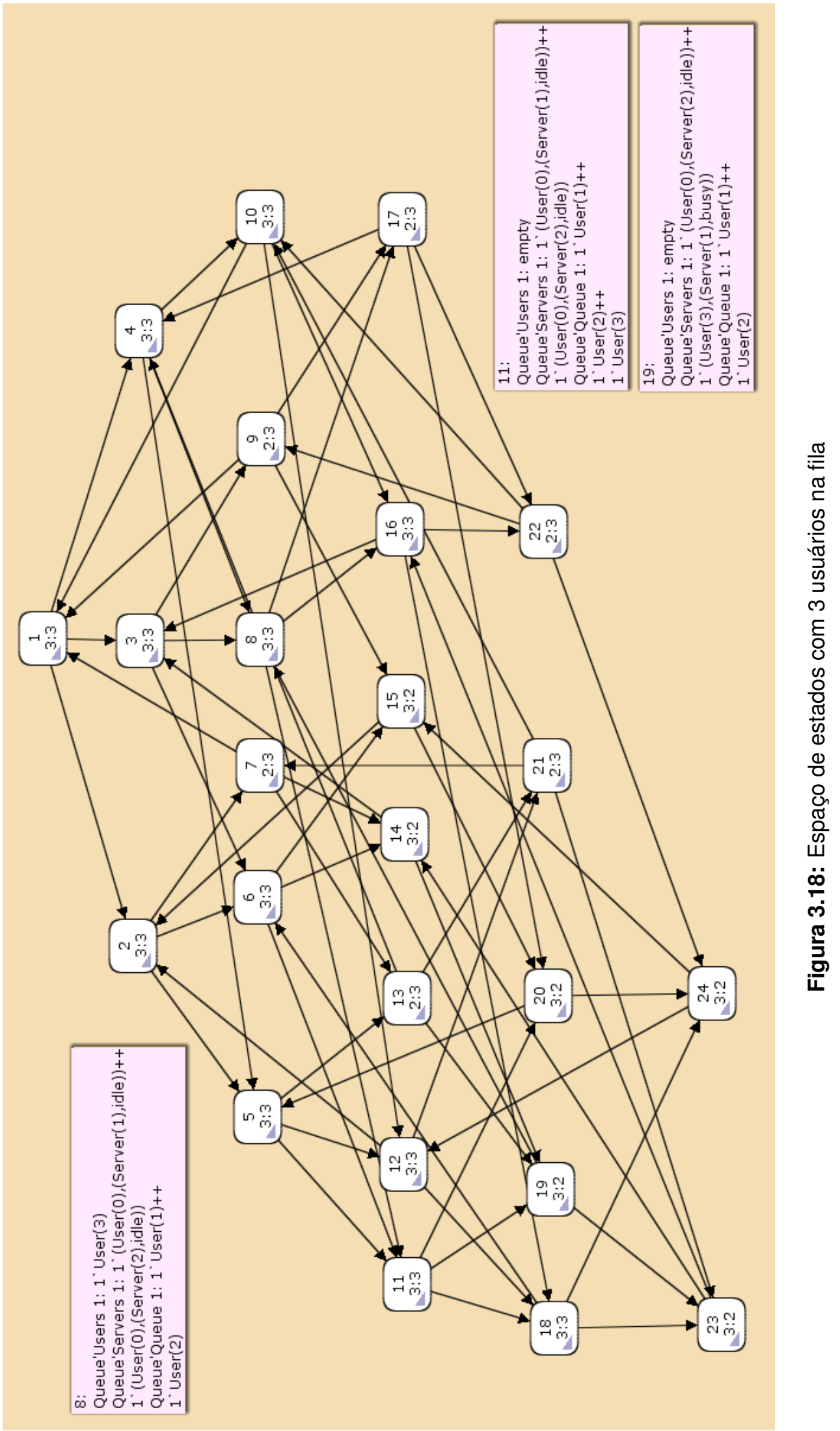




\subsection{Aplicações de Rede de Petri}

A principal aplicabilidade de RP é a modelagem e simulação de sistemas baseados em eventos. Simulação é um conceito muito amplo e, basicamente, pode ser definido como o processo de elaboração de um modelo de um sistema real e a condução de experimentos com a finalidade de entender o comportamento deste sistema ou avaliar sua funcionalidade.

Um evento é definido (LUCKHAM; SCHULTE, 2008) simplesmente como a ocorrência de uma atividade, ou, no contexto de sistemas de computação, definido como a representação de uma atividade computacional. Pode ser entendido como uma ação acontecendo instantaneamente e que provoca transições de um determinado valor de estado para outro diferente.

Uma simulação pode ser classificada basicamente em três categorias distintas: simulação Monte Carlo, simulação Contínua e simulação de Eventos Discretos, de acordo com a taxonomia proposta por Nance (1993).

A simulação Monte Carlo é aquela em que um problema, notadamente não probabilístico, é solucionado através de um processo estocástico, não existindo uma representação explícita do tempo. No caso das simulações Contínua e de Eventos Discretos, o tempo é considerado. A simulação contínua utiliza-se de equações diferenciais para o cálculo das mudanças das variáveis de estado ao longo do tempo. Por outro lado, a simulação de eventos discretos é utilizada para modelar sistemas que mudam o seu estado em pontos discretos no tempo, a partir da ocorrência de eventos.

A simulação de Sistemas de Eventos Discretos é uma técnica bem conhecida e utilizada, por sua habilidade inerente de avaliar sistemas complexos e considerar seu comportamento dinâmico. Por apresentar essas características, nós a consideramos ideal para tratar o problema de pesquisa desta tese de doutorado.

RP aparece com bastante frequência na área de métodos formais, que são ferramentas que visam reduzir significativamente os erros de especificação (PRESSMAN, 2006). O "método formal" é entendido como uma linguagem formal de especificação com sólida base matemática (JENSEN; KRISTENSEN, 2009). Essa base formal permite criar especificações mais completas, consistentes e não ambíguas quando comparadas aos métodos convencionais. 
Dentre os principais benefícios ganhos com a utilização de métodos formais durante o projeto de Sistemas Distribuídos, podemos destacar (JANCZURA; BILLINGTON, 1998):

- uma especificação completa e sem ambiguidades do sistema, que pode ser verificada para satisfazer os requisitos dos projetistas;

- geração automática dos códigos do programa a partir da especificação formal do sistema; e

- descrição formal de aspectos funcionais passíveis de análise de consistência, segurança (security), escalabilidade e desempenho.

\section{Exemplo 3 - Workflow de uma conferência}

Na Figura 3.19, está descrito, através de uma rede de Petri colorida, um workflow genérico de submissão e avaliação de artigos em uma conferência. Em um primeiro momento, artigos estão disponíveis para serem submetidos pelos autores. No instante em que ocorre a submissão de um artigo, o Chair da conferência atribui um revisor para avaliar tal trabalho. Em um contexto real, cada artigo deverá ter no mínimo 3 revisores, mas, para nossa análise, esse aspecto é redundante, então consideramos apenas 1 revisor por artigo com o objetivo de simplificar nossa modelagem.

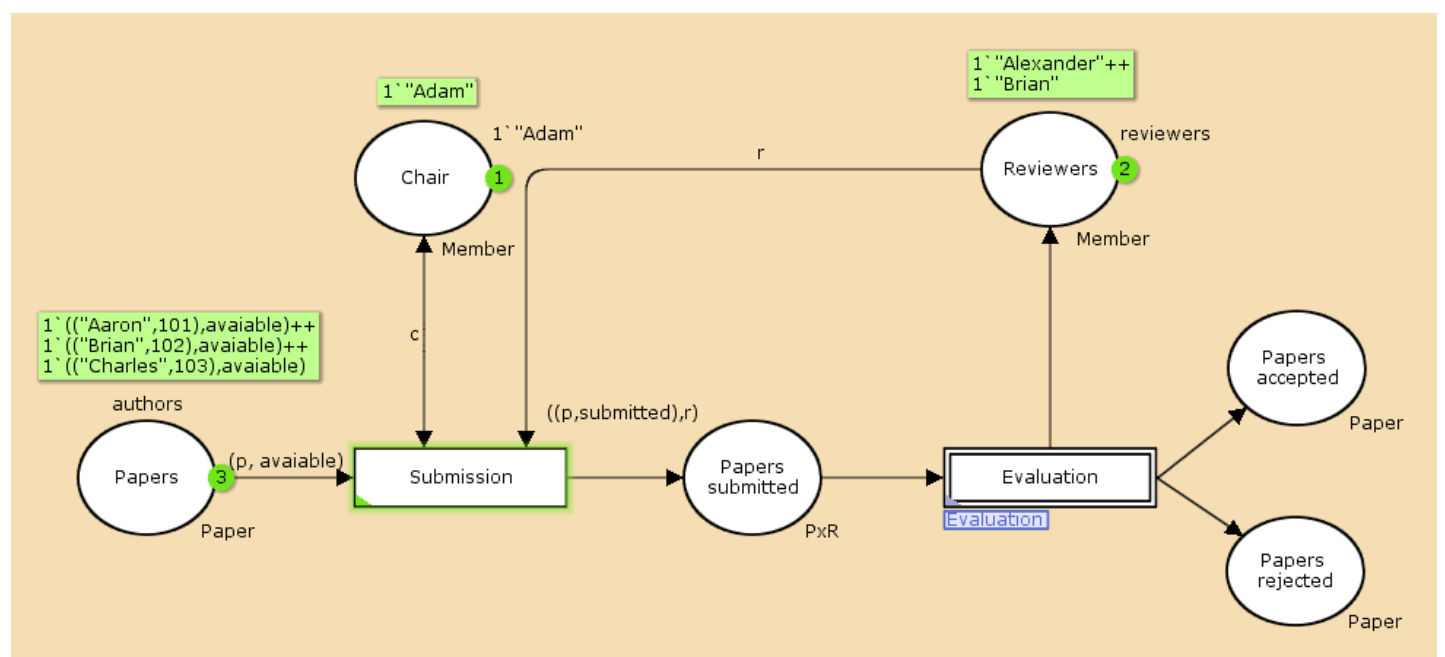

Figura 3.19: Workflow de uma conferência

Na Figura 3.21, aparece o processo de avaliação presente na transição Evaluation, e que é realizada pelo revisor. É comum conferências adotarem como regra aceitar 
apenas 30\% dos artigos submetidos; sendo assim, em nosso workflow, a função accept() é responsável por atribuir o status de "accepted" a no máximo $30 \%$ de todos os artigos submetidos para a conferência. Obviamente, teremos cerca de $70 \%$ dos artigos submetidos com status "rejected" no final da execução do workflow.

Como mostrado na Figura 3.20, as cores relevantes para o workflow da conferência foram declaradas para representar um membro qualquer da conferência, o estado de um artigo e a própria estrutura do artigo que precisa de um autor e um id para ser identificado. Uma vez definidas as cores, o próximo passo é definir as variáveis que aparecem nas funções de guarda e inscrições dos arcos.

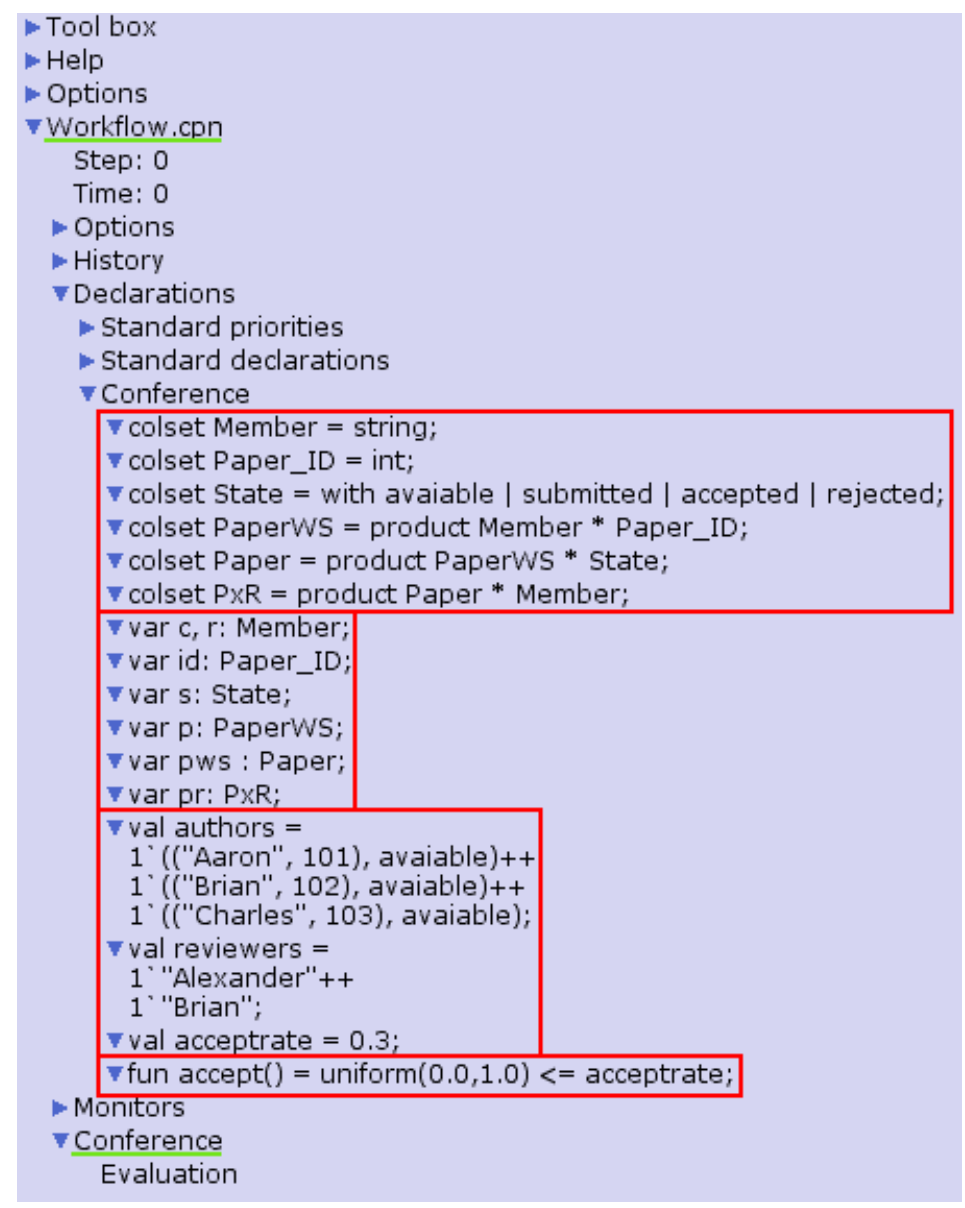

Figura 3.20: Declaração de cores e variáveis para o Workflow

$\mathrm{Na}$ área de declaração, também foram definidos como valores constantes a lista de artigos com autores e $i d$ e o estado inicial disponível para submissão. A lista de nomes de revisores que irão avaliar os artigos também pode ser definida como constante. Além disso, é definido como constante e fixada em 0.3 a taxa de aceitação de 
submissões da conferência. Por fim, é definida uma função que retorna o valo boleano true $30 \%$ das vezes que é invocada de acordo com a taxa de aceitação.

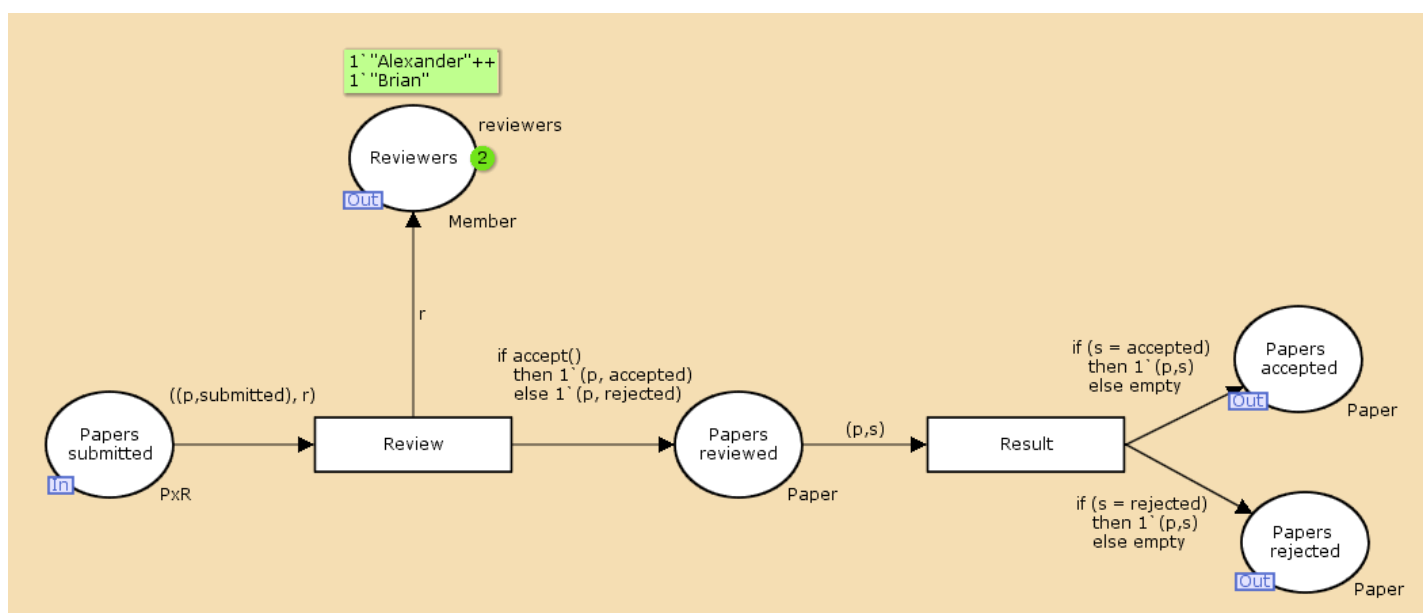

Figura 3.21: SubPage Evaluation do Workflow

Aparentemente, o workflow da Figura 3.19 está correto; sua simulação produz o resultado esperado. Porém, é possível observar que existe um revisor chamado Brian que também é autor de um dos artigos submetidos. Daí, queremos descobrir se é possível existir algum estado no workflow em que Brian revisa seu próprio artigo. Para isso é preciso fazer uma consulta ao espaço de estados da rede de Petri colorida do workflow para determinar se existe um ou mais estados em que Brian é revisor do próprio artigo. Essa consulta aparece na Figura 3.22 e retorna uma lista de 31 estados nos quais isso é possível.

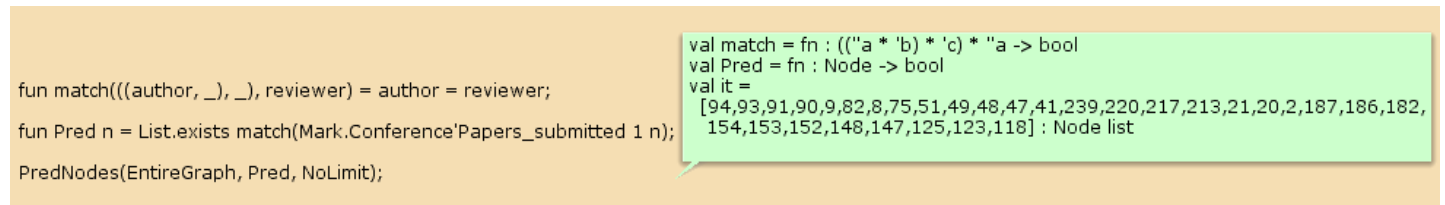

Figura 3.22: Detecção de inconsistência

A rede de Petri colorida da Figura 3.19 possui 272 estados possíveis, dos quais 31 apresentam problema de inconsistência. Pelo fato de ser inviável desenhar o espaço de estados completo, optamos por mostrar apenas 3 estados entre os 35 retornados pela consulta, para confirmarmos visualmente, pelo menos nesses casos, a detecção de inconsistência.

Para corrigir a inconsistência detectada no workflow da conferência, é preciso aplicar uma regra para dizer que um revisor não pode avaliar um artigo submetido por ele 


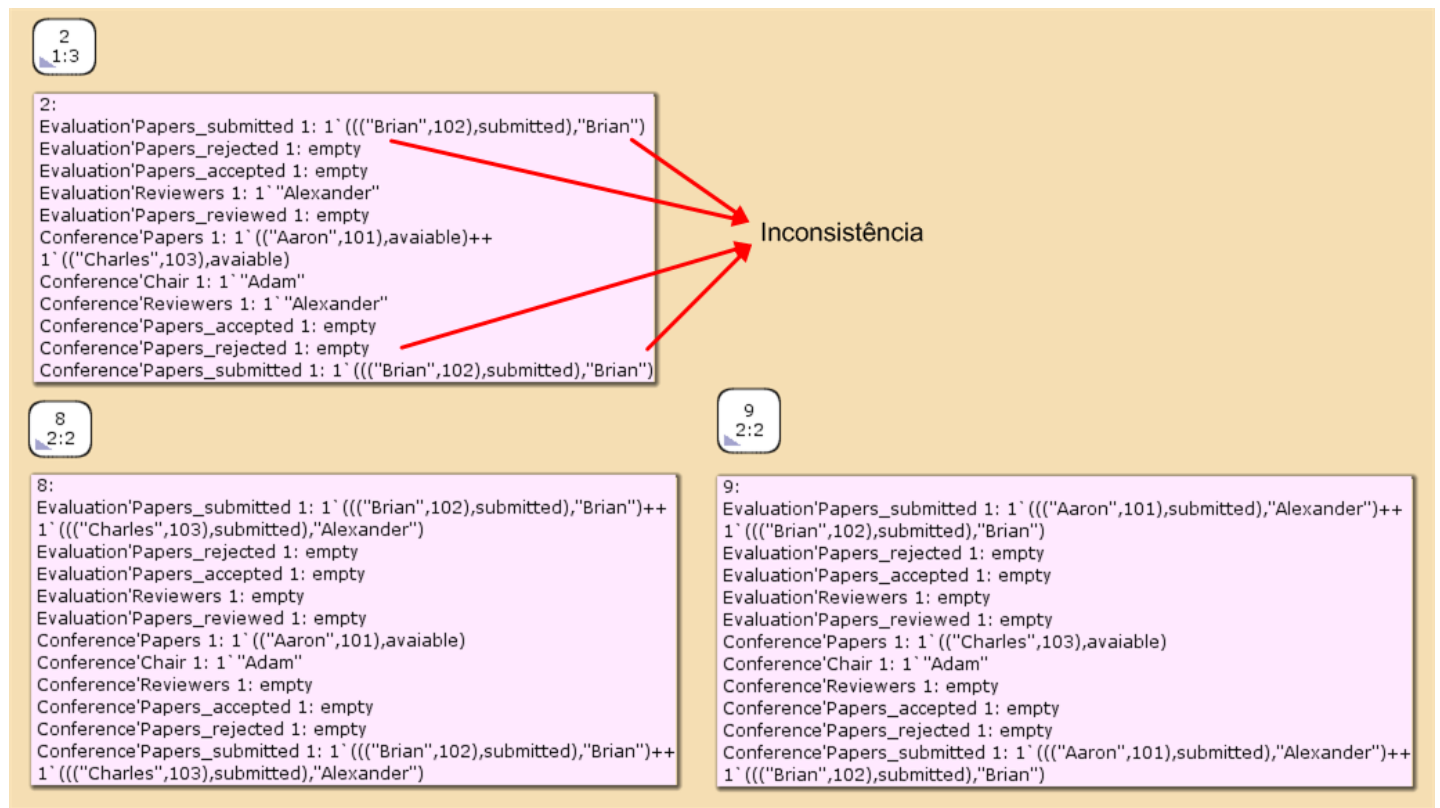

Figura 3.23: Representação de 3 nós do espaço de estados que satisfazem a consulta da Figura 3.22

próprio. Isso pode ser feito através da aplicação da função de guarda [\#1p <> r] na transição Submission, como pode ser visto na Figura 3.24.

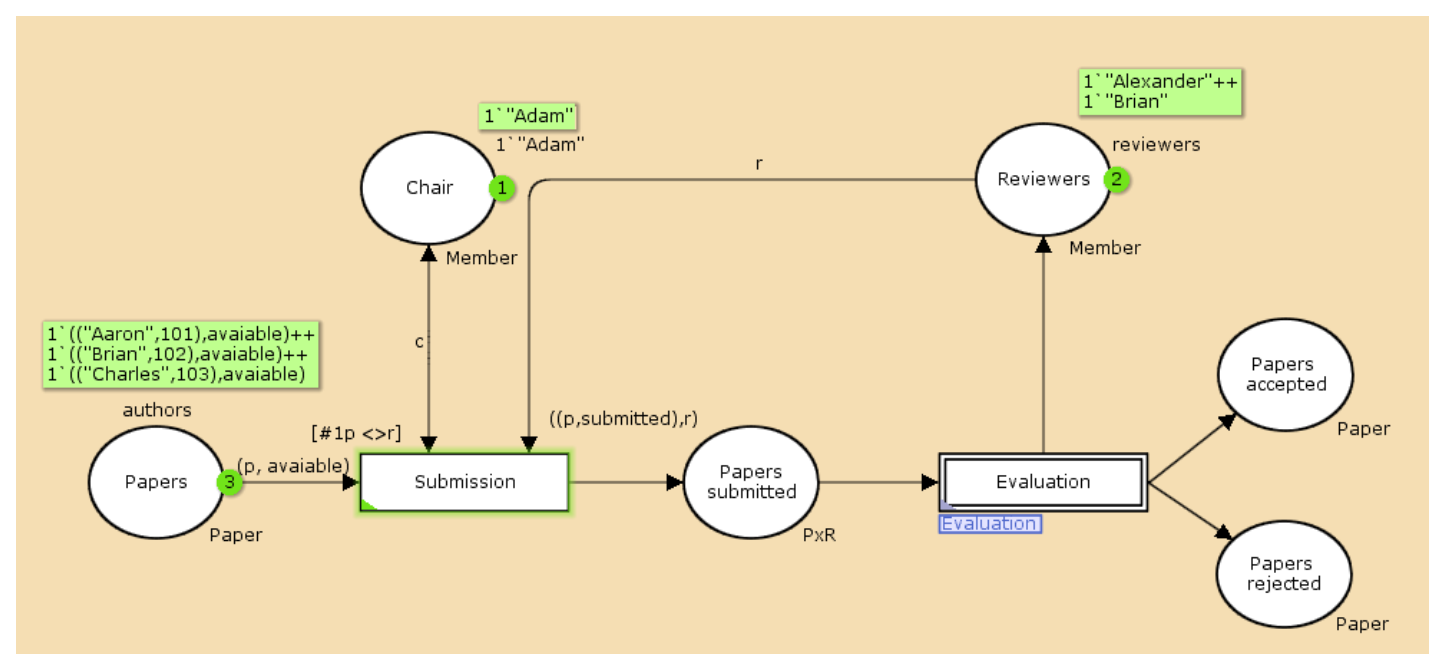

Figura 3.24: Workflow de uma conferência com regra de autorização

Depois de corrigir o problema de inconsistência representado pelo fato de um revisor estar autorizado a avaliar um artigo que foi submetido por ele mesmo, geramos novamente o espaço de estados e aplicamos a mesma consulta de antes. Dessa vez, a consulta retorna uma lista vazia, e dessa forma não existe um estado alcançável em que o revisor Brian pode avaliar seu próprio artigo. A Figura 3.25 apresenta a consulta 
após aplicação da função guarda na transição Submission. É possível verificar que a inconsistência deixou de existir.

fun match(((author,_),_), reviewer $)$ = author = reviewer;

val match $=$ fn : (("a* 'b) * 'c) * "a -> bool val Pred $=f n$ : Node $\rightarrow$ bool

fun Pred $\mathrm{n}=$ List.exists match(Mark.Conference'Papers_submitted $1 \mathrm{n}$ );

val it $=[]$ : Node list

PredNodes(EntireGraph, Pred, NoLimit);

Figura 3.25: Inconsistência corrigida

A Figura 3.26 apresenta o estado final da simulação da rede de Petri do workflow da conferência, considerando que houve 10 submissões de artigos. Note que apenas $30 \%$ dos artigos submetidos foram aceitos. Além disso, é interessante perceber que Charles teve 1 artigo aceito e 1 rejeitado; mas, independentemente disso, nossa modelagem, apesar de simplificada, possui funcionalidade para aceitar várias submissões do mesmo autor.

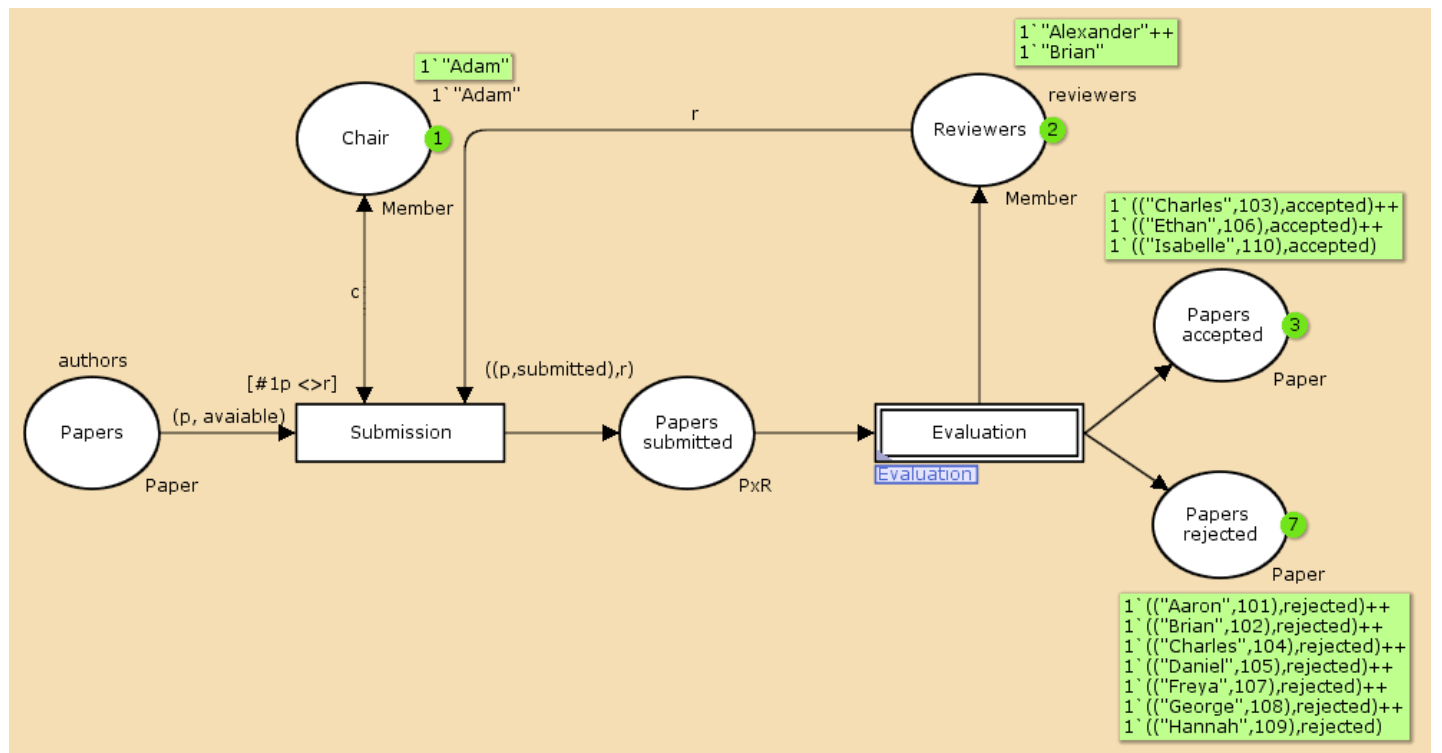

Figura 3.26: Estado final do Workflow da conferência com 10 submissões

\subsection{Síntese e Desafios de Pesquisa}

Este capítulo apresentou princípios da teoria de rede de Petri, com ênfase na rede de Petri colorida. A modelagem de sistemas com rede de Petri colorida permite realizar vários tipos de análises de propriedades de um sistema. A forma mais comum de 
proceder à análise de uma rede de Petri colorida é considerando o espaço de estados gerados pela rede.

Um dos principais desafios ligados à rede de Petri diz respeito a conseguir técnicas mais eficientes para analisar suas propriedades comportamentais e estruturais. Além disso, desenvolver ferramentas computacionais que auxiliem nas análises é outra questão importante.

Através de alguns exemplos, foi demonstrada a eficácia da ferramenta CPN Tools para modelagem e geração de espaço de estados de uma rede de Petri colorida. Apesar desta ferramenta computacional ainda estar em fase de desenvolvimento, ela já apresenta a maturidade necessária e suficiente para o tipo de resultado que esta pesquisa pretende atingir.

Para o escopo de interesse desta tese, o aspecto desafiador refere-se a modelar e depois analisar a consistência de políticas de controle de acesso baseado em papéis utilizando rede de Petri colorida com a ferramenta CPN Tools.

Apesar de o formalismo da rede de Petri colorida permitir diversos tipos de análises, nesta tes, e vamos nos ater apenas à análise de alcançabilidade em espaço de estados para tentar descobrir violações em uma política de controle de acesso baseado em papéis. 


\section{Método de Pesquisa}

\subsection{Introdução}

Este capítulo introduz e discute de forma sucinta alguns métodos de pesquisa empregados na área de segurança e que são aplicáveis às questões de pesquisa desta tese. Discorre também sobre os aspectos importantes sobre simulação de sistemas, que foi o método científico adotado para a condução dessa pesquisa de doutorado. Também são apresentadas características importantes sobre um ambiente educacional, com ênfase em educação a distância - um cenário cheio de possibilidades para realizar estudos sobre políticas de controle de acesso, devido sobretudo às questões de dinamismo. Além disso, educação a distância vem se consolidando como forte tendência mundial na área de educação, o que representa um desafio para sistemas de apoio ao ensino.

\subsection{Métodos de Pesquisa na Área de Segurança}

Conhecimento científico e tecnológico na área de segurança é obtido usando-se principalmente as seguintes metodologias: pesquisa analítica, pesquisa quantitativa, pesquisa qualitativa, pesquisa bibliográfica. A pesquisa quantitativa e a qualitativa são coletivamente chamadas de pesquisa empírica.

A pesquisa analítica (FACHIN, 2001) é o método mais comum de gerar/obter conhecimento sobre algoritmos e sofware. A pesquisa analítica faz algumas pressuposições sobre os dados de um determinado software ou sobre a máquina na qual o aplicativo vai ser executado, e prova matematicamente que o software apresenta algumas propriedades interessantes. A análise de complexidade assintótica de algoritmos (CORMEN et al., 2001) é uma forma de pesquisa analítica - há um conjunto de pressuposições sobre a infraestrutura computacional na qual o algoritmo executa, e prova-se 
propriedades sobre tempo de execução, uso de memória, etc. Análise de algoritmos e programas em que se modela a distribuição de probabilidade dos dados são também exemplos de pesquisa analítica.

A pesquisa quantitativa (GODOY, 1995) é baseada em medidas (normalmente numérica) de poucas variáveis, com ênfase em comparação de resultados e no uso intensivo de técnicas estatísticas. Podemos destacar entre os principais métodos quantitativos da literatura:

- uso de dados sintéticos: benchmarks, simulações e competições;

- técnicas estatísticas para a comparação de conjuntos de medidas;

- uso de questionários (surveys); e

- representações experimentais.

A pesquisa qualitativa (CRESWELL, 2010) baseia-se na observação cuidadosa dos ambientes na qual o sistema está sendo usado ou em que será usado, do entendimento das várias perspectivas dos usuários ou potenciais usuários do sistema, etc. Destacamse entre os métodos qualitativos os seguintes:

- estudos qualitativos observacionais;

- pesquisa-ação (ou estudos qualitativos intervencionistas); e

- outras formas de avaliação qualitativa provenientes da sociologia e antropologia, como Grounded Theory (GLASER; HOLTON, 1967) ou Etnografia.

A pesquisa bibliográfica (FACHIN, 2001), que não será abordada em todos os seus detalhes neste capítulo, não significa apenas coletar e resumir alguns artigos relevantes à pesquisa, como tem sido feito em artigos e teses em computação. Por pesquisa científica bibliográfica, referimos-nos a duas práticas comuns: revisão sistemática e meta-análises. Em ambas, o objetivo é coletar todos os artigos publicados que reportam algum estudo experimental (seja ele quantitativo ou qualitativo) na área de interesse e sintetizar os vários resultados e limitações. 
A revisão sistemática (KITCHENHAM, 2004) enfatiza uma avaliação qualitativa e/ou quantitativa desses vários resultados (por exemplo, distribuição e homogeneidade dos resultados), enquanto que a meta-análise usa técnicas estatísticas avançadas para agregar os vários resultados experimentais em um único resultado numérico.

É comum a pesquisa em Segurança da Informação envolver, na maioria dos casos, o desenvolvimento de um software, de um modelo, de um algoritmo ou de um sistema. Para nossos interesses específicos de pesquisa, estamos interessados em modelar, simular e avaliar um workflow que representa um sistema com certas características que serão melhor detalhadas à frente. Vale ressaltar que avaliação deve ser contrastada com dois outros conceitos importantes: verificação e validação. Verificação é o processo de julgar a aderência de um sistema com a sua especificação; e validação é o processo de decidir o quão bem um sistema resolve o problema para o qual ele foi concebido (CHWIF; MEDINA, 2007).

\subsection{Simulação de Sistemas}

Shannon (1975) argumenta que, ao contrário de muitas tecnologias que são classificadas de acordo com a disciplina na qual ela se origina (física ou química, por exemplo), a simulação pode ser aplicada a todas as disciplinas. Incontáveis trabalhos, relatórios, teses de mestrado e doutorado, revistas e livros mostram vários campos de aplicação para a simulação, como negócios, economia, marketing, educação, política, ciências sociais, ciência comportamental, relações internacionais, transportes, estudos urbanos, e muitos sistemas produtivos dos mais diferentes setores da economia.

Em síntese, os modelos de simulação são valiosos e necessários, uma vez que fórmulas fechadas e equações analíticas raramente conseguem descrever, de forma adequada, sistemas reais complexos (WIDMAN; LOPARO; NIELSEN, 1989). Uma grande vantagem da simulação é permitir estudos de sistemas reais sem modificá-los, de maneira rápida e com baixo custo. Alternativas de mudanças para o sistema podem ser testadas e estudadas de forma sistemática sem interferir no sistema real.

A rápida evolução do software e do hardware nas últimas décadas tem facilitado e muito o desenvolvimento de ferramentas para simulação. Esses simuladores podem ser de grande valia quando decisões precisam ser tomadas em um sistema que não é 
completamente conhecido, devido às diversas interações existentes neste. Dessa forma simulação é uma técnica muito útil e aplicada para projetar os mais variados tipos de sistemas.

A simulação de sistemas é uma metodologia experimental que busca descrever o comportamento de um sistema (KELTON, 1983). Esta metodologia constrói formas de quantificar o comportamento observado, além de tentar prever comportamentos futuros do sistema.

A proposta da simulação é produzir dados (e ela é uma grande geradora de números) que, quando analisados, identificarão importantes aspectos do sistema estudado, auxiliando na explicação, compreensão e melhoria deste (BANKS, 1998).

Shannon (1975) coloca que o desenvolvimento de um processo de simulação é mais uma extensão das artes do que das ciências. Esta característica talvez explique a dificuldade de se apresentar um mecanismo sistemático para que um usuário interessado possa desenvolver simulações. Apesar das dificuldades, podem-se estabelecer os elementos que participam de um modelo de simulação e alguns passos que, se seguidos, podem ajudar um "modelador", mesmo novato, a ter um bom desempenho no desenvolvimento de simulações.

Para realizar a simulação de um modelo, pelo menos cinco passos devem ser observados (MULLER; PFAHL, 2008):

- formulação da sentença do problema (objetivo de modelagem);

- especificação do comportamento de referência (baseado em observação ou hipotético);

- identificação de conceitos do modelo (processos físicos, fluxo de informação, regras de decisão);

- implementação do modelo formal executável; e

- calibração e experimentação do modelo.

De acordo com Muller e Pfahl (2008), os passos da simulação podem ser organizados em um processo iterativo de modelagem. O primeiro passo em qualquer projeto de simulação é a identificação explícita do problema. Uma sentença do problema define 
quais são os objetivos, propósito e escopo da modelagem, contribuindo para organizar as atividades subsequentes do projeto de simulação.

Para fazer com o que o problema seja solucionável por meio de uma estratégia baseada em simulação, é necessário especificar o comportamento de referência (LAW; KELTON, 1999). Ele captura os atributos-chave do mundo real e suas variações dinâmicas esperadas. O comportamento de referência pode ser tanto um cenário problemático observado, que se deseja analisar e melhorar, quanto um comportamento que se deseja atingir.

O comportamento de referência é importante para a simulação por dois motivos. Primeiro, ele ajuda a identificar parâmetros importantes do modelo de simulação, o que auxilia os passos seguintes do projeto. Em segundo lugar, ele é essencial para a validação do modelo, visto que permite comparar os resultados da simulação com o comportamento esperado (ou desejado).

O próximo passo é definir os conceitos do modelo (LAW; KELTON, 1999), que inclui descrever processos existentes, regras de decisão implícitas ou explícitas, padrões típicos de comportamento observados, fluxo de informações e políticas. Esses conceitos em geral são expressados através de modelagem quantitativa ou qualitativa, cujas abstrações dos comportamentos vêm do que é observado na realidade.

Esses conceitos capturam o conhecimento tácito de especialistas da área em modelagem e são formalizados por meio de regras. Nesse passo, é crucial que as informações relevantes do mundo real sejam adicionadas ao modelo, enquanto algumas são descartadas de acordo com o problema em estudo.

Com os conceitos do modelo desenvolvidos, agora é possível implementar a ferramenta de simulação. A ferramenta é uma implementação do modelo formal executável (LAW; KELTON, 1999) em um computador. Para isso, é necessário que um especialista na técnica de simulação transforme o modelo formal em uma representação que será executada em um computador.

O último passo é a calibração e experimentação do modelo (LAW; KELTON, 1999), produzindo os resultados da simulação. Experimentos devem ser realizados primeiro para entender o comportamento do modelo que, em paralelo, é calibrado pelo especialista. Esse passo de ajuste do modelo de simulação (e seus parâmetros) é 
importante para que a saída do modelo reflita o mundo real. Muitas vezes, esse ajuste é feito por meio do uso de dados históricos de sistemas reais.

A experimentação é realizada para entender o comportamento observado, para avaliar alternativas ou para promover algum tipo de melhoria. Esse processo é iterativo na medida em que o modelo é executado, variáveis e estruturas do modelo são modificadas e os resultados das diversas execuções comparados uns com os outros. Portanto, a experimentação não apenas provê os resultados da simulação, mas também valida o modelo em si.

\subsubsection{Verificação e Validação de Modelos}

No encaminhamento de um estudo de simulação, uma das principais etapas consiste na modelagem do sistema sob estudo, para que se possa observar seu comportamento sob determinadas condições, de forma a, cientificamente, estudá-los e entendêlos. Neste processo, procura-se imitar e criar uma história artificial da atuação e desempenho do sistema real, o que implica na realização de um procedimento experimental (via simulação computacional), posterior à etapa de modelagem.

A modelagem pressupõe um processo de criação e descrição, envolvendo um determinado grau de abstração que, na maioria das vezes, acarreta numa série de simplificações sobre a organização e o funcionamento do sistema real (CHWIF; MEDINA, 2007). Usualmente, esta descrição toma a forma de relações matemáticas ou lógicas que, no seu conjunto, constituem o que se denomina de modelos.

A qualidade e a validade de um modelo de simulação são medidas pela proximidade entre os resultados obtidos pelo modelo e aqueles originados do sistema real (CHWIF; MEDINA, 2007). Uma vez que uma série de pressupostos e simplificações sobre o comportamento do sistema real costuma ser realizada no desenvolvimento do modelo, qualquer tomada de decisão com base em seus resultados deve ser precedida de uma avaliação de sua qualidade e apropriação. Esta avaliação está subdividida em duas etapas.

A primeira etapa consiste em avaliar se estes pressupostos e estas simplificações foram corretamente implementados no modelo computacional. A segunda etapa corresponde a saber se, apesar dos pressupostos e das simplificações implementados, o 
modelo ainda é valido, isto é, comporta-se à semelhança do sistema real que foi considerado para modelagem e simulação.

As duas etapas são chamadas de verificação e validação, respectivamente (CHWIF; MEDINA, 2007). Em outras palavras, validação relaciona-se com a representatividade dos pressupostos enquanto que verificação diz respeito à correção, isto é, ausência de erros, das implementações computacionais. Pode-se dizer também que verificação é a etapa na qual assegura-se que o modelo realiza o que se pretende que seja realizado.

\subsection{Características de um Ambiente Educacional}

Para chegarmos nos resultados almejados desta tese e respondermos às duas questões de pesquisa que faltam, escolhemos como estudo de caso um ambiente educacional. Este cenário apresenta comportamento dinâmico através de interações em atividades de ensino entre os diversos papéis e objetos envolvidos. Através deste exemplo de cenário, poderemos desenvolver um modelo detalhado com a finalidade de analisar uma política de controle de acesso e chegar a conclusões gerais que podem ser estendidos a cenários reais com maior cardinalidade de usuários e papéis.

Nesta seção, apresentamos os principais aspectos de um ambiente educacional, com ênfase para Ensino a Distância $(\mathrm{EaD})$. As principais razões para a atual expansão do Ensino a Distância (EaD), não só no país, mas em todo o mundo, são basicamente três (BEHAR; PASSERINO; BERNARDI, 2007): (1) o aumento da demanda por formação ou qualificação; (2) a multiplicação de meios técnicos capazes de garantir materialmente a efetivação desse tipo de educação; e (3) a emergência de uma cultura que já não vê com muito estranhamento o estabelecimento de situações de interação envolvendo pessoas situadas em contextos locais distintos.

Avanços tecnológicos têm possibilitado uma revolução nos recursos utilizados no processo ensino/aprendizagem, necessário na educação continuada exigida pelo mercado de trabalho (PALOFF; PRATT; FIGUEIRA, 2002). Alguns dos principais componentes relacionados ao ensino, como escolas, universidades, professores e alunos, vêm tendo sensíveis mudanças em relação ao desempenho de suas funções diante desse paradigma.

Em seu sentido mais fundamental, EaD significa a separação física e/ou temporal 
entre o professor e o aluno. Para que ela seja caracterizada, é necessária a presença de alguns elementos importantes (SÁ, 2000), sendo eles:

1. a existência de separação espacial e temporal entre: professores - alunos, e ensino/aprendizagem;

2. o controle da aprendizagem é realizado mais intensamente pelo aluno do que pelo professor; e

3. a interação comunicativa entre professores e alunos é realizada por meio de recursos tecnológicos.

$\mathrm{EaD}$ não é um tema que surgiu recentemente e suas origens primitivas remontam a séculos e séculos atrás. Com o advento da escrita, o homem pôde passar para o papel o que antes só podia ser dito, nascendo, tempos depois, a primeira forma de interação entre o educador e o educando: a correspondência. Chaves (2009) cita que as epístolas do Novo Testamento são claros exemplos de $\mathrm{EaD}$, pois possuem um caráter didático nítido e foram destinadas a comunidades inteiras.

O processo de desenvolvimento do $\mathrm{EaD}$ hoje está diretamente ligado ao avanço das tecnologias que ele utiliza como meio para disseminar informação. Essas tecnologias evoluíram gradativamente e algumas delas se tornaram obsoletas devido a problemas como falta de recursos audiovisuais e lentidão na comunicação entre professor e aluno. De acordo com Castro (2000), são estas as quatro gerações de tecnologias utilizadas para EaD Correspondência, Rádio e televisão, Sistemas multimídia integrados e Informática.

Antes da expansão da ciência da computação, a correspondência através dos correios era a única forma de comunicação para os indivíduos que faziam parte de um curso a distância. Com o tempo, foi percebido que era necessária a existência de recursos que excedessem a utilização de textos e figuras, pois certos elementos eram extremamente difíceis de explicar.

$\mathrm{O}$ rádio e a televisão deram suporte para o fim desse problema, envolvendo recursos de áudio e vídeo na elaboração do conteúdo das aulas (CASTRO, 2000). Com a utilização conjunta dos elementos impressos, do rádio e da televisão chega-se aos sistemas multimídia integrados. Após isso, o crescimento do uso do computador e 
o surgimento da internet permitiram que todas as tecnologias antes utilizadas fossem concentradas em um só local, criando um meio de comunicação muito mais interativo e atraente tanto para professores quanto para alunos.

EaD é uma realidade incontestável e há uma grande tendência do seu uso aumentar muito mais nos próximos anos, pois vários ambientes já estão implementados e disponibilizados na Web. Cada um deles procurou trazer inovações em relação aos seus concorrentes anteriores, iniciando uma busca saudável pela melhoria da tecnologia e do processo remoto de ensino e aprendizagem. Tal fato resultou em ambientes com uma grande quantidade de recursos úteis para professores e alunos.

Com a disponibilização de ambientes de $\mathrm{EaD}$ na Web, surgiu a necessidade de se criarem mecanismos de segurança que controlem o acesso dos usuários legítimos a tais ambientes (DURAIPANDIAN; SHANMUGHANEETHI; C.CHELLAPPAN, 2006). Com isso, a área de Ensino a Distância $(\mathrm{EaD})$ fornece um cenário propício para a aplicação de modelos de controle de acesso dinâmico, pois envolve diversas atividades interativas que são realizadas através de acesso remoto dos usuários.

Os usuários são representados pelos participantes das atividades de EaD. Usuários podem ser indivíduos, grupos ou sistemas. Um sistema está, diretamente ou indiretamente, associado a um indivíduo, que é o responsável por sua administração.

O processo de aprendizagem pode ser composto por diversos tipos de atividades interativas, envolvendo diferentes participantes. Neste processo, os diversos participantes colaboram para atingir um objetivo pedagógico (BEHAR; PASSERINO; BERNARDI, 2007). A realização desta atividade colaborativa possui um objetivo específico, a partir do qual pode ser extraído um conjunto de recursos e operações necessárias para a realização da atividade didática. Os participantes envolvidos em uma atividade didática desempenham papéis específicos no processo de aprendizagem.

$\mathrm{O}$ ambiente de $\mathrm{EaD}$ sugere a existência de alguns papéis, que podem ter direitos distintos dependendo do contexto de aprendizagem em que estão inseridos. Papéis básicos e fundamentais que devem aparecer em $\mathrm{EaD}$ são os de professor, aluno, monitor, por exemplo. Além disso, ambientes de EaD são formados por diversas ferramentas que auxiliam no processo de aprendizagem e na realização de atividades colaborativas. 
Portanto, existem várias entidades, usuários, papéis que compõem a arquitetura de uma ambiente $E a D$. Tal cenário dinâmico e distribuído necessita de um modelo de controle de acesso dinâmico para que requisitos fundamentais de segurança sejam garantidos.

\subsection{Síntese e Desafios de Pesquisa}

Neste capítulo, foram discutidos os principais métodos de pesquisa adotados em investigações na área de ciência da computação, em especial segurança da informação. O método de pesquisa bibliográfica apresentada na seção 4.2 foi aplicado no Capítulo 2, quando descrito o mapeamento sistemático que investigou quais são as principais abordagens para estabelecimento da relação papel-permissão em modelos de controle de acesso baseado em papéis.

Este capítulo também apresentou as principais características de simulação de sistemas, uma vez que a abordagem com rede de Petri colorida na qual se baseia esta tese pertence a essa classe de métodologia científica. Através da modelagem, simulação e análise de um cenário detalhado, será possível inferir resultados importantes sobre cenários reais. Por fim, foram apresentados aspectos importantes para que possamos realizar a modelagem de um sistema educacional que dê suporte para atividades de um ambiente EaD.

A modelagem e simulação de sistemas é uma atividade de pesquisa desafiadora, porque os modelos são representações que capturam apenas aspectos mínimos para que conclusões sobre os sistemas reais possam ser aferidas. No contexto desta tese, o desafio é modelar, simular e analisar um sistema que incorpore uma política de controle de acesso baseado em papéis, com o objetivo de responder se é possível avaliar a sua consistência neste caso. 


\section{Modelagem de Política de Controle de Acesso com Rede de Petri Colorida}

\subsection{Introdução}

Neste capítulo, inicialmente, caracterizamos quais são as principais entidades e atividades envolvidas em um cenário educacional. Uma vez compreendidos os aspectos relevantes desse ambiente, é preciso definir uma política mínima de controle de acesso envolvendo seus papéis. A etapa seguinte deste capítulo é dedicada a mostrar a modelagem do cenário que estamos considerando utilizando rede de Petri colorida e a ferramenta computacional CPN Tools (JENSEN; KRISTENSEN; WELLS, 2007).

O ambiente educacional considerado neste capítulo foi inicialmente modelado com UML (Unified Modeling Language), que é uma linguagem de modelagem bastante difundida e utilizada para especificar sistemas. Apesar de UML ser muito útil, ela apresenta limitações, não sendo possível realizar simulações ou verificar certas propriedades que se deseja analisar no contexto da avaliação de uma política de controle de acesso.

A finalidade principal deste capítulo é destacar o processo de metamodelagem de uma política de controle de acesso baseado em papéis. O ambiente educacional no contexto desta pesquisa serve como exemplo de caso para que possamos atingir nossos objetivos. Outro tipo de ambiente, como o financeiro, poderia ter sido considerado; todavia, os resultados desta tese independem do tipo de cenário escolhido. 


\subsection{Ambiente Educacional}

\subsubsection{Atores e Objetos}

Para realizar a modelagem de um cenário educacional, o primeiro aspecto que se deve pensar é quais são os atores do sistema e quais são os objetos sobre os quais tais atores vão atuar. Qualquer tentativa de manipulação de um objeto que não estiver especificado na política de controle de acesso é considerada uma ameaça de segurança.

Por ser extremamente colaborativo, o ambiente educacional, em particular $\mathrm{EaD}$ (Ensino a Distância), envolve diversos tipos de interações entre atores e objetos do sistema (DURAIPANDIAN; SHANMUGHANEETHI; C.CHELLAPPAN, 2006). Tal ambiente é complexo, mas também oferece um cenário rico de possibilidades de análises de modelos de controle de acesso.

O processo de aprendizagem pode ser composto por diversos tipos de atividades interativas, envolvendo diferentes participantes. Nesse processo, os diversos participantes colaboram para atingir um objetivo pedagógico.

A realização dessa atividade colaborativa possui um objetivo específico, a partir do qual pode ser extraído um conjunto de recursos e operações necessárias para a realização da atividade didática. Os participantes envolvidos em uma atividade didática desempenham papéis específicos no processo de aprendizagem.

Um ambiente educacional sugere a existência de alguns atores, que podem ter direitos e obrigações distintas dependendo das atividades de aprendizagem em que estão inseridos. No contexto de trabalho desta tese, tais atores na verdade são os papéis do modelo de controle de acesso baseado em papéis.

Diversos papéis podem existir em um cenário educacional; mas, para efeitos de simplificação de nossa modelagem, vamos considerar apenas um pequeno subconjunto formado por Professor, Aluno e Monitor, pois são os papéis mais frequentes em um contexto educacional.

Uma vez definidos os atores do nosso ambiente, é preciso conhecermos os tipos de objetos. No caso de um cenário educacional e em muitos outros tipos de cenários, a noção de objeto é abstrata, pois, não necessariamente, um objeto precisa ser algo físico como um hardware, como estamos habituados. Tais objetos também não vão 
se restringir apenas aos conceitos de arquivos que podem ser manipulados por algum sistema operacional ou aplicativo computacional.

Podemos listar vários objetos que aparecem em um cenário educacional, porém, para simplificar a modelagem do sistema apresentado neste capítulo, vamos considerar apenas disciplina, aula e prova como sendo os mais significativos e suficientes para nossos objetivos. Professores, alunos e monitores interagem através de atividades dentro das disciplinas e aulas, podendo inclusive haver prova. Dessa forma, intuitivamente, temos elementos mínimos para desenvolver um sistema educacional on-line, que pode ser utilizado, por exemplo, para dar suporte à $\mathrm{EaD}$.

Uma ressalva interessante é que objetos não necessariamente aparecem de forma independente. No caso de disciplina e aula, sabemos que uma disciplina é constituída por uma sequência de aulas. Isso nos mostra que objetos podem aparecer de forma hierarquizada em um cenário educacional.

\subsubsection{Direitos, Obrigações e Responsabilidades}

Vimos, na seção anterior, quais são os principais atores e objetos para a modelagem a ser realizada e descrita nesta tese. Estes atores, ou melhor dizendo, papéis, podem realizar determinadas ações sobre os objetos. Por exemplo, um professor pode decidir ofertar uma disciplina sob sua responsabilidade em determinado semestre letivo de aula, bem como um aluno pode decidir se matricular na disciplina desse professor se ela pertence a seu programa de ensino que precisa ser cumprido. Dessa forma, um mesmo objeto promove a interação entre dois papéis.

De forma clara, podemos classificar ações que papéis podem realizar sobre objetos como facultativas ou obrigatórias. Por exemplo, um professor tem o direito de oferecer uma disciplina, porém não existe algo que o obrigue a fazer isso, caracterizando um ato facultativo. Por outro lado, se um professor está oferecendo uma disciplina, ele tem a obrigação de ministrar as aulas desta disciplina, não podendo simplesmente deixá-la sem atividades para os alunos.

Na verdade, quando papéis têm direitos ou obrigações sobre determinados objetos, entendemos que eles assumiram responsabilidades. Tais responsabilidades devem ser respeitadas, e isto justifica a existência das políticas de segurança baseadas em papéis. 


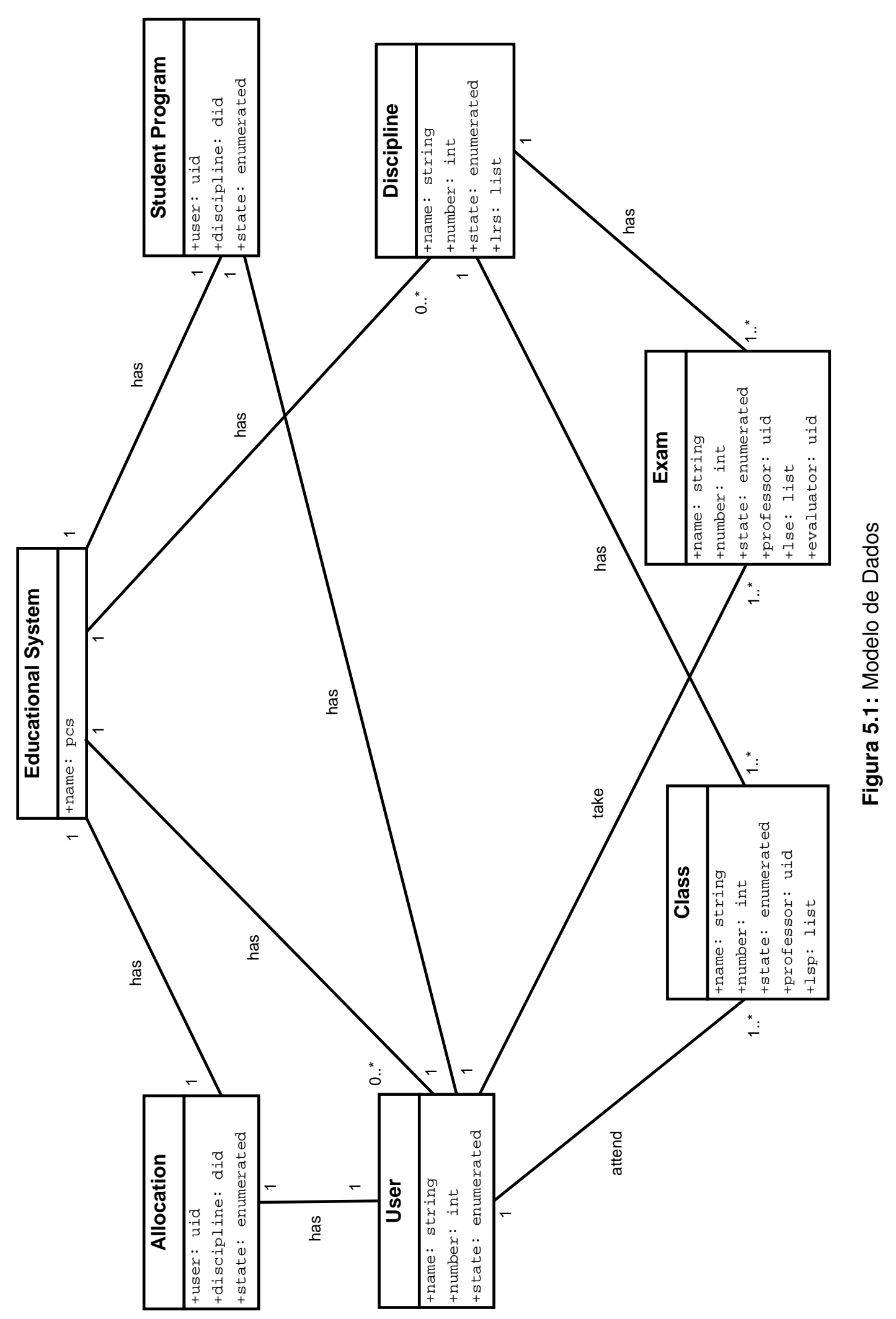


A Figura 5.1 apresenta um modelo de dados descrito em UML relativamente simples, que descreve um cenário educacional típico. Mais adiante, descrevemos como construir um modelo deste sistema com rede de Petri colorida a partir deste modelo de dados.

No modelo da Figura 5.1, é possível notar que um usuário (User) do sistema, que pode ser um professor, aluno ou monitor, pode participar de disciplina (Discipline), aula (Class) e prova (Exam). No modelo também está representado que, se um usuário é um aluno, ele tem um programa de estudante (Student Program) em que constam as disciplinas que ele tem a obrigação de cursar. Da mesma forma, se um usuário pode assumir o papel de professor ou monitor, existe uma tabela de alocação (Allocation) com as disciplinas que eles podem participar.

Antes de realizar a modelagem através de rede de Petri colorida, precisamos definir e compreender que tipo de política mínima de controle de acesso deve ser definida para este cenário educacional. A próxima seção dá ênfase a esse importante aspecto.

\subsection{Política de Controle de Acesso do Cenário Proposto}

Uma política de segurança é um conjunto de regras estabelecidas para assegurar metas específicas com relação ao que se deseja proteger em um sistema (LANDWEHR, 2001). Uma política de controle de acesso consiste de regras de autorizações que podem ser específicas em diferentes linguagens (SAMARATI; VIMERCATI, 2001). Estas regras definem quais ações os papéis têm autorização de realizar e quais os objetos do sistema podem sofrer tais ações. Em outras palavras, um política de controle de acesso especifica o que papéis podem ou não fazer.

Quando existe uma tentativa (intencional ou não) de agir contra alguma das regras de autorização da política de controle de acesso, é caracterizada como uma ameaça ao estado de segurança do sistema. Quando uma violação à política é consumada, dizemos que a segurança do sistema foi comprometida. Com isso, políticas de controle de acesso devem ser especificadas de tal forma que assegurem que violações das regras de autorização não aconteçam.

A Tabela 5.1 apresenta a relação usuário-papel, presente em RBAC, do cenário educacional relacionado ao modelo de dados apresentado na Figura 5.1 da seção an- 
terior. Note que, através desta tabela, é possível saber que um único usuário pode ser associado a mais de um papel; no caso, o usuário 2 pode ser aluno e também monitor. Este tipo de situação acontece em sessões em um modelo RBAC. Porém, no momento, não conseguimos saber em quais circunstâncias tal fato pode ocorrer apenas com as informações desta tabela.

Tabela 5.1: Relação Usuário-Papel

\begin{tabular}{ll}
\hline Usuário & Papel \\
\hline Usuário 1 & Professor \\
Usuário 2 & Aluno \\
Usuário 3 & Monitor \\
\hline
\end{tabular}

A Tabela 5.2 apresenta determinadas ações sobre certos objetos do sistema, ou seja, permissões possíveis. Por exemplo, alguém pode oferecer uma disciplina e, nesse caso, ele deve receber a obrigação de lecioná-la. É importante percebermos que, apesar de certas ações sobre objetos sugerirem atores bem definidos do cenário educacional, nem sempre isso se confirma. No caso da permissão "corrigir prova", não temos como ter certeza se tal permissão vai ser executada por um professor ou um monitor. Enfim, podemos dizer que apenas com as Tabelas 5.1 e 5.2 nosso cenário ainda não está bem caracterizado, e precisamos de mais informação.

Tabela 5.2: Permissões no modelo de controle de acesso

\begin{aligned} & \hline Ação Objeto \\ & \hline Ofertar \\ & Fechar \\ & Ministrar Disciplina \\ & Matricular \\ & Cursar \\ & Ministrar Aula \\ & Assistir \\ & Aplicar \\ & Fazer Prova \\ & Corrigir \\ & \hline\end{aligned}

Para efeitos de simplificação do nosso modelo com rede de Petri colorida, estamos considerando poucas permissões; contudo, é de se esperar que um cenário real 
precise de muito mais ações e objetos. Apesar de reduzido, o modelo de workflow que incorpora a política de controle de acesso baseado em papéis deste capítulo atende às necessidades exigidas para a realização da análise de consistência que será feita mais adiante, no próximo capítulo.

Como mencionamos no início deste capítulo, atores de um sistema têm direitos e obrigações, sendo que muitas vezes alguns direitos podem ser facultativos. Na verdade, esses dois tipos de responsabilidades facultativas ou obrigatórias representam permissões que um papel pode ter. A Tabela 5.3 apresenta a relação papel-permissão, ou seja, determina o que cada papel pode fazer.

Tabela 5.3: Relação Papel-Permissão

\begin{tabular}{|c|c|c|}
\hline Papel & Facultativo & Obrigatório \\
\hline Professor & $\begin{array}{l}\text { Ofertar disciplina } \\
\text { Aplicar prova }\end{array}$ & $\begin{array}{l}\text { Fechar disciplina } \\
\text { Ministrar disciplina } \\
\text { Ministrar aula } \\
\text { Corrigir prova }\end{array}$ \\
\hline Aluno & $\begin{array}{l}\text { Matricular em disciplina } \\
\text { Assistir aula }\end{array}$ & $\begin{array}{l}\text { Cursar disciplina } \\
\text { Fazer prova }\end{array}$ \\
\hline Monitor & $\begin{array}{l}\text { Matricular em disciplina } \\
\text { Assistir aula } \\
\text { Ministrar aula } \\
\text { Corrigir prova }\end{array}$ & $\begin{array}{l}\text { Cursar disciplina } \\
\text { Fazer prova }\end{array}$ \\
\hline
\end{tabular}

Conhecer as permissões e as relações usuário-papel e papel-permissão não são suficientes para caracterizarmos uma política de controle de acesso baseado em papéis sobre o cenário educacional. Até o presente momento, através das Tabelas 5.1, 5.2 e 5.3, podemos interpretar apenas o que pode ser feito, mas não temos como saber o que não pode ser efetuado. Para isso, é preciso ter uma quarta tabela com regras de restrição de autorização para uma política definida com base nas permissões e relacionamentos usuário-papel e papel-permissão. A Tabela 5.4 apresenta algumas regras de autorização, ou restrições de controle de acesso, para o cenário educacional que estamos considerando.

Note que os objetos disciplina, aula e prova apresentam interação com os papéis professor, aluno e monitor. Porém, muitas das ações dos papéis sobre os objetos são aplicados em contextos distintos, caracterizando permissões com diferentes semânticas. Por exemplo, ministrar disciplina e ministrar aula são permissões diferentes, pois, 
apesar de a ação ser a mesma, os objetos disciplina e aula são distintos mesmo estando relacionados. O modelo RBAC do NIST considera permissões positivas, porém, é livre a adoção de permissões negativas (SANDHU; FERRAIOLO; KUHN, 2000). As regras descritas na Tabela 5.4 foram definidas de forma negativa para facilitar o processo de análise da consistência da política no próximo capítulo.

Tabela 5.4: Restrições de controle de acesso

\begin{tabular}{l}
\hline Regras \\
\hline Um usuário não pode ser professor e aluno de uma mesma disciplina \\
Um usuário não pode ser professor e monitor de uma mesma disciplina \\
Um aluno não pode ministrar aulas \\
Um monitor não pode ofertar uma disciplina \\
Um monitor não pode corrigir prova de uma disciplina se ele estiver matriculado nela
\end{tabular}

Muitas das regras de uma política emergem a partir de comportamentos em situações típicas que aparecem no ambiente em que é aplicada esta política. No caso do ambiente educacional, um monitor oferecer uma disciplina representa claramente uma violação da política de controle de acesso, pois apenas o professor tem direito de realizar tal ação sobre o objeto disciplina. Assim, temos uma regra que foi gerada a partir da observação das interações naturais entre os papéis professor e monitor com o objeto disciplina. A política descrita na Tabela 5.4 ilustra algumas regras importantes que devem ser seguidas por uma política de controle de acesso em um ambiente educacional, porém não tem a finalidade de ser exaustiva.

\subsection{Modelagem do Sistema com Rede de Petri Colorida}

\subsubsection{Workflow Operacional}

Depois de caracterizado o cenário educacional e a política de controle de acesso baseado em papéis que deve ser aplicada, foi possível desenvolver uma modelagem desse ambiente utilizando rede de Petri colorida. A Figura 5.6 mostra a representação do cenário educacional modelado com a ferramenta CPN Tools.

Por questões de simplificação do modelo, foram considerados como usuários no sistema apenas 2 professores e 4 alunos, sendo que um destes alunos é monitor. Para 
representar um papel na modelagem, foi definido uma cor do tipo enumerável com alguns possíveis valores: Professor, Aluno, Monitor. Para isso, nós definimos essa cor com a declaração colset roleid $=$ with professor $\mid$ aluno $\mid$ monitor; em linguagem ML, a linguagem de modelagem da ferramenta CPN Tools. A Figura 5.2 apresenta em destaque todas a cores que foram necessárias definir para a rede de Petri colorida.

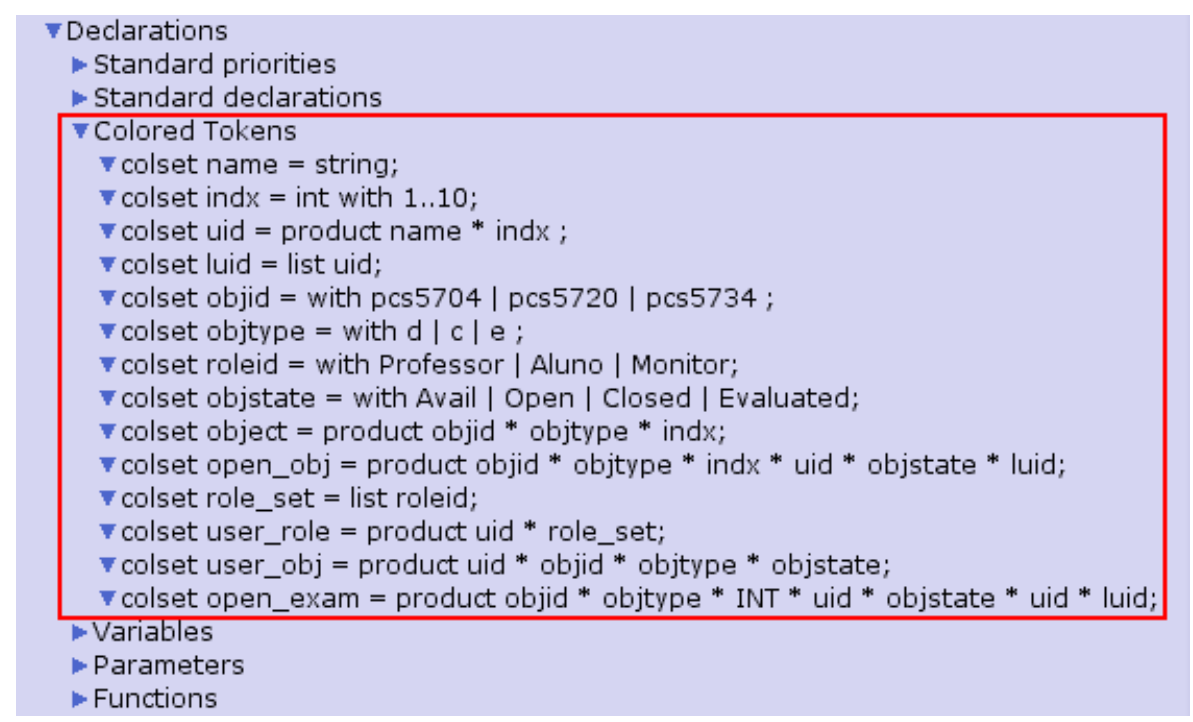

Figura 5.2: Tokens Coloridos da Rede do Workflow

Além dos papéis professor, aluno e monitor, também definimos cores em nosso modelo para representar os objetos Disciplina, Aula e Prova. Para Disciplina e Aula, foi declarado a cor open_obj e, para o objeto Prova, temos a cor open_exam. Para as tabelas de alocação de disciplinas de professores e programa dos estudantes foi declarada a cor user_obj. Também foi declarada uma cor user_role que associa cada usuário à lista de papéis que ele pode assumir.

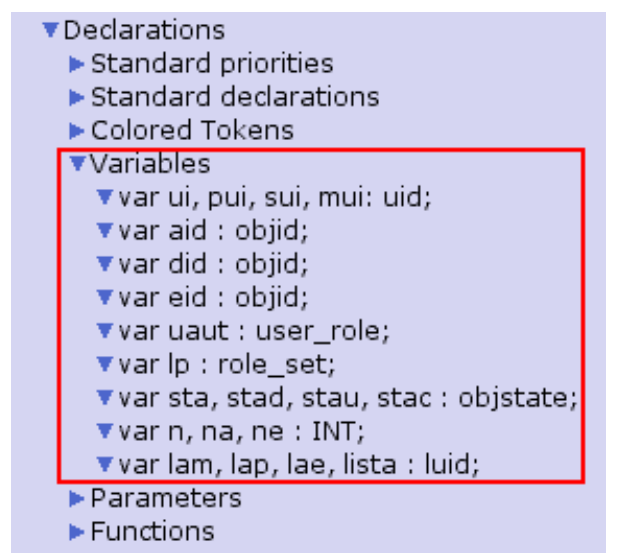

Figura 5.3: Variáveis da Rede do Workflow 
Uma vez definidas todas as cores que serão utilizadas na rede de Petri colorida e aplicadas para estabelecer os tipos dos lugares, é preciso definir as variáveis da rede. A Figura 5.3 apresenta todas as variáveis que foram necessárias no modelo do workflow operacional. Tais variáveis são importantes para a definição das expressões inscritas nos arcos da rede de Petri colorida.

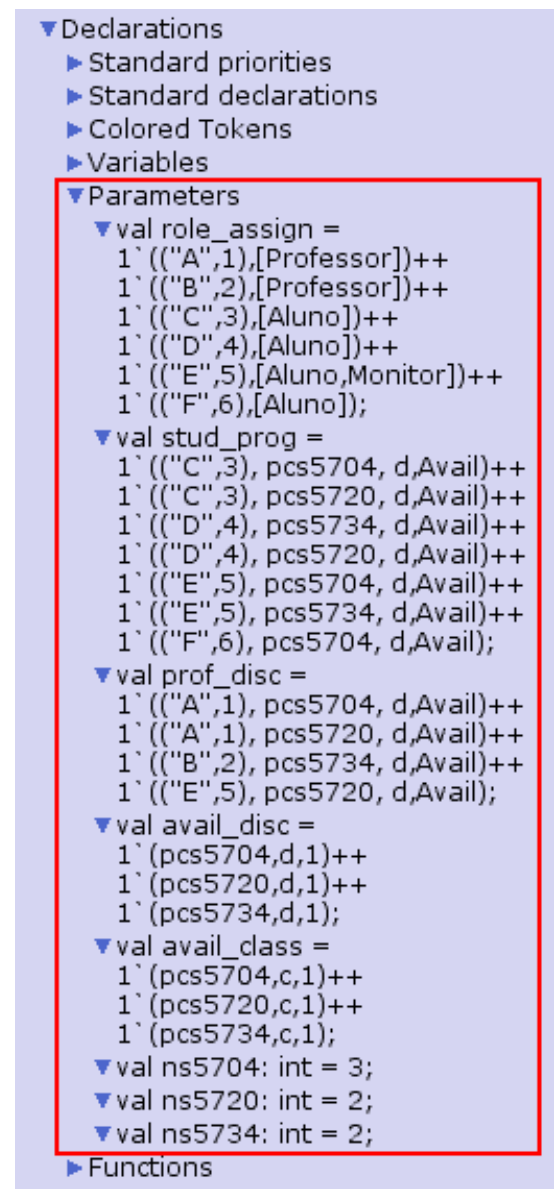

Figura 5.4: Parâmetros constantes da Rede do Workflow

Para simplificar a visualização eliminando informações que possam aparecer na área de trabalho do ambiente da ferramenta CPN Tools de maneira repetida, definimos tais valores como constantes por meio do comando val como definido na Figura 5.4. Além de deixar a interface da rede mais clara também evitamos repetição de códigos com o recurso de definição de constantes. Dessa forma, foi possível representar, por meio de tabelas, as associações de usuários com seus papéis, a lista de disciplinas que cada professor pode oferecer, o programa de disciplinas que os alunos precisam seguir e quais disciplinas e aulas estão disponíveis em determinado momento de execução do workflow operacional do cenário educacional. 
Por fim, para encerrar a parte de declarações da rede de Petri colorida, definimos funções, através do comando fun, que são utilizadas na modelagem do cenário educacional. As funções que precisaram ser desenvolvidas são mostradas na Figura 5.5. As funções inList() e uidinList() inserem um papel e um usuário em uma lista, respectivamente. A função remove() retira um usuário de uma lista e member() responde se um elemento pertence a uma lista. Por último, a função inorder() insere um usuário em uma lista e ordena essa lista.

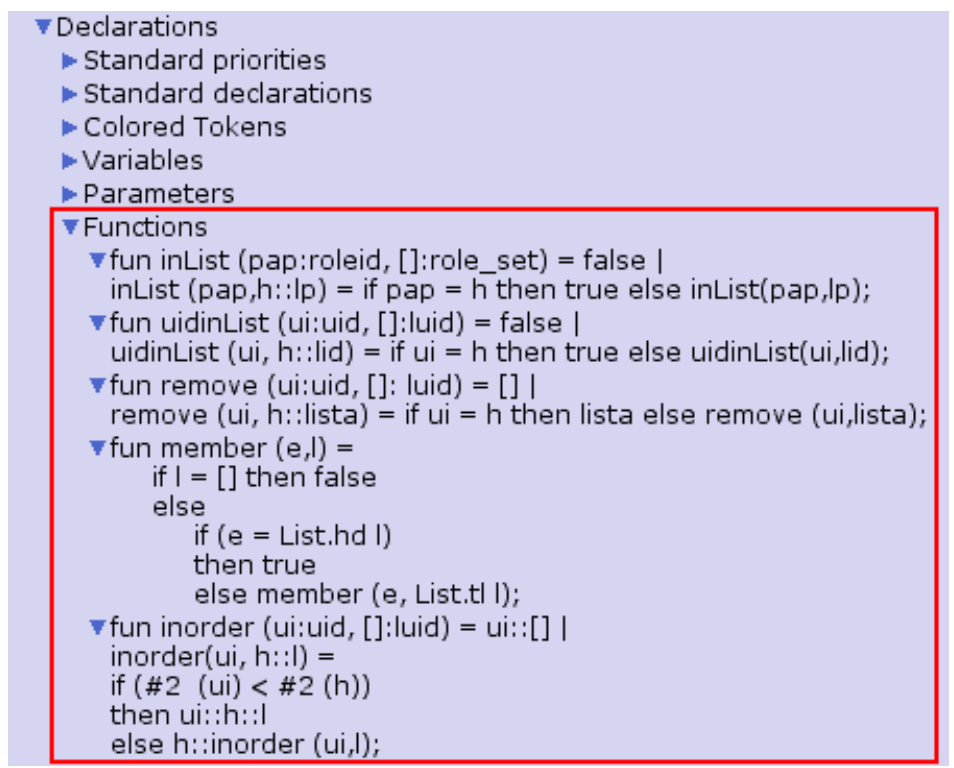

Figura 5.5: Funções Definidas na Rede do Workflow

Discutimos, no início deste capítulo, a possibilidade de haver hierarquias de objetos no cenário educacional. A ferramenta CPN Tools permitiu modelar também esta hierarquia. Quando um aluno vai cursar uma disciplina, ele precisar assistir uma sequência de aulas até chegar o momento de fazer um exame final e encerrar a disciplina. A modelagem apresentada na Figura 5.6 é constituída de vários módulos que passamos a apresentar mais adiante em detalhes.

A ferramenta CPN Tools permite desenvolver uma rede de Petri colorida de forma hierárquica, ou seja, é possível subdividir o modelo em submodelos, sendo que cada um destes módulos aparece em uma subpage da área de trabalho do software. Por sua vez, cada uma dessas subpage está associada a uma transição do modelo principal.

Na rede de Petri da Figura 5.6, os objetos Disciplina, Aula e Prova são lugares da rede chamados de Disc, Class e Exam, respectivamente. 


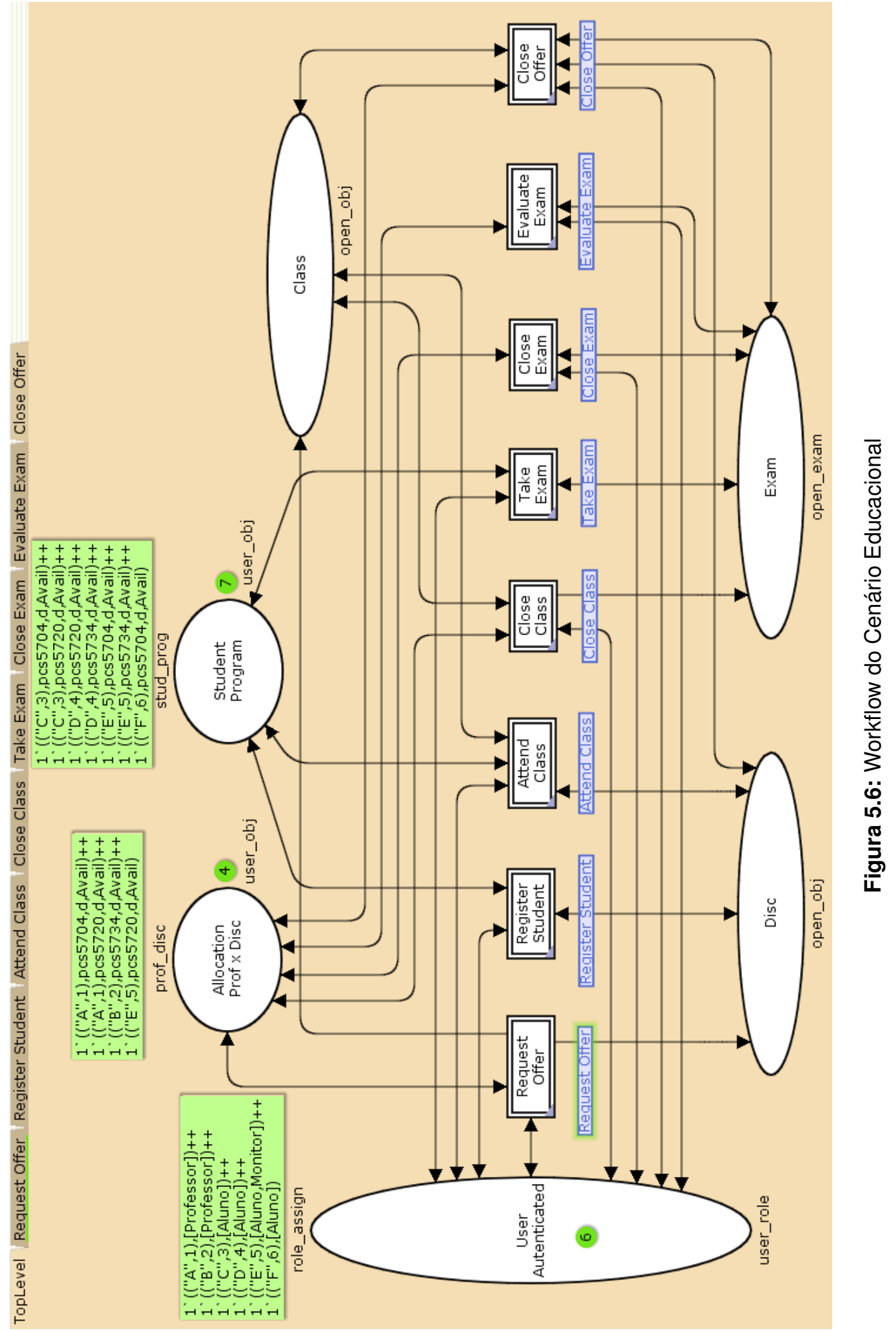


A rede apresenta ainda duas tabelas de alocações representadas por lugares também. A primeira tabela serve para indicar quais disciplinas um professor pode ofertar e ministrar e a segunda contém o programa de disciplinas que cada aluno pode se matricular e cursar.

Para simplificar o processo de modelagem e representação do ambiente educacional, consideramos que os usuários permanecem sempre autenticados no sistema, desde o estado inicial até o estado final de uma simulação da rede.

A regras de autorização, ou melhor dizendo, a política de controle de acesso que foi especificada para os papéis Professor, Aluno, Monitor puderam ser capturadas pela modelagem com rede de Petri colorida. Uma modelagem do mesmo cenário com UML, por exemplo, seria mais fácil de ser realizada, pois é uma linguagem de modelagem bem difundida e mais fácil de aprender. Porém, UML não permite um processo de análise mais conclusivo com relação a propriedades de um sistema. A modelagem com rede de Petri colorida possibilita uma série de análises mais detalhadas, em particular, a verificação de consistência de uma política de controle de acesso via análise de espaço de estados.

As regras da política de controle de acesso são representadas nas inscrições presentes nos arcos e nas funções guarda das transições. A seguir, apresentamos uma descrição detalhada de cada módulo do modelo principal do ambiente educacional. Esses módulos irão ajudar a compreender melhor como é modelada a política de controle de acesso baseado em papéis.

\section{Módulos Específicos do Workflow}

A Figura 5.7 apresenta o módulo "Request Offer", em que um usuário no papel de professor pode dar início ao oferecimento de uma disciplina. A transição Request Offer dispara apenas se o usuário que possui o papel de professor estiver alocado na tabela de alocação de disciplinas que aparece no modelo principal da rede de Petri.

A Figura 5.8 apresenta o módulo "Register Student", em que um aluno pode se matricular em uma disciplina que esteja alocado para ele no programa de estudante. Além disso, a disciplina precisa ter sido oferecida por um professor para que este aluno tenha o direito de fazer matricula e a transição Register Student possa ser disparada. Quando uma disciplina na tabela de alocação de disciplinas está com status Open é 


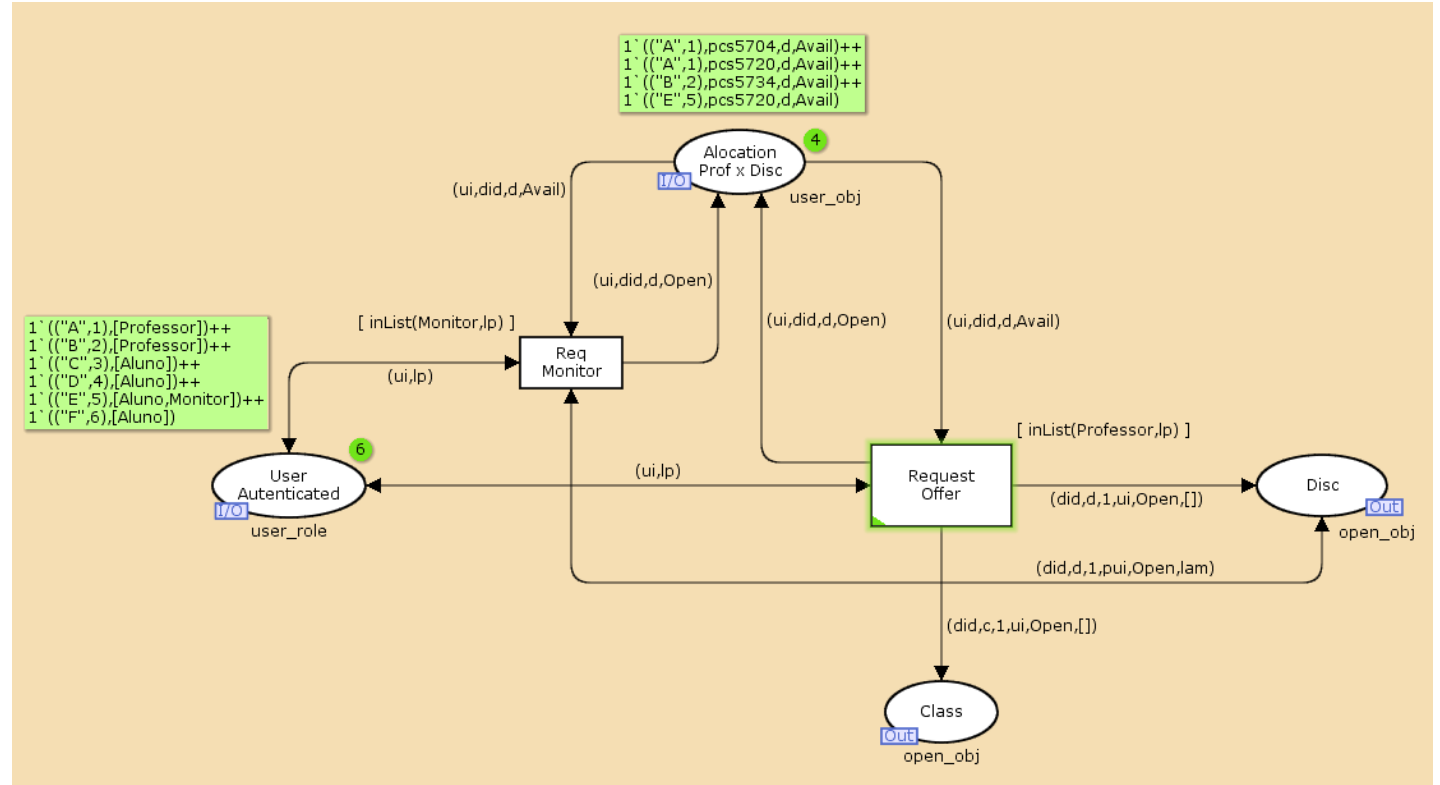

Figura 5.7: Módulo Request Offer

sinal que um professor está oferecendo e alunos podem se matricular. Após um aluno fazer a matricula em uma disciplina, ele é inserido na lista da disciplina que aparece no lugar Disc.

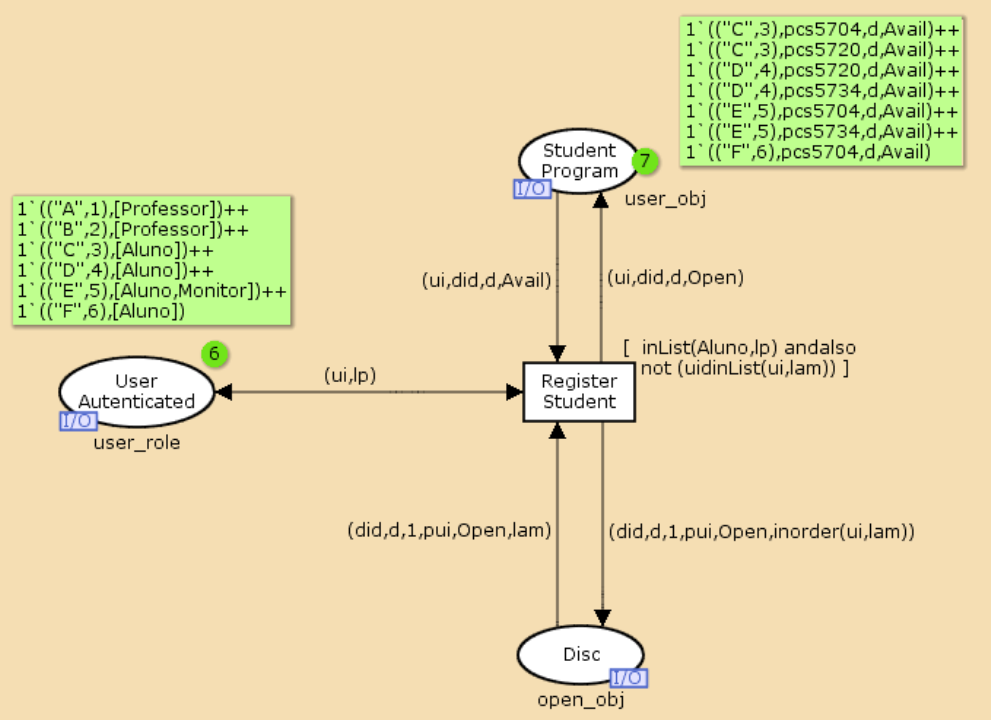

Figura 5.8: Módulo Register Student

A Figura 5.9 apresenta o módulo "Attend Class", em que os alunos podem dar início à participação nas aulas das disciplinas que estão abertas. Note que, para que a transição Attend Class seja disparada, é necessário que o aluno esteja matriculado. 


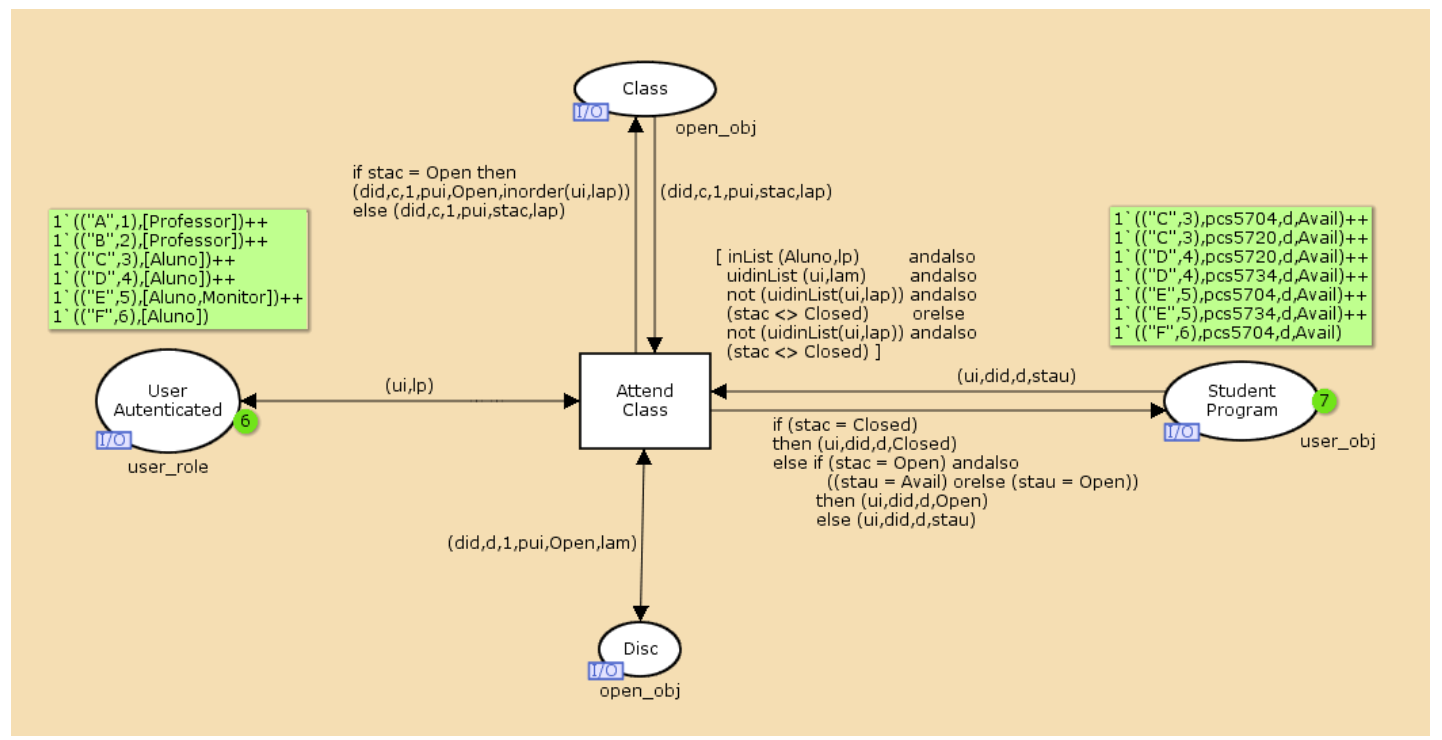

Figura 5.9: Módulo Attend Class

A Figura 5.10 apresenta o módulo "Close Class", que encerra as aulas de uma disciplina para que ocorra a prova final. Note que a transição Close Class só é disparada quando a quantidade exata de alunos alocados para aquela disciplina na tabela programa do estudante estiver sido completada. Neste módulo, a função de guarda fica responsável por verificar quando é atingida a condição necessária para a transição ser disparada. É importante ressaltar também que o status da disciplina no lugar Class muda de Open para Closed.

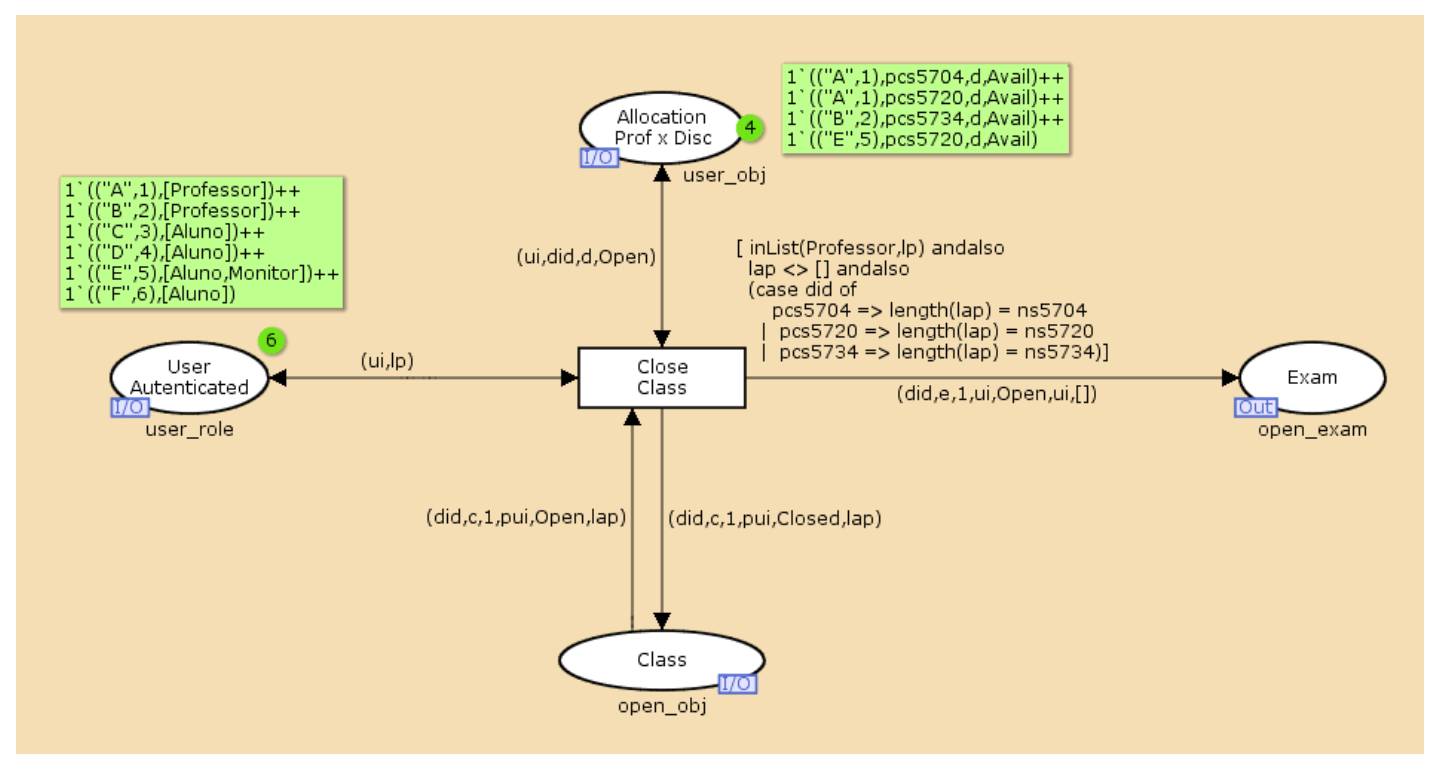

Figura 5.10: Módulo Close Class 
A Figura 5.11 apresenta o módulo "Take Exam”, em que os alunos que concluíram as aulas de uma disciplina podem fazer exame. A transição Attend Exam torna-se habilitada assim que as aulas de uma disciplina são fechadas no módulo "Close Class".

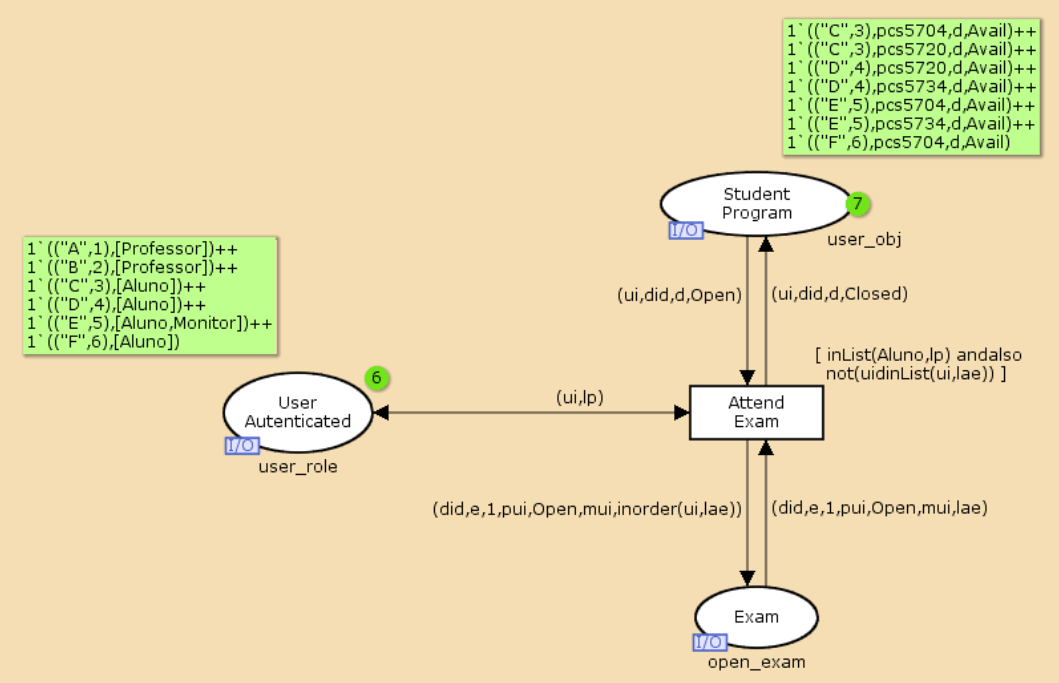

Figura 5.11: Módulo Take Exam

A Figura 5.12 apresenta o módulo “Close Exam”, responsável por fechar um exame toda vez que os alunos terminam de realizar o exame. Perceba que a transição Close Exam só é habilitada quando todos os alunos matriculados em uma disciplina fizeram o exame.

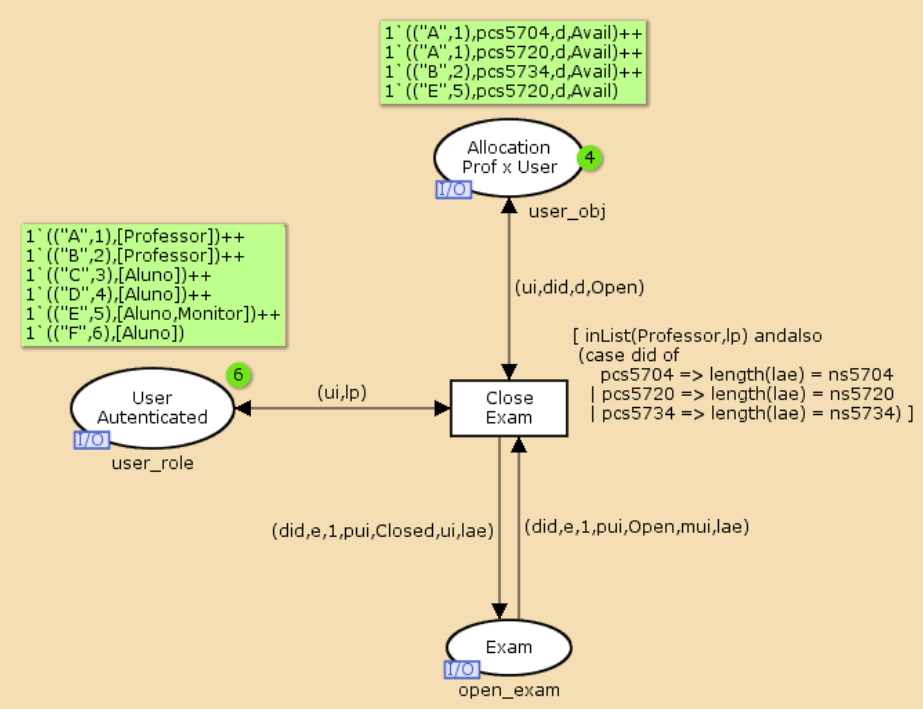

Figura 5.12: Módulo Close Exam 
A Figura 5.13 apresenta o módulo "Evaluate Exam”, responsável pela correção de um exame que acabou de ser fechado no módulo "Close Exam".

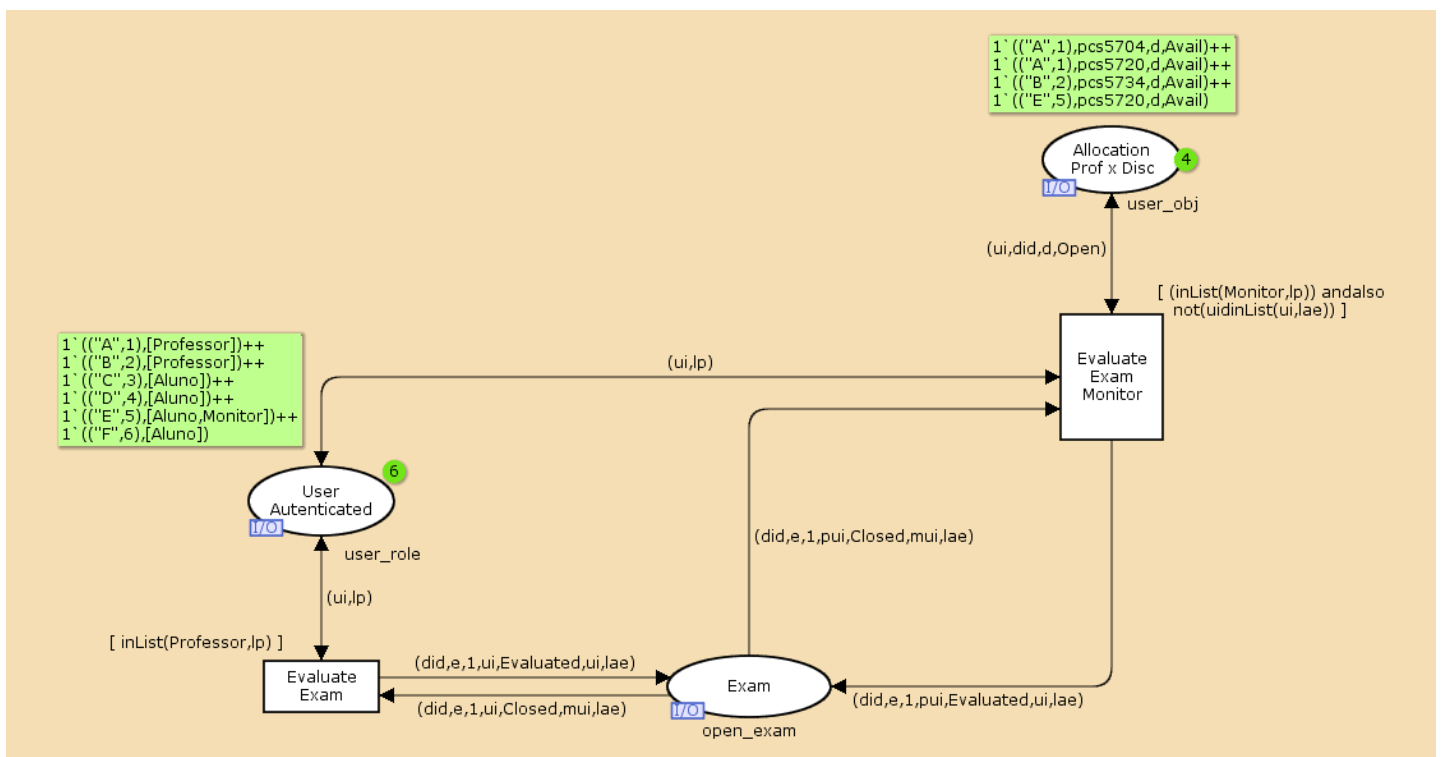

Figura 5.13: Módulo Evaluate Exam

A Figura 5.14 apresenta o módulo "Close Offer", que é responsável por fechar o oferecimento de uma disciplina depois que os alunos participaram das aulas, fizeram o exame, que por sua vez foi corrigido.

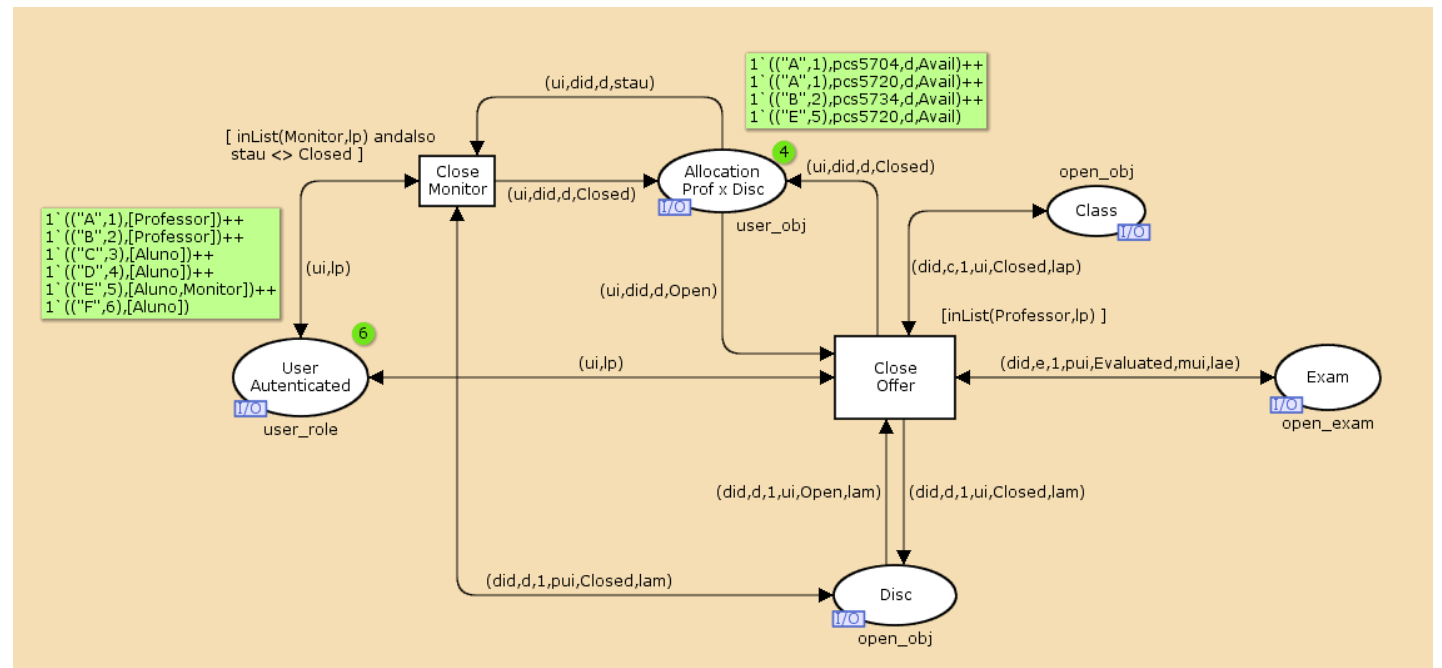

Figura 5.14: Módulo Close Offer

A Figura 5.15 apresenta o modelo da Figura 5.6 depois de uma simulação com 2 professores e 4 alunos, sendo um deles monitor. É importante notar que, depois de uma simulação da rede de Petri, o status de todas as disciplinas nos lugares Disc, Class 


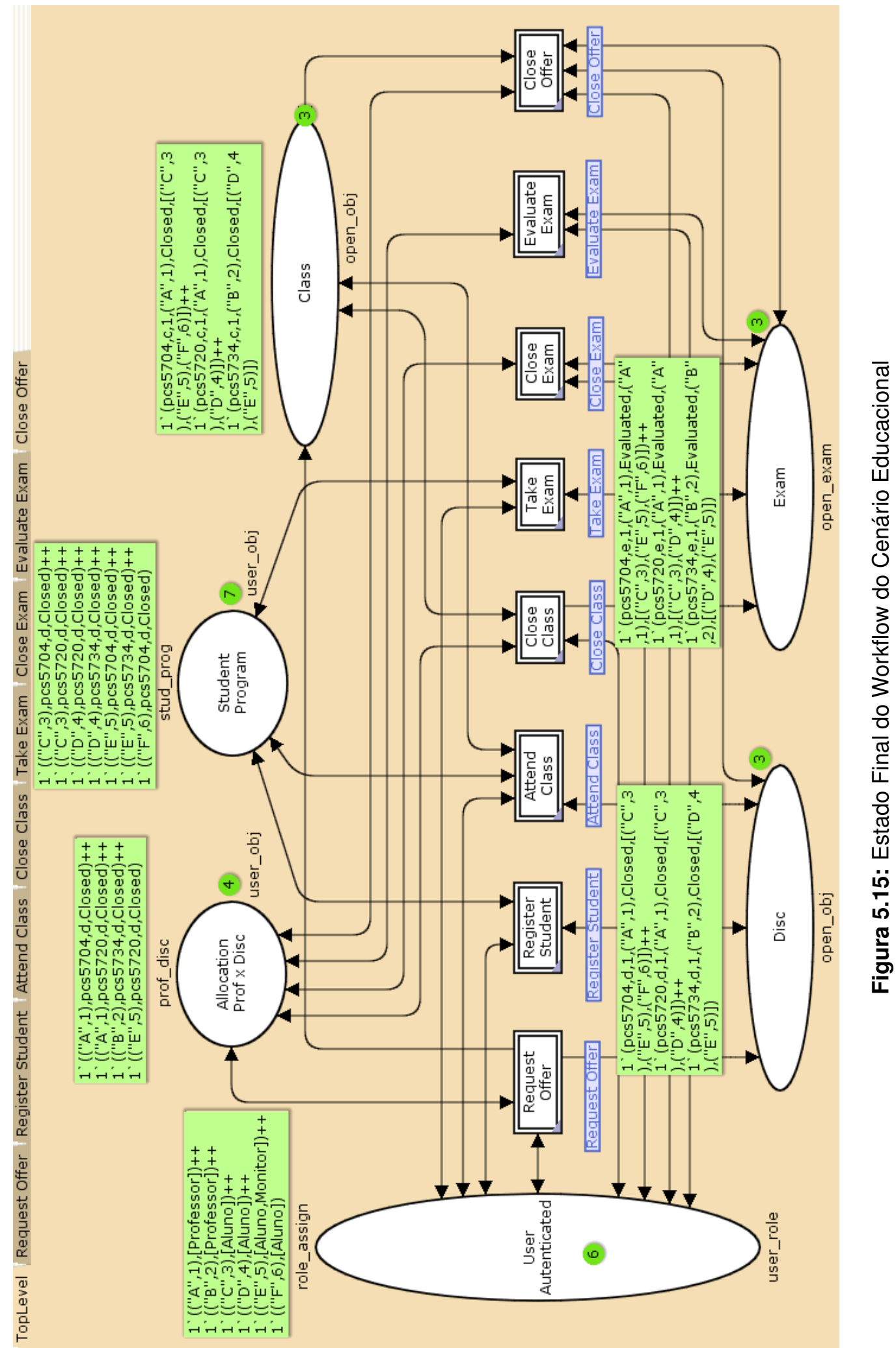


e nas tabelas de alocação é Closed. Deve-se notar também que, no lugar Exam, os status de exame de todas as disciplinas é Evaluated.

A ferramenta CPN Tools nos permitiu criar um modelo de um cenário educacional e simular suas atividades através do disparo de tokens fixados em marcações iniciais. No modelo, foram considerados três lugares com marcações iniciais, o lugar com usuários autenticados e associados a seus respectivos papéis, a tabela de alocação de disciplina dos professores e a tabela com o programa de disciplinas dos estudantes.

Neste ponto, já foi possível perceber que regras da política de controle de acesso são claramente mapeadas em uma rede de Petri colorida através de suas inscrições nos arcos e funções guarda. Por exemplo, no primeiro módulo que vimos do sistema, a transição Request Offer só dispara se receber um usuário professor do lugar User Autenticaded. Se for um aluno, esta transição não é disparada, e é a condição presente na função guarda que garante a aplicação desta regra de controle de acesso.

A ferramenta CPN Tool permite mais do que apenas modelar e simular uma rede de Petri que representa um cenário educacional. Ela permite realizar análise de alcançabilidade em um espaço de estados. Porém, esta análise para avaliar a consistência da política de controle de acesso que foi modelada é assunto para o próximo capítulo.

\subsection{Metamodelo}

O processo de modelagem de um cenário educacional genérico a partir do seu modelo de dados nos permitiu desenvolver regras de mapeamento que podem ser aplicadas em qualquer tipo de ambiente, independentemente de ser educacional. Essas regras caracterizam um metamodelo e são apresentadas na Tabela 5.5.

Usuários e papéis do cenário educacional e da política de controle de acesso baseado em papéis são representados como tokens na rede de Petri colorida. Objetos são representados como lugares e, ações, como transições. Apesar de não estar explícito na rede de Petri, permissões são caracterizados como transições e lugares, uma vez que uma permissão corresponde a uma ação sobre um objeto, ou seja, um par (ação,objeto).

Para representar sessões do modelo RBAC, foi definido uma cor que é um par ordenado em que o primeiro elemento é um usuário e o segundo constitui uma lista 
de papéis a que esse usuário está associado. No lugar User Autenticated, aparecem os tokens do tipo user_role que estabelecem sessões no workflow.

Tabela 5.5: Metamodelo

\begin{aligned} & \hline Entidades Representação \\ & \hline Usuários tokens \\ & Papéis tokens \\ & Objetos lugares \\ & Ações transições \\ & Permissões transições e lugares \\ & Sessões tokens \\ & Restrições funções de guarda e expressões em arcos \\ & Estados atributos \\ & \hline Relacionamentos lugares \\ & \hline\end{aligned}

Restrições da política de controle de acesso baseado em papéis são representadas através de funções de guarda e expressões inscritas em arcos da rede de Petri. Como já sabemos, esses elementos são responsáveis pelo binding das variáveis na rede e, dessa forma, conseguem controlar o movimento de tokens de um lugar a outro da rede.

Durante as atividades realizadas pelo workflow operacional, papéis e objetos interagem, e tais objetos podem possuir estados. Por exemplo, uma disciplina na tabela de alocação de professores no lugar Allocation Prof $\times$ Disc na marcação inicial da Figura 5.6 está com estado avail (disponível), mas, quando a transição Request Offer é disparada devido ao fato de um professor resolver oferecer a disciplina, ela muda seu seu estado para Open. Dessa forma, definimos estados como atributos de um determinado objeto no sistema.

Também representamos relacionamentos no modelo da rede de Petri colorida. Um relacionamento aparece como um lugar na rede e costuma ser uma tabela que pode associar entidades umas com as outras. Por exemplo, o lugar Student Program na Figura 5.6 representa um relacionamento que associa alunos com as disciplinas em que eles podem se matricular e cursar. 


\subsection{Síntese}

Neste capítulo, foi apresentada a caracterização de um cenário educacional e, com base no conhecimento das propriedades comportamentais desse ambiente, foi possível definir uma política de controle de acesso. Em seguida, o cenário educacional e a política de controle de acesso foram capturados e modelados através da aplicação da teoria de rede de Petri colorida, com auxílio da ferramenta CPN Tools.

Apesar da utilização da teoria de rede de Petri (PETRI, 1962) contar com a ajuda da ferramenta CPN Tools (entre outras), a curva de aprendizado da representação gráfica de rede de Petri colorida é mais lenta do que outras notações gráficas, como por exemplo UML. Um desafio de pesquisa relacionado a esse assunto é a transformação automática ou quase automática de modelos UML em representação gráfica com rede de Petri colorida.

Este capítulo apresentou uma contribuição importante, pois, através da modelagem de um exemplo, foi possível desenvolver um metamodelo que pode ser aplicado para modelar qualquer tipo de ambiente, não sendo necessário se prender apenas a cenários educacionais. Apesar da rede de Petri desenvolvida neste capítulo apresentar cardinalidade baixa por considerar poucos usuários e papéis, o modelo foi capaz de capturar muitos aspectos dinâmicos importantes presentes em um ambiente educacional. 


\section{Avaliação de Consistência da Política}

\subsection{Introdução}

Neste capítulo, é utilizada a técnica de análise de estados em rede de Petri colorida para verificar a consistência de uma política de segurança baseada em papéis. Mostramos como é possível detectar violações de autorização, que podem acontecer na política de controle de acesso, aplicando análise de alcançabilidade no espaço de estados da rede de Petri colorida. A seção 6.2 discute o ciclo de vida de uma política, que não é estática e se modifica ao longo do tempo. A seção 6.3 descreve como analisar a segurança da política modelada no Capítulo 5 utilizando a ferramenta CPN Tools. A seção 6.4 avalia a política considerando a dinamicidade que se manifesta através de novos papéis, ações e objetos. A seção 6.5 discute os resultados produzidos por este capítulo. Por fim, a seção 6.6 apresenta a síntese deste capítulo.

\subsection{Ciclo de Vida de uma Política}

Políticas de controle de acesso são definidas para impedir que autorizações de acesso a diversos tipos de recursos não sejam violadas (SANDHU, 1998). Mudanças nas propriedades dos sistemas estão acontecendo a todo momento, com isso uma política de controle de acesso está suscetível à necessidade de ter que sofrer alterações a qualquer instante.

Toda política de controle de acesso apresenta ciclos de vida, ou seja, ela se modifica ao longo do tempo. É uma questão difícil saber quando um ciclo de vida chega ao fim e regras da política de controle de acesso precisam ser revistas (RINDERLE; 
REICHERT, 2005). No caso de um modelo baseado em papéis, é preciso verificar se determinado estado $\mathrm{E}$ inconsistente pode aparecer em algum momento. Se o método de verificação que utilizarmos mostrar que tal estado nunca é atingido, então, naquele momento, considerando uma certa configuração do sistema, existe consistência com relação aquela propriedade, ou melhor dizendo, regra de autorização.

Se a técnica de verificação da consistência da propriedade, considerando a configuração baseada em papéis inicial, mostrar que o estado é alcançável, então o sistema está inseguro para aquele tipo de ocorrência de violação (RINDERLE; REICHERT, 2007).

A Figura 6.1 ilustra o processo que acabamos de descrever. Nesta tese, propomos realizar a técnica de verificação através de análise de espaço de estados em rede de Petri colorida. A vantagem de utilizar modelagem, simulação e análise de espaço de estados para verificar a segurança de sistemas é que é possível descobrir de forma determinística se um estado inseguro poderá aparecer no sistema.

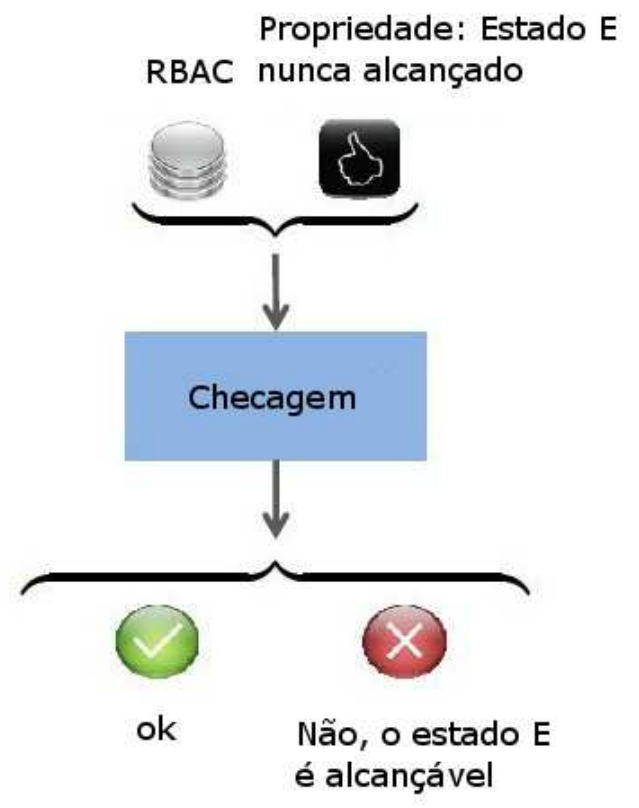

Figura 6.1: Verificação de Propriedade na Modelagem

O restante do capítulo vai ser dedicado a verificar a aderência da política RBAC incorporada ao workflow do cenário educacional que foi modelado no Capítulo 5. 


\subsection{Técnica para Análise de Políticas com Rede de Pe- tri Colorida}

\subsubsection{Análise de Alcançabilidade}

Em uma rede de Petri colorida, o espaço de estados é representado por um grafo de alcançabilidade que descreve o comportamento dinâmico da rede. Assim, é necessário ter à disposição mecanismos que permitam representar e manipular eficientemente este espaço de estados (HADJIDJ; BOUCHENEB, 2011). A Ferramenta CPN Tools possui recursos para que possamos fazer isso com o modelo desenvolvido no Capítulo 5.

Poucas décadas atrás, devido ao problema da explosão do espaço de estados, era inviável verificar sistemas considerados complexos. Devido a esta limitação, especulavase que a verificação automática ou parcialmente automática de modelos jamais poderia ser utilizada na prática.

Mas a possibilidade de verificar sistemas complexos surgiu no início dos anos 80 com a definição de novas estruturas de dados mais eficientes que possibilitaram representar relações de transições de estados em sistemas de forma mais adequada.

No caso da rede de Petri colorida, nas interpretações feitas sobre o espaço de estados, mais especificamente sobre sua representação por um grafo de ocorrência, consideram-se tanto informações dos nós como dos arcos deste grafo (JENSEN; KRISTENSEN, 2009). Em cada nó, aparecem as marcações de todos os lugares da rede, enquanto, nos arcos, a indicação de movimentação dos tokens de um estado para outro.

Para o propósito da análise desta tese, estamos interessados na propriedade de alcançabilidade para descobrir estados inconsistentes que violam regras da política de controle de acesso baseada em papéis (KAHLOUL et al., 2010). A análise de alcançabilidade indicará ocorrência ou não de determinada marcação de lugares que pode ser atingida pelo disparo de um número finito de transições, a partir de um estado inicial do modelo do ambiente educacional.

Com a ferramenta CPN Tools é possível realizar a análise de alcançabilidade no espaço de estados de uma rede de Petri colorida. É possível fazer consultas para determinar se estados específicos considerados inconsistentes podem ocorrer, ou seja, é possível verificar uma propriedade como descrito na Figura 6.1. 
Como discutido, o problema da explosão do espaço de estados pode tornar a análise de alcançabilidade inviável (KRISTENSEN, 2010). Algumas soluções para esse problema baseiam-se na diminuição da representação do espaço de estados. Outras soluções concentram-se em otimizar o percurso feito através do espaço de estados. Para contornar essa dificuldade, consideramos um modelo mínimo, mas que é adequado o suficiente para capturar as características que desejamos analisar.

\subsubsection{Verificação de Violação da Política}

Neste ponto, estamos prontos para aplicar a técnica de análise de alcançabilidade no espaço de estados do modelo do Capítulo 5, para verificar a consistência da política de controle de acesso modelada. Consideramos duas classes de regras da política de controle de acesso que merecem atenção. Primeiro, regras que dizem respeito à associação de usuários e papéis, ou seja a relação Usuário-Papel. Segundo, a relação Papel-Permissão, que é responsável por permitir que um papel interaja com um objeto através de ações.

A seguir, analisamos estas duas categorias, com base na política de controle de acesso definida no Capítulo 5, que apresentamos novamente na Tabela 6.1.

Tabela 6.1: Restrições Política de Controle de Acesso do Capítulo 5

\begin{tabular}{l}
\hline Regras \\
\hline Um usuário não pode ser professor e aluno de uma mesma disciplina \\
Um usuário não pode ser professor e monitor de uma mesma disciplina \\
Um aluno não pode ministrar aulas \\
Um monitor não pode ofertar uma disciplina \\
Um monitor não pode corrigir prova de uma disciplina se ele estiver matriculado nela \\
\hline
\end{tabular}

\section{Consulta considerando a Relação Usuário-Papel}

A primeira consulta que desejamos fazer e verificar se acontece no espaço de estados vai verificar a consistência da regra da primeira linha da Tabela 6.1. Assim, desejamos saber se existe um estado em que um usuário pode ser professor e aluno de uma mesma disciplina. A Figura 6.2 apresenta o código da consulta em linguagem ML na ferramenta CPN Tools. Esta consulta verifica se, no lugar Disc na página principal TopLevel do modelo, existe algum caso em que um professor e aluno são idênticos. A 
resposta para esta consulta é uma lista vazia, ou seja, esta regra da política de controle de acesso é consistente, levando em consideração o estado inicial mostrado na rede de Petri do Capítulo 5.

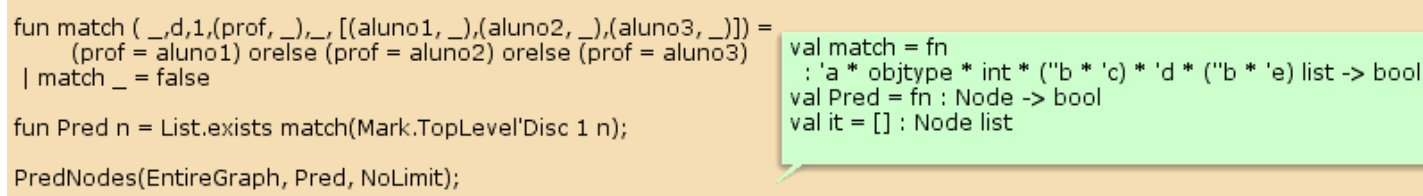

Figura 6.2: Consulta para determinar conflito entre Professor e Aluno

\section{Consulta considerando a Relação Papel-Permissão}

A segunda regra da política de controle de acesso que vamos analisar diz respeito à relação Papel-Permissão. Gostaríamos de saber se um papel por alguma razão tem o direito de fazer algo que não deveria. Enfim, desejamos saber se um monitor pode corrigir prova em uma disciplina em que ele está matriculado. Esta consulta aparece na Figura 6.3 e, como existe apenas um monitor que atua somente na disciplina pcs5720, verificamos se no lugar Exam existe algum estado no qual quem avaliou a prova também era um aluno da disciplina. A resposta para esta consulta é uma lista vazia e desta forma podemos dizer que esta regra da política de controle de acesso também é consistente.

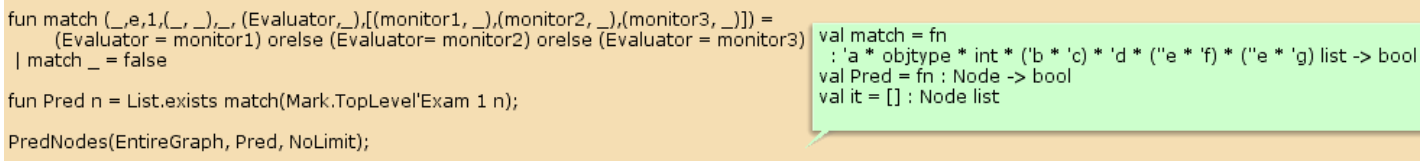

Figura 6.3: Consulta para determinar autorização não permitida do papel Monitor

\subsection{Avaliação com Dinamicidade de Papéis, Ações e Ob- jetos}

\subsubsection{Dinamicidade Causada por Permissões Existentes}

Como já foi discutido neste capítulo, políticas de controle de acesso sofrem alterações com o tempo; e um dos principais motivos que faz isso acontecer é a dinamicidade causada pelo surgimento de novos papéis. Para ilustrar tal situação, consideramos uma 
primeira situação na qual o surgimento de um papel é caracterizado apenas por uma nova combinação de permissões que já existem. Para demonstrar este fenômeno, vamos considerar o surgimento de um aluno ouvinte no ambiente educacional modelado com rede de Petri. A Tabela 6.2 descreve as ações e objetos associados a este novo papel.

Tabela 6.2: Permissões para o papel ouvinte

\begin{tabular}{cc}
\hline Ação & Objeto \\
\hline Assistir & Disciplina \\
Participar & Aula \\
\hline
\end{tabular}

É importante notar que nenhuma nova ação ou objeto surgiu para que o novo papel aluno ouvinte fosse criado. Porém, o surgimento deste novo papel tem implicações sobre as política de controle de acesso da Tabela 6.1. Com este novo papel, surgem também novas regras de autorização que não existiam antes. Na Tabela 6.2, temos a nova política de controle de acesso após a criação do papel aluno ouvinte.

Tabela 6.3: Restrições da política de controle de acesso com papel aluno ouvinte

\begin{tabular}{l}
\hline Regras \\
\hline Um usuário não pode ser professor e aluno de uma mesma disciplina \\
Um usuário não pode ser professor e monitor de uma mesma disciplina \\
Um aluno não pode ministrar aulas \\
Um monitor não pode ofertar uma disciplina \\
Um monitor não pode corrigir prova de uma disciplina se ele estiver matriculado nela \\
Um ouvinte não pode ministrar aulas \\
Um ouvinte não pode ofertar uma disciplina \\
Um ouvinte não pode fazer prova \\
Um ouvinte não pode corrigir prova
\end{tabular}

O surgimento de um novo papel acarreta a mudança no ciclo de vida da política de controle de acesso, pois a atual configuração de política pode apresentar falhas de consistência de segurança devido à dinamicidade de papéis. O modelo workflow do ambiente educacional do Capítulo 5 precisou ser alterado, sendo que um novo papel foi adicionado ao modelo. A definição e representação de rede de Petri colorida permite que componentes sejam incorporados a um modelo com certa facilidade. A Figura 6.4 apresenta a nova rede de Petri depois da adição do papel ouvinte. 


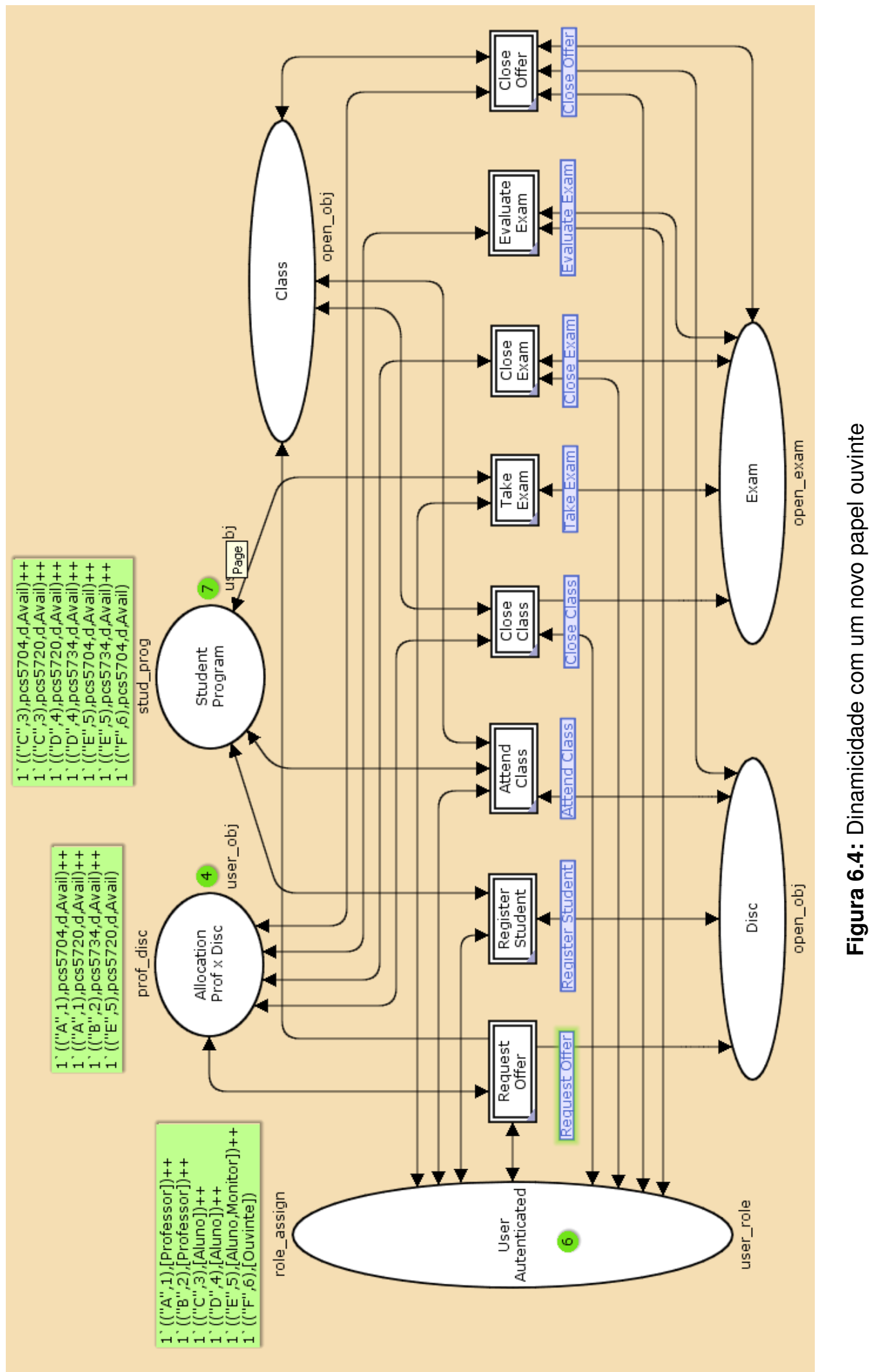


Para evitar o problema de um aluno ouvinte fazer prova, pois esta permissão não foi associada a ele, foi necessário atualizar o módulo "Take Exam" para que apenas alunos e não ouvintes tenham o direito de fazer prova. A Figura 6.5 apresenta a mudança estrutural na rede de Petri.

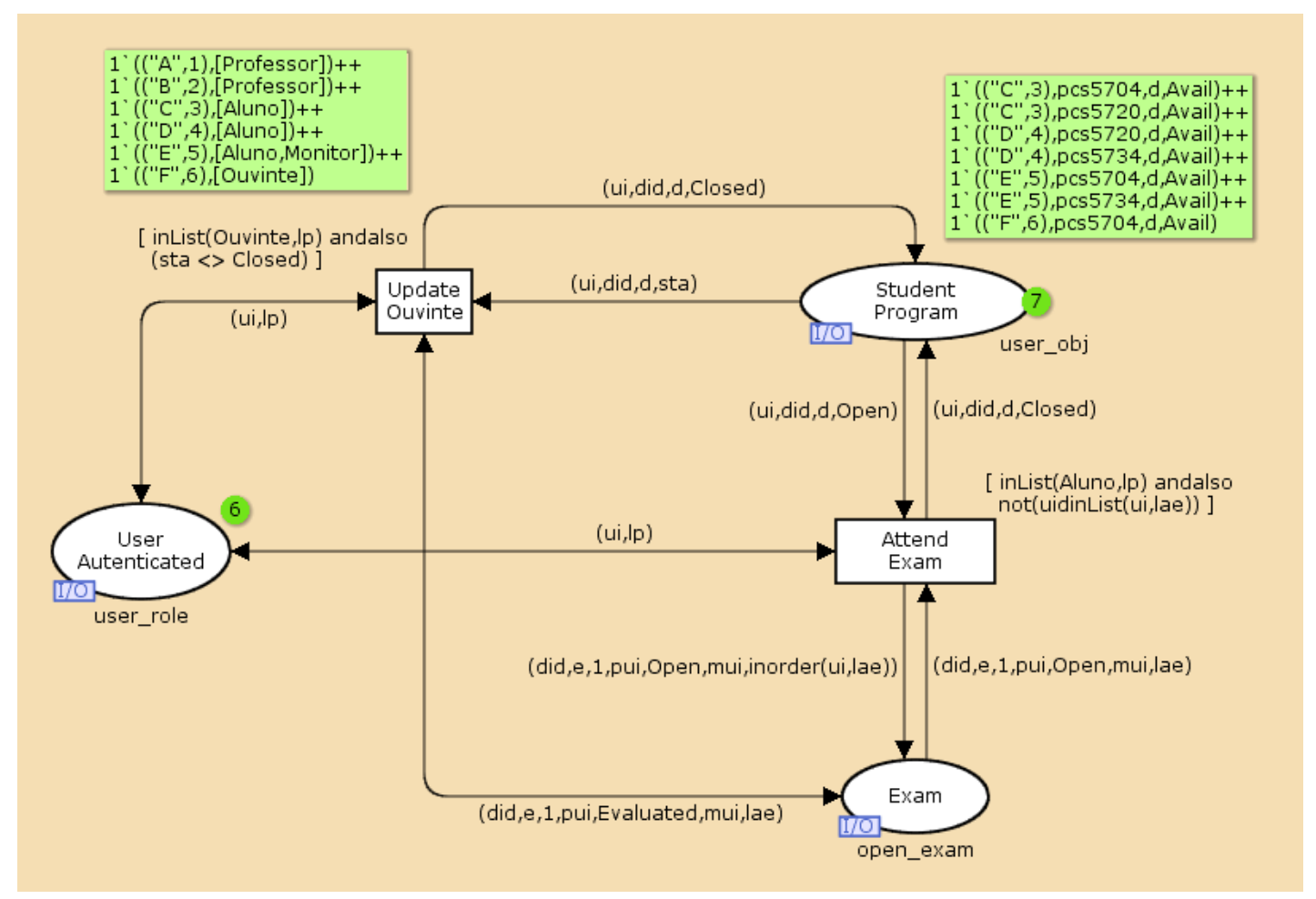

Figura 6.5: Módulo Take Exam com papel Ouvinte

Uma vez que a dinamicidade de um novo papel causou certa adição de estrutura no modelo além de novas regras na política de controle de acesso, precisamos analisar o efeito deste fato com relação à consistência de segurança da política. Assim como fizemos na seção 6.3.2, queremos saber se existe conflito na relação usuário-papel. Para isso elaboramos uma consulta ao espaço de estados para determinar se existe algum estado em que um usuário pode ser professor e ouvinte em uma mesma disciplina. $\mathrm{O}$ código para esta consulta e a resposta aparecem na Figura 6.6.

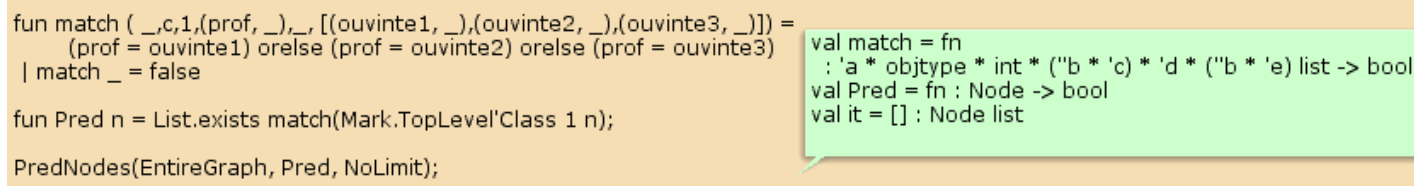

Figura 6.6: Consulta para determinar conflito entre Professor e Ouvinte

Como foi comentado, a dinamicidade representada pelo novo papel ouvinte fez 
com que precisássemos modificar o módulo "Take Exam". Precisamos saber se a regra da política de controle de acesso que diz que um aluno ouvinte não pode corrigir prova é de fato respeitada. Para verificarmos esta consistência, precisamos considerar se, no lugar Exam em TopLevel, existe algum estado em que o usuário ("F",6), ou seja, o único aluno ouvinte no sistema, pode ocupar o lugar de avaliador de cada uma das disciplinas. A resposta para esta consulta é uma lista vazia e desta forma esta regra da política de controle de acesso também está consistente.

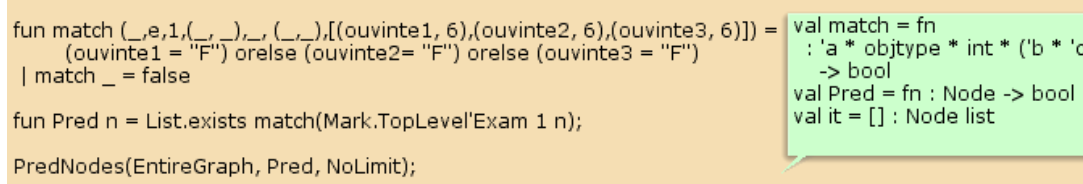

Figura 6.7: Consulta para determinar autorização não permitida do papel Ouvinte

\subsubsection{Dinamicidade Causada por Novas Permissões}

Dinamicidade de papéis também pode ocorrer com o aparecimento de novas permissões. Neste caso, existem três possibilidades para isso acontecer - surgimento de novos objetos, novas ações ou novas combinações de ações e objetos. Já vimos que a criação de uma novo papel, por mais simples que seja, provoca grandes mudanças que vão desde necessidade de adicionar novas regras de autorização na política de controle de acesso a ser preciso alterar a estrutura da rede de Petri. A seguir, discorremos sobre as três situações envolvendo dinamicidade devido ao aparecimento de novas permissões.

\section{Novos Objetos}

O aparecimento de um novo objeto é o caso que provavelmente envolve maior número de mudanças na estrutura da rede de Petri. Em primeiro lugar, um novo objeto caracteriza-se pelo surgimento de um novo lugar na rede de Petri e isso tem implicação direta no aumento do número de nós no espaço de estados que é essencial para realização da análise de alcançabilidade.

Além disso, com um novo objeto, é preciso que existam ações que atuem sobre ele; caso contrário, não existiria interação nenhuma do novo objeto no sistema. O surgimento de novos pares de ações existentes com este novo objeto vai implicar no aparecimento de novas permissões que, por sua vez, serão atribuídas a papéis. Desta 
forma, mais uma vez, acesso baseada em papéis.

Já discutimos como é o procedimento para analisar a consistência das regras de uma política de controle de acesso baseado em papéis. Para ilustrar uma situação na qual um novo objeto pode aparecer, consideremos a rede de Petri do ambiente educacional sem o objeto exame representado pelo lugar Exam. Nesta configuração que estamos considerando, não são necessárias as transições Take Exam, Close Exam e Evaluate Exam. O modelo da rede de Petri apresentaria um espaço de estados com uma quantidade de nós bem menor que a configuração atual.

Considerando esta rede de Petri reduzida, podemos verificar a consistência das regras da política de controle de acesso seguindo os passos que já foram explicados utilizando análise de alcançabilidade. Considere que, em determinado momento, o objeto exame que não existia surgiu; neste caso, é preciso que existam determinadas ações sobre este novo objeto, como as transições Take Exam, Close Exam e Evaluate Exam.

É fácil perceber que o surgimento de um único objeto apresenta como consequência uma grande modificação estrutural na rede de Petri do ambiente educacional. Porém, esta configuração com objeto exame já foi avaliada com relação à consistência de regras da política. Se não soubéssemos o resultado desta análise, seria preciso elaborar novas consultas ao espaço de estados com a finalidade de descobrir se existem estados inconsistentes que violam a política de controle de acesso.

\section{Novas Combinações de Ações e Objetos}

Uma segunda maneira de aparecer novas permissões seria quando ações e objetos já existentes combinam-se formando novos pares (ação, objeto), ou melhor dizendo, novas permissões. Para entender melhor este tipo de situação, imaginemos o modelo do ambiente educacional de tal maneira que haja uma nova regra no processo de aprendizagem do sistema que diz que, para fazer um exame não é obrigatório estar matriculado em uma disciplina, bastaria se inscrever ou matricular para fazer um exame. Desta forma, poderia acontecer uma situação na qual um aluno que já assistiu às aulas de uma disciplina em algum período do passado e não foi aprovado no exame possa apenas se matricular para fazer o exame no período corrente.

Neste cenário hipotético, a ação matricular já existe assim como o objeto exame, 
mas antes não existia este tipo de combinação. Este tipo de dinamicidade com certeza afetaria a política de controle de acesso, e uma das restrições que seria considerada é o fato de qualquer aluno ter assistido todas as aulas de uma disciplina matriculado antes de poder se matricular para fazer uma prova. Este tipo de dinamicidade tem um impacto baixo sobre a adição de mais estrutura na rede de Petri do modelo de ambiente educacional, pois a ação matricular e o objeto exame já estão presentes na rede.

\section{Novas Ações}

Uma terceira possibilidade de aparecer novas permissões é quando surgem novas ações que não tinham sido consideradas. Na verdade, essas ações poderiam existir mas estariam inativas por algum motivo. Para exemplificar este tipo de situação imaginemos que apareça uma nova ação chamada trancar que, aplicada ao objeto disciplina, permitiria um aluno poder trancar sua matricula a tempo de não ser reprovado devido suas notas insatisfatórias.

Na rede de Petri colorida, esta nova ação manifestar-se-ia em forma de uma nova transição; assim como existe um módulo Register Student para um aluno matricular-se em uma disciplina, também iria existir um outro módulo chamado, por exemplo, Lock Registration para que o aluno matriculado pudesse trancar uma disciplina.

Também existiriam consequências sobre a política de controle de acesso. Uma violação de segurança seria um aluno poder ou conseguir trancar a matricula de um outro aluno. Com o novo ciclo de vida, a política precisaria incorporar novas regras que, da mesma forma como foi explicado anteriormente, poderiam ser analisadas através de análise de alcançabilidade de estados.

\subsection{Discussão}

A verificação de consistência da política da seção 6.3 quando analisou a relação usuário-papel, no caso em que um usuário não pode ser professor e aluno de uma disciplina, caracterizou a separação estática de tarefas do modelo de controle de acesso baseado em papéis, que foi discutida em detalhes no Capítulo 2.

A análise de consistência da política de controle de acesso que considerou inclusive casos de dinamicidade quando surgem novos papéis, ações ou objetos, é bem de- 
talhada e representa um cenário minimalista. Porém, podemos inferir os resultados da análise do modelo para cenários com alta cardinalidade. No contexto da configuração inicial que consideramos, estão capturados os diversos tipos de conflitos que podem aparecer.

Se no estado inicial da rede de Petri considerarmos 3 professores no lugar de 2, o impacto seria sobre o número de nós do espaço de estados, e as regras da política de controle de acesso não iriam sofrer modificações. No caso do papel aluno, se tivéssemos apenas 1 usuário aluno não seria possível analisar muitos aspectos do ambiente, pois teríamos pouca concorrência. Considerando 3 ou 4 alunos como fizemos é suficiente para capturar o comportamento deste papel no sistema.

A cardinalidade do número de monitores tem um impacto considerável sobre o tamanho do espaço de estados, pois este papel incorpora ações tanto de aluno como de professor, e isso implica no disparo de muitas transições que podem ocorrer. Mesmo assim uma cardinalidade alta de usuários monitores vai criar redundância.

O papel que apresenta menos impacto de cardinalidade na rede de Petri é o de aluno ouvinte. É fácil perceber este fato, pois é um papel que tem poucas permissões, e desta forma irá percorrer poucas transições no modelo.

Nossa análise da política de controle de acesso por meio de rede de Petri colorida, considerando inclusive efeitos de dinamicidade, representa um forte indício da veracidade da conjectura que adotamos nesta pesquisa de doutorado.

Conjectura. Dado um sistema $S$, existe um modelo com cardinalidade mínima representado por uma rede de Petri colorida que captura todos os aspectos relevantes do sistema, e cuja análise pode ser utilizada para inferir conclusões sobre S.

A veracidade desta conjectura assegura que, apesar de termos desenvolvido a modelagem de um ambiente considerando baixa cardinalidade, os resultados da análise de alcançabilidade deste modelo reduzido pode ser estendido para um contexto real de cenário educação suportado por um sistema de computação.

Por cardinalidade estamos nos referindo à quantidade de usuários, papéis, permissões e restrições da política de segurança que foi incorporada ao workflow do sistema. Um número muito elevado de qualquer um destes elementos tem impacto direto no aumento do tamanho do espaço de estados da rede de Petri colorida. 
Apesar da cardinalidade de elementos do modelo da rede de Petri colorida ser pequena, esse fator não inviabiliza a aplicação do estudo realizado nesta tese para analisar cenários com cardinalidades elevadas.

Para analisar um cenário complexo, seria necessário seguir uma estratégia de divisão e conquista. Apesar de uma política de uma determinada organização apresentar muitas regras, é possível separará-las em categorias de tal maneira que poderia ser utilizada modelagem e análise de alcançabilidade em espaço de estados para a análise de cada um dos subconjuntos de regras separadamente.

Portanto, a propriedade de separabilidade das regras de uma política de controle de acesso de um sistema permite que sejam realizadas análises de submodelos menores que podem aferir a consistência desta política.

\subsection{Síntese}

Neste capítulo, foi apresentado um processo de avaliação de consistência de uma política de controle de acesso através da propriedade de alcançabilidade no espaço de estados de uma rede de Petri colorida. Essa análise, porém, tem limitações que procuramos contornar. A dificuldade do método que apresentamos é analisar modelos em que o número de estados seja muito elevado. A solução desse problema no âmbito da teoria de rede de Petri está fora do escopo de pesquisa desta tese.

Os resultados deste capítulo, porém, demonstram de maneira não formal que é possível representar um cenário complexo com um modelo mínimo que captura todas as características necessárias para realizarmos uma análise robusta da política de controle de acesso, que pode ser depois inferida para comportamentos em ambientes reais com cardinalidade maior.

É muito importante conseguir detectar possíveis violações da política, mesmo antes delas acontecerem. A abordagem desta tese utiliza modelagem, simulação e análise de alcançabilidade com rede de Petri colorida para detectar possíveis estados inseguros que podem aparecer em um sistema.

Nossa análise destaca-se pelo fato de considerar os aspectos de dinamismo de papéis. Quando surge um novo papel no sistema, decorrente de novas permissões 
ou novas combinações de permissões existentes, queremos saber se isso pode provocar inconsistência na política de controle de acesso.

Muitas pesquisas estão sendo direcionadas para desenvolver técnicas para tratar o problema que investigamos (KAHLOUL et al., 2010; LAID; DJOUANI; TFAILI, 2010). Abordagens recentes estão tentando tratar este problema aplicando conhecimentos de lógica temporal e propriedades em grafos.

Uma questão que não foi tratada diz respeito à correção da política de controle de acesso. No exemplo desta tese, é considerado um modelo com pouca cardinalidade, ou seja, apresenta poucos usuários, papéis, ações e objetos.

Um dos desafios de pesquisa que existe mas não abordamos está relacionado ao desenvolvimento de softwares computacionais que ajudem administradores de sistemas a lidar com as constantes mudanças nas consistências de políticas de controle de acesso provocadas por aspectos dinâmicos.

A análise que conduzimos representa um passo importante, pois foi possível mostrar que é concebível analisar a consistência de uma política de controle de acesso levando em consideração o aspecto dinâmico provocado pelo aparecimento de novos papéis. Além disso, foi possível tirar conclusões gerais através da avaliação de um modelo restrito e detalhado.

Acreditamos que pesquisas que estão abordando técnicas de transformação de outras linguagem de modelagem como UML para rede de Petri colorida vão contribuir para o avanço da aplicabilidade de rede de Petri colorida em modelagem, simulação e análise de sistemas similares ao que exploramos nesta tese. 


\section{Conclusão}

\subsection{Principais Contribuições}

Esta tese de doutorado abordou o problema de verificar se uma determinada política de controle de acesso baseada em papéis aplicada a um sistema genérico é consistente. A verificação levou em conta dois aspectos importantes - segurança e dinamicidade de papéis. As etapas conduzidas durante a pesquisa com ênfase na proposta de metamodelagem e análise baseada em alcançabilidade de estados permitiram responder a questões importantes para contribuirmos com a literatura científica da área.

O mapeamento sistemático (UEDA; RUGGIERO, 2012) que apresentamos como parte do Capítulo 2 representa a primeira contribuição da tese. Nele, foram identificadas abordagens propostas para tratar o estabelecimento da relação papel-permissão em modelos baseados em papéis. Analisamos de maneira crítica todas as abordagens encontradas considerando os seguintes critérios: corretude, segurança, desempenho, escalabilidade e dinamicidade de papéis. Não encontramos na literatura da área nenhum estudo sistemático com resultados similares ao mapeamento realizado. Portanto, conseguimos uma contribuição que é relevante para a comunidade científica.

A segunda contribuição, discutida no Capítulo 5, consiste no processo de modelagem do sistema educacional que adota política de controle de acesso utilizando rede de Petri colorida. A representação da política com esse tipo de rede de Petri possibilita gerar um processo de avaliação de segurança e também dinamicidade de papéis. Linguagens de modelagem como UML são populares e úteis para modelar sistemas; porém, não permitem realizar simulações e análise exaustiva de espaço de estados. Nossa abordagem destaca-se por considerar a interação do workflow com a política de controle de acesso baseado em papéis. A modelagem e análise realizada em Kahloul et al. (2010) e Laid, Djouani e Tfaili (2010) não considerou tal interação. Além disso, 
nossa contribuição também constitui um processo de metamodelagem que pode ser utilizada para representar qualquer sistema através de rede de Petri colorida.

O Capítulo 6 apresentou a terceira contribuição - um método de verificação de consistência de políticas de controle de acesso através da análise de espaço de estados da rede de Petri colorida. Nossos resultados demonstram que é possível analisar a consistência de segurança de uma política e também o aspecto de dinamicidade de papéis envolvendo ações e objetos utilizando a propriedade de alcançabilidade de estados na rede de Petri colorida com a ferramenta CPN Tools. O aspecto de dinamicidade de papéis, ações ou objetos não foi bem equacionado e tratado por (KAHLOUL et al., 2010) e (LAID; DJOUANI; TFAILI, 2010). Além disso, também identificamos que é possível analisar uma política de controle de acesso baseado em papéis extensa aplicando uma técnica de separabilidade nas regras da política para que elas sejam agrupadas em categorias que podem ser analisadas independentemente.

Por fim, os capítulos 2, 3 e 4 desta tese também apresentaram vários desafios de pesquisa relacionados à temática que foi conduzida por esta pesquisa de doutorado.

\subsection{Publicações}

Nesta seção, listamos os artigos produzidos como resultado desta pesquisa de doutorado. Além disso, comentamos sucintamente a relevância de cada um deles. A seguir, tais publicações aparecem classificadas em ordem cronológica.

\section{Artigos Publicados em Conferências e Periódicos}

- "A Systematic Mapping on the Role-Permission Relationship in Role Based Access Control Models” (UEDA; RUGGIERO, 2010). 10 International Information and Telecommunication Technologies Conference - I2TS'2011.

A contribuição desse artigo foi identificar na literatura relacionada a controle de acesso baseado em papéis quais são as principais propostas para estabelecimento da relação papel-permissão. Esse artigo é importante para a comunidade interessada em pesquisar segurança baseada em papéis, pois sintetiza as áreas mais exploradas - e seus temas, limitações e possíveis direções para novas pesquisas. Além disso, buscas em bases de dados acadêmicas indicam que nosso artigo é 
um dos pioneiros na área de controle de acesso a utilizar o método científico de mapeamento sistemático, o que representa uma contribuição significativa.

- "A Systematic Mapping on the Role-Permission Relationship in Role Based Access Control Models" (UEDA; RUGGIERO, 2012). IEEE Latin America Transactions, 2012.

Este artigo é uma extensão do artigo publicado no I2TS'2011. Os revisores da conferência recomendaram fortemente estender para ser publicado no IEEE Latin America Transactions. Uma análise crítica das estratégias identificadas pelo mapeamento sistemático foi acrescentada com a finalidade de dar maior destaque às perspectivas de pesquisas envolvendo os estudos selecionados.

\section{Artigos em Fase de Elaboração para Submissão em Periódicos}

- "A Meta-Modeling Approach of RBAC Policies using Colored Petri Net” (Full Paper).

Através da modelagem com rede de Petri colorida de um caso de sistema educacional que utiliza controle de acesso baseado em papéis, esse artigo apresenta como resultado um metamodelo que pode ser empregado para modelar qualquer outro tipo de ambiente. As regras da política de controle de acesso dependem das entidades e características do cenário; porém, o metamodelo produz um processo de modelagem com rede de Petri colorida que não apresenta este aspecto de dependência.

- "Analyzing Dynamicity of Policies in Role Based Access Control Models with Colored Petri Net" (Full Paper).

Nesse artigo, é apresentado o principal resultado da pesquisa que foi conduzida durante o doutorado. A modelagem de políticas de controle de acesso utilizando rede de Petri colorida e a análise de sua consistência através da propriedade de alcançabilidade de estados são discutidas. O destaque desse estudo é considerar, além do aspecto de segurança de uma política de controle de acesso, a dinamicidade envolvendo papéis, ações e objetos, que afetam diretamente o ciclo de vida de uma política. 


\subsection{Limitações}

A principal limitação que encontramos durante esta pesquisa está relacionada ao crescimento exponencial do número de nós no espaço de estados à medida que o modelo com rede de Petri cresce. A questão da quantidade excessiva de marcas (tokens), que representam alta cardinalidade de papéis no modelo, pode ser mitigada considerando-se um número mínimo de usuários necessários para que possamos capturar as situações de conflitos relevantes da política de forma a realizar sua análise de consistência.

Entretanto, ao considerarmos novos objetos no modelo, ocorre o surgimento de novos lugares (places), o que implica em uma mudança estrutural da rede de Petri colorida. A maior consequência disso é um espaço de estados totalmente diferente e, em geral, muito maior do que o apresentado pelo modelo original.

Essa limitação referente ao crescimento exponencial do espaço de estados da rede de Petri colorida não é um problema que será tratado na área de controle de acesso. Pesquisas que busquem resolver ou ao menos minimizar essa dificuldade são conduzidas por pesquisadores com foco em redes de Petri. Dessa forma, encontrar uma solução para eliminar essa restrição não pertence ao escopo desta pesquisa de doutorado.

Uma outra limitação que percebemos diz respeito à configuração da marcação inicial da rede de Petri colorida. A realização de várias análises sem alteração da estrutura da rede, mas com configurações iniciais diferentes, demonstrou experimentalmente que são produzidos espaços de estados com números de nós distintos.

Possivelmente, existe uma relação entre a configuração da marcação inicial da rede de Petri colorida e o número de nós do espaço de estados gerado. Essa relação será única para cada modelo específico construído com rede de Petri colorida. Se ela fosse determinada, seria possível prever (através de alguns cálculos) o número de nós no espaço de estados para determinadas configurações. Dessa forma, haveria uma indicação de como desenvolver os modelos com rede de Petri colorida minimizando o número de nós no espaço de estados para posterior análise de propriedades. Porém, acreditamos que não é viável tentar descobrir tal relação uma vez que estamos considerando o aspecto de dinamicidade. 


\subsection{Trabalhos Futuros}

As possibilidades de continuidade desta pesquisa de doutorado são diversas. Vamos descrever a seguir cinco que consideramos as mais interessantes.

Revisão Sistemática sobre Engenharia de Papéis. O mapeamento sistemático que conduzimos revelou uma informação importante sobre uma das abordagens identificadas. Segundo evidências, engenharia de papéis é um segmento de pesquisa que vem recebendo muita atenção de pesquisadores nos últimos anos. Essa é uma linha de pesquisa extremamente ativa no momento, por isso representaria uma contribuição valiosa a elaboração de uma revisão sistemática específica para identificar quais são as principais técnicas propostas. Além disso, seria necessário efetuar uma análise detalhada de cada uma dessas propostas para podermos encontrar questões de pesquisa que mereçam atenção futura.

Modelagem de Função de Autorização. A modelagem realizada nesta tese utilizou inscrições nos arcos e funções guarda para aplicar as regras de autorização da política de controle de acesso baseada em papéis. Uma outra possível estratégia para conseguir o mesmo efeito seria modelar uma única função de autorização geral que considerasse todos os casos definidos nas regras da política, para ser aplicada em cada transição da modelagem.

Análise de Desempenho. Investigar estratégias para análise de desempenho utilizando rede de Petri colorida em modelos de controle de acesso baseados em papéis. Devem ser considerados métodos para mensurar o impacto do efeito de dinamicidade de papéis em uma política de segurança baseada em papéis e sua relação ao desempenho de um sistema.

Análise de Escalabilidade. Pesquisar a viabilidade de aplicação de rede de Petri colorida para analisar políticas de segurança baseada em papéis em organizações que apresentam redes de larga escala. Em geral, sistemas que utilizam controle de acesso baseado em papéis possuem milhares de usuários e centenas de papéis. Porém, a teoria desenvolvida até o presente momento sobre redes de Petri colorida ainda não permite análise de espaço de estados muito grandes de maneira rápida.

Ferramenta para Análise de Política. Desenvolver uma ferramenta computacional que pudesse ser utilizada para automatizar a análise de políticas a partir do processo 
de metamodelagem, simulação e análise de estados discutidos nesta tese. Essa ferramenta poderia auxiliar administradores de sistemas no gerenciamento da robustez das políticas de controle de acesso que estão sendo especificadas por eles. 


\section{Referências}

BANKS, J. Handbook of Simulation : Principles, Methodology, Advances, Applications, and Practice. [S.1.]: Wiley-Interscience, 1998. Hardcover. ISBN 0471134031.

BEHAR, P. A.; PASSERINO, L. M.; BERNARDI, M. Modelos pedagógicos para educação a distância: pressupostos teóricos para a construção de objetos de aprendizagem. Porto Alegre, 2007.

BERTINO, E.; BONATTI, P. A.; FERRARI, E. TRBAC: A temporal role-based access control model. ACM Trans. Inf. Syst. Secur., ACM, New York, NY, USA, v. 4, p. 191-233, August 2001. ISSN 1094-9224.

BIOLCHINI, J.; MIAN, P. G.; CANDIDA, A.; NATALI, C. Systematic review in software engineering. Engineering, Springer Berlin Heidelberg, v. 679, n. May, p. 165-176, 2005.

BLUNDO, C.; CIMATO, S. A simple role mining algorithm. In: Proceedings of the 2010 ACM Symposium on Applied Computing. New York, NY, USA: ACM, 2010. (SAC'10), p. 1958-1962. ISBN 978-1-60558-639-7.

CASTRO, R. O. Uma Arquitetura de Segurança para Ambientes de Educação a Distância. Dissertação (Mestrado) — Universidade Federal de São Carlos, 2000.

CHAE, S.; KIM, W.; KIM, D. A novel approach to role-based access control. In: Proceedings of the 2003 international conference on Computational science. Berlin, Heidelberg: Springer-Verlag, 2003. (ICCS'03), p. 1060-1068. ISBN 3-540-40197-0.

CHANGHUA, L.; YAQIN, L.; ZHENSONG, L. A novelty approach for checking consistency of security policy. In: Proceedings of the 2009 International Forum on Information Technology and Applications - Volume 03. Washington, DC, USA: IEEE Computer Society, 2009. (IFITA '09), p. 319-324. ISBN 978-0-7695-3600-2.

CHAVES, E. Ensino a distância: Conceitos básicos. 2009.

CHOI, J. H.; KANG, D. H.; JANG, H.; EOM, Y. I. Adaptive access control scheme utilizing context awareness in pervasive computing environments. In: Performance, Computing and Communications Conference, 2008. IPCCC 2008. IEEE International. [S.1.: s.n.], 2008. p. 491 -498. ISSN 1097-2641.

CHOLVY, L.; CUPPENS, F. Analyzing consistency of security policies. In: IEEE Symposium on Security and Privacy. [S.l.: s.n.], 1997. p. 103-112. 
CHWIF, L.; MEDINA, A. C. Modelagem e Simulação de Eventos Discretos: Teoria e Aplicações. 3nd. ed. [S.1.: s.n.], 2007.

COLANTONIO, A.; PIETRO, R. D.; OCELLO, A. A cost-driven approach to role engineering. In: Proceedings of the 2008 ACM symposium on Applied computing. New York, NY, USA: ACM, 2008. (SAC'08), p. 2129-2136. ISBN 978-1-59593-753-7.

COLANTONIO, A.; PIETRO, R. D.; OCELLO, A.; VERDE, N. V. Taming role mining complexity in RBAC. Computers and Security, v. 29, n. 5, p. 548-564, 2010.

CONSTANTINESCU, R.; TOMA, A. A closer look to the V-model approach for role engineering. W. Trans. on Comp., World Scientific and Engineering Academy and Society (WSEAS), Stevens Point, Wisconsin, USA, v. 8, p. 1631-1640, October 2009. ISSN 1109-2750.

CORMEN, T. H.; STEIN, C.; RIVEST, R. L.; LEISERSON, C. E. Introduction to Algorithms. 2nd. ed. [S.1.]: McGraw-Hill Higher Education, 2001. ISBN 0070131511.

COYNE, E. J. Role engineering. In: ACM Workshop on Role-Based Access Control. [S.l.: s.n.], 1995.

CRESWELL, J. W. Introdução à pesquisa qualitativa e suas possibilidades. Porto Alegre: ArtMed, 2010.

DURAIPANDIAN, N.; SHANMUGHANEETHI, V.; C.CHELLAPPAN. Information security architecture-context aware access control model for educational applications. In: IJCSNS. [S.1.: s.n.], 2006.

FACHIN, O. Fundamentos de Metodologia. São Paulo: Saraiva, 2001.

FERRAIOLO, D.; KUHN, R. Role-based access control. In: In 15th NIST-NCSC National Computer Security Conference. [S.1.: s.n.], 1992. p. 554-563.

FERRAIOLO, D. F.; SANDHU, R.; GAVRILA, S.; KUHN, D. R.; CHANDRAMOULI, R. Proposed NIST Standard for Role-Based Access Control. 2001.

FRANK, M.; BASIN, D.; BUHMANN, J. M. A class of probabilistic models for role engineering. In: Proceedings of the 15th ACM conference on Computer and communications security. New York, NY, USA: ACM, 2008. (CCS '08), p. 299-310. ISBN 978-1-59593-810-7.

FRANK, M.; BUHMANN, J. M.; BASIN, D. On the definition of role mining. In: Proceeding of the 15th ACM symposium on Access control models and technologies. New York, NY, USA: ACM, 2010. (SACMAT'10), p. 35-44. ISBN 978-1-4503-0049-0.

FRANK, M.; STREICH, A. P.; BASIN, D.; BUHMANN, J. M. A probabilistic approach to hybrid role mining. In: Proceedings of the 16th ACM conference on Computer and communications security. New York, NY, USA: ACM, 2009. (CCS'09), p. 101-111. ISBN 978-1-60558-894-0. 
GALlAHER, M. P.; CONNOR, A. C.; KROPP, B. The Economic Impact of Role-Based Access Control. [S.1.], 2002.

GIBLIN, C.; GRAF, M.; KARJOTH, G.; WESPI, A.; MOLLOY, I.; LOBO, J.; CALO, S. Towards an integrated approach to role engineering. In: Proceedings of the 3rd ACM workshop on Assurable and usable security configuration. New York, NY, USA: ACM, 2010. (SafeConfig'10), p. 63-70. ISBN 978-1-4503-0093-3.

GLASER, B. G.; HOLTON, J. Discovery of Grounded Theory. 1967.

GODOY, A. Projeto de Pesquisa: Métodos Qualitativo, Quantitativo e Misto. São Paulo: Revista de Administração de Empresas, 1995.

GUO, Q.; VAIDYA, J.; ATLURI, V. The role hierarchy mining problem: Discovery of optimal role hierarchies. In: Computer Security Applications Conference, 2008. ACSAC 2008. Annual. [S.1.: s.n.], 2008. p. 237 -246. ISSN 1063-9527.

HADJIDJ, R.; BOUCHENEB, H. Efficient reachability analysis for time petri nets. IEEE Trans. Comput., IEEE Computer Society, Washington, DC, USA, v. 60, n. 8, p. 1085-1099, ago. 2011. ISSN 0018-9340.

HEUSER, C. (Ed.). Modelagem Conceitual de Sistemas. Campinas, SP, Brasil: IV Escola Brasileiro-Argentina de Informática, 1991.

JANCZURA, W.; BILLINGTON, P. J. Modelling and Analysis of Railway Network Control Logic using Coloured Petri Nets. 1998.

JENSEN, K.; KRISTENSEN, L. M. Coloured Petri Nets - Modelling and Validation of Concurrent Systems. [S.1.]: Springer, 2009. I-XI, 1-384 p. ISBN 978-3-642-00283-0.

JENSEN, K.; KRISTENSEN, L. M.; WELLS, L. Coloured petri nets and cpn tools for modelling and validation of concurrent systems. In: INTERNATIONAL JOURNAL ON SOFTWARE TOOLS FOR TECHNOLOGY TRANSFER. [S.1.: s.n.], 2007. p. 2007.

KAHLOUL, L.; DJOUANI, K.; TFAILI, W.; ALLAOUA, C.; AMIRAT, Y. Modeling and verification of rbac security policies using colored petri nets and cpn-tool. In: ZAVORAL, F.; YAGHOB, J.; PICHAPPAN, P.; EL-QAWASMEH, E. (Ed.). Networked Digital Technologies - Second International Conference, NDT 2010, Prague, Czech Republic, July 7-9, 2010. Proceedings, Part II. [S.1.]: Springer, 2010. (Communications in Computer and Information Science, v. 88), p. 604-618. ISBN 978-3-642-14305-2.

KELTON, W. D. Simulation analysis. In: Proceedings of the 15th conference on Winter simulation - Volume 1. Piscataway, NJ, USA: IEEE Press, 1983. (WSC '83), p. 159-168.

KITCHENHAM, B. Procedures for performing systematic reviews. Keele UK Keele University, Citeseer, v. 33, 2004. 
KRISTENSEN, L. M. A perspective on explicit state space exploration of coloured petri nets: past, present, and future. In: Proceedings of the 31st international conference on Applications and Theory of Petri Nets. Berlin, Heidelberg: Springer-Verlag, 2010. (PETRI NETS1́0), p. 39-42. ISBN 3-642-13674-5, 978-3-642-13674-0.

KUMAR, R.; SURAL, S.; GUPTA, A. Mining RBAC roles under cardinality constraint. Lecture Notes in Computer Science (including subseries Lecture Notes in Artificial Intelligence and Lecture Notes in Bioinformatics), v. 6503 LNCS, p. 171-185, 2010.

LAID, K.; DJOUANI, K.; TFAILI, W. Using timed colored petri nets and cpn-tool to model and verify trbac security policies. In: Fourth International Workshop on Verification and Evaluation of Computer and Communication Systems (VECoS 2010). [S.1.: s.n.], 2010.

LANDWEHR, C. E. Computer security. Int. J. Inf. Sec., v. 1, n. 1, p. 3-13, 2001.

LAW, A. M.; KELTON, D. M. Simulation Modeling and Analysis. 3rd. ed. [S.1.]: McGraw-Hill Higher Education, 1999.

LI, M.; WANG, H.; PLANK, A.; YONG, J. Advanced permission-role relationship in role-based access control. In: Proceedings of the 13th Australasian conference on Information Security and Privacy. Berlin, Heidelberg: Springer-Verlag, 2008. (ACISP'08), p. 391-403. ISBN 978-3-540-69971-2.

LI, N.; TRIPUNITARA, M. V. Security analysis in role-based access control. ACM Trans. Inf. Syst. Secur., ACM, New York, NY, USA, v. 9, p. 391-420, November 2006. ISSN 1094-9224.

LUCKHAM, D. C.; SCHULTE, R. Event Processing Glossary - Version 1.1. July 2008. Online Resource. . Disponível em: < http://complexevents.com/2008/08/31/event-processing-glossary-version-11/>.

MOLLOY, I.; CHEN, H.; LI, T.; WANG, Q.; LI, N.; BERTINO, E.; CALO, S.; LOBO, J. Mining roles with semantic meanings. In: Proceedings of the 13th ACM symposium on Access control models and technologies. New York, NY, USA: ACM, 2008. (SACMAT’08), p. 21-30. ISBN 978-1-60558-129-3.

MOLLOY, I.; CHEN, H.; LI, T.; WANG, Q.; LI, N.; BERTINO, E.; CALO, S.; LOBO, J. Mining roles with multiple objectives. Acm Transactions On Information and System Security, v. 13, n. 4, p. 36, dez. 2010.

MOLLOY, I.; LI, N.; LI, T.; MAO, Z.; WANG, Q.; LOBO, J. Evaluating role mining algorithms. In: Proceedings of the 14th ACM symposium on Access control models and technologies. New York, NY, USA: ACM, 2009. (SACMAT'09), p. 95-104. ISBN 978-1-60558-537-6. 
MOLLOY, I.; LI, N.; QI, Y. A.; LOBO, J.; DICKENS, L. Mining roles with noisy data. In: Proceeding of the 15th ACM symposium on Access control models and technologies. New York, NY, USA: ACM, 2010. (SACMAT'10), p. 45-54. ISBN 978-1-4503-0049-0.

MOON, C. J.; PAIK, W.; KIM, Y. G.; KWON, J. H. The conflict detection between permission assignment constraints in role-based access control. Information Security and Cryptology, Proceedings, v. 3822, p. State Key Lab Informat Secur, Chinese Acad Sci, 2005.

MOON, C. J.; PARK, D. H.; PARK, S. J.; BAIK, D. K. Symmetric RBAC model that takes the separation of duty and role hierarchies into consideration. Computers \& Security, v. 23, n. 2, p. 126-136, mar. 2004.

MULLER, M.; PFAHL, D. Simulation methods. Guide to Advanced Empirical Software Engineering, Springer London, v. 12, n. 3, p. 409-431, 2008.

MURATA, T. Petri nets: Properties, analysis and applications. Proceedings of the IEEE, v. 77, n. 4, p. 541-580, abr. 1989. ISSN 00189219.

NANCE, R. E. A history of discrete event simulation programming languages. SIGPLAN Not., ACM, New York, NY, USA, v. 28, p. 149-175, March 1993. ISSN 0362-1340.

NEUMANN, G.; STREMBECK, M. A scenario-driven role engineering process for functional rbac roles. In: Proceedings of the seventh ACM symposium on Access control models and technologies. New York, NY, USA: ACM, 2002. (SACMAT'02), p. 33-42. ISBN 1-58113-496-7.

$\mathrm{OH}, \mathrm{S}$.; SANDHU, R. A model for role administration using organization structure. In: Proceedings of the seventh ACM symposium on Access control models and technologies. New York, NY, USA: ACM, 2002. (SACMAT'02), p. 155-162. ISBN 1-58113-496-7.

PALOFF, R. M.; PRATT, K.; FIGUEIRA, V. Construindo comunidades de aprendizagem no ciberespaço. Porto Alegre, 2002.

PARK, S.-H.; EOM, J.-H.; CHUNG, T.-M. Context-based role engineering for ubiquitous computing environment. In: Advanced Communication Technology (ICACT), 2011 13th International Conference on. [S.1.: s.n.], 2011. p. 542 -547. ISSN 1738-9445.

PERWAIZ, N. Structured management of role-permission relationships. In: Proceedings of the sixth ACM symposium on Access control models and technologies. New York, NY, USA: ACM, 2001. (SACMAT'01), p. 163-169. ISBN 1-58113-350-2.

PETRI, C. A. Kommunikation mit Automaten. Tese (Doutorado) - Institut für instrumentelle Mathematik, Bonn, 1962. 
PONISZEWSKA-MARANDA, A. Role engineering of information system using extended RBAC model. In: Enabling Technologies: Infrastructure for Collaborative Enterprise, 2005. 14th IEEE International Workshops on. [S.1.: s.n.], 2005. p. 154 159. ISSN 1524-4547.

PRESSMAN, R. S. Engenharia de software. 6. ed. São Paulo: McGraw-Hill, 2006.

RAKKAY, H.; BOUCHENEB, H. Transactions on computational science iv. In: GAVRILOVA, M. L.; TAN, C. J.; MORENO, E. D. (Ed.). Berlin, Heidelberg: Springer-Verlag, 2009. cap. Security Analysis of Role Based Access Control Models Using Colored Petri Nets and CPNtools, p. 149-176. ISBN 978-3-642-01003-3.

REISIG, W. A Primer in Petri Net Design. Berlin, Heidelberg, New York, Tokyo: Springer, 1991.

RIBEIRO, C.; ZUQUETE, A.; FERREIRA, P.; GUEDES, P. Security policy consistency. CoRR, 2000.

RINDERLE, S.; REICHERT, M. On the controlled evolution of access rules in cooperative information systems. In: Proceedings of the 2005 Confederated international conference on On the Move to Meaningful Internet Systems. Berlin, Heidelberg: Springer-Verlag, 2005. (OTM0́5), p. 238-255. ISBN 3-540-29736-7, 978-3-540-29736-9.

RINDERLE, S.; REICHERT, M. Journal on data semantics ix. In: SPACCAPIETRA, S.; ATZENI, P.; FAGES, F.; HACID, M.-S.; KIFER, M.; MYLOPOULOS, J.; PERNICI, B.; SHVAIKO, P.; TRUJILLO, J.; ZAIHRAYEU, I. (Ed.). Berlin, Heidelberg: Springer-Verlag, 2007. cap. A formal framework for adaptive access control models, p. 82-112. ISBN 3-540-74982-9, 978-3-540-74982-0.

SÁ, P. S. S. Gerador Automático de Arquivos HTML de Ajuda para Aplicação em Educação a Distância. Dissertação (Mestrado) — Instituto de Ciências Matemáticas e de Computação de São Carlos, 2000.

SAMARATI, P.; VIMERCATI, S. de. Access control: Policies, models, and mechanisms. In: FOCARDI, R.; GORRIERI, R. (Ed.). Foundations of Security Analysis and Design. Berlin, Heidelberg: Springer Berlin / Heidelberg, 2001, (Lecture Notes in Computer Science, v. 2171). cap. 3, p. 137-196. ISBN 978-3-540-42896-1.

SANDHU, R.; FERRAIOLO, D.; KUHN, R. The nist model for role-based access control: towards a unified standard. In: RBAC'00: Proceedings of the fifth ACM workshop on Role-based access control. New York, NY, USA: ACM, 2000. p. 47-63. ISBN 1-58113-259-X.

SANDHU, R. S. Role-Based Access Control. 1998.

SCHLEGELMILCH, J.; STEFFENS, U. Role mining with ORCA. In: Proceedings of the tenth ACM symposium on Access control models and technologies. New York, NY, USA: ACM, 2005. (SACMAT'05), p. 168-176. ISBN 1-59593-045-0. 
SHANNON, R. Systems simulation: the art and science. [S.1.]: Prentice-Hall, 1975. ISBN 9780138818395.

SIMÃO, A. da S. Aplicação da análise de mutantes no contexto do teste e validação de redes de Petri coloridas. Tese (Doutorado) — Universidade de São Paulo, 2004.

SOHR, K.; DROUINEAUD, M.; AHN, G.-J.; GOGOLLA, M. Analyzing and managing role-based access control policies. IEEE Trans. on Knowl. and Data Eng., IEEE Educational Activities Department, Piscataway, NJ, USA, v. 20, p. 924-939, July 2008. ISSN 1041-4347.

STREMBECK, M. Scenario-driven role engineering. IEEE Security and Privacy, IEEE Educational Activities Department, Piscataway, NJ, USA, v. 8, p. 28-35, January 2010. ISSN 1540-7993.

TAKABI, H.; JOSHI, J. B. StateMiner: An efficient similarity-based approach for optimal mining of role hierarchy. In: Proceeding of the 15th ACM symposium on Access control models and technologies. New York, NY, USA: ACM, 2010. (SACMAT'10), p. 55-64. ISBN 978-1-4503-0049-0.

TEAM, T. J. JabRef Reference Manager. 2011. Disponível em: < http://jabref.sourceforge.net/>.

UEDA, E. T.; RUGGIERO, W. V. A systematic mapping on the role-permission relationship in role based access control models. In: Proceedings of the 10th International Information Technology Symposium. [S.l.: s.n.], 2010. (I2TS'11). ISBN 978-85-89264-11-2.

UEDA, E. T.; RUGGIERO, W. V. A systematic mapping on the role-permission relationship in role based access control models. IEEE Latin America Transactions, v. 10, n. 1, p. 1243-1250, Janeiro 2012.

VAIDYA, J.; ATLURI, V.; GUO, Q. The role mining problem: Finding a minimal descriptive set of roles. In: Proceedings of the 12th ACM symposium on Access control models and technologies. New York, NY, USA: ACM, 2007. (SACMAT'07), p. 175-184. ISBN 978-1-59593-745-2.

VAIDYA, J.; ATLURI, V.; GUO, Q. The role mining problem: A formal perspective. ACM Trans. Inf. Syst. Secur., ACM, New York, NY, USA, v. 13, p. 27:1-27:31, July 2010. ISSN 1094-9224.

VAIDYA, J.; ATLURI, V.; GUO, Q.; ADAM, N. Migrating to optimal RBAC with minimal perturbation. In: Proceedings of the 13th ACM symposium on Access control models and technologies. New York, NY, USA: ACM, 2008. (SACMAT'08), p. 11-20. ISBN 978-1-60558-129-3.

VAIDYA, J.; ATLURI, V.; GUO, Q.; LU, H. Edge-RMP: Minimizing administrative assignments for role-based access control. J. Comput. Secur., IOS Press, Amsterdam, The Netherlands, The Netherlands, v. 17, p. 211-235, April 2009. ISSN 0926-227X. 
VAIDYA, J.; ATLURI, V.; GUO, Q.; LU, H. Role mining in the presence of noise. In: Proceedings of the 24th annual IFIP WG 11.3 working conference on Data and applications security and privacy. Berlin, Heidelberg: Springer-Verlag, 2010. (DBSec'10), p. 97-112. ISBN 3-642-13738-5, 978-3-642-13738-9.

VAIDYA, J.; ATLURI, V.; WARNER, J. RoleMiner: Mining roles using subset enumeration. In: Proceedings of the 13th ACM conference on Computer and communications security. New York, NY, USA: ACM, 2006. (CCS'06), p. 144-153. ISBN 1-59593-518-5.

VAIDYA, J.; ATLURI, V.; WARNER, J.; GUO, Q. Role engineering via prioritized subset enumeration. IEEE Trans. Dependable Secur. Comput., IEEE Computer Society Press, Los Alamitos, CA, USA, v. 7, p. 300-314, July 2010. ISSN 1545-5971.

WANG, H.; YONG, J.; LI, J.; PENG, M. Authorization approaches for advanced permission-role assignments. In: CSCWD. [S.1.: s.n.], 2008. p. 277-282.

WIDMAN, L.; LOPARO, K.; NIELSEN, N. Artificial intelligence, simulation, and modeling. [S.1.]: Wiley, 1989. (Wiley-Interscience publication). ISBN 9780471605997.

ZHANG, D.; RAMAMOHANARAO, K.; EBRINGER, T. Role engineering using graph optimisation. In: Proceedings of the 12th ACM symposium on Access control models and technologies. New York, NY, USA: ACM, 2007. (SACMAT'07), p. 139-144. ISBN 978-1-59593-745-2.

ZHANG, D.; RAMAMOHANARAO, K.; EBRINGER, T.; YANN, T. Permission set mining: Discovering practical and useful roles. In: Annual Computer Security Applications Conference 2008. [S.1.: s.n.], 2008. p. 247-256.

ZHANG, D.; RAMAMOHANARAO, K.; VERSTEEG, S.; ZHANG, R. RoleVAT: Visual assessment of practical need for role based access control. 25th Annual Computer Security Applications Conference, p. Appl Comp Secur Assoc, 2009.

ZHANG, D.; RAMAMOHANARAO, K.; VERSTEEG, S.; ZHANG, R. Graph based strategies to role engineering. In: Proceedings of the Sixth Annual Workshop on Cyber Security and Information Intelligence Research. New York, NY, USA: ACM, 2010. (CSIIRW'10), p. 25:1-25:4. ISBN 978-1-4503-0017-9.

ZHAO, X.; ZHANG, Y.; ZHU, Y. An organization-structure oriented access control model and it's administration. In: Proceedings of the 2009 International Symposium on Information Engineering and Electronic Commerce. Washington, DC, USA: IEEE Computer Society, 2009. p. 569-573. ISBN 978-0-7695-3686-6.

ZHAO, X.; ZHANG, Y.; ZHU, Y. An organization-structure oriented access control policy and it's formal description. In: Proceedings of the 2009 International Conference on Networks Security, Wireless Communications and Trusted Computing - Volume 02. Washington, DC, USA: IEEE Computer Society, 2009. p. 516-519. 
ZHOU, M. C.; DICESARE, F. Petri net synthesis for discrete event control of manufacturing systems. [S.l.]: Kluwer Academic Publishers, 1993. 